UNIVERSIDADE DE SÃO PAULO

Escola de Engenharia de São Carlos

Departamento de Engenharia de Transportes

Programa de Pós-Graduação em Engenharia de Transportes

Felipe Costa Bethonico

\title{
Calibração de simuladores microscópicos de tráfego através de medidas macroscópicas
}



Felipe Costa Bethonico

\title{
Calibração de simuladores \\ microscópicos de tráfego através \\ de medidas macroscópicas
}

\begin{abstract}
Dissertação de Mestrado submetida à Escola de Engenharia de São Carlos, da Universidade de São Paulo, como parte dos requisitos para a obtenção do título de Mestre em Ciências, Programa de Pós-Graduação em Engenharia de Transportes. Área de Concentração: Planejamento e Operação de Sistemas de Transportes
\end{abstract}

Orientador: Prof. Dr. José Reynaldo Setti

São Carlos

2016 
AUTORIZO A REPRODUÇÃO TOTAL OU PARCIAL DESTE TRABALHO, POR QUALQUER MEIO CONVENCIONAL OU ELETRÔNICO, PARA FINS DE ESTUDO E PESQUISA, DESDE QUE CITADA A FONTE.

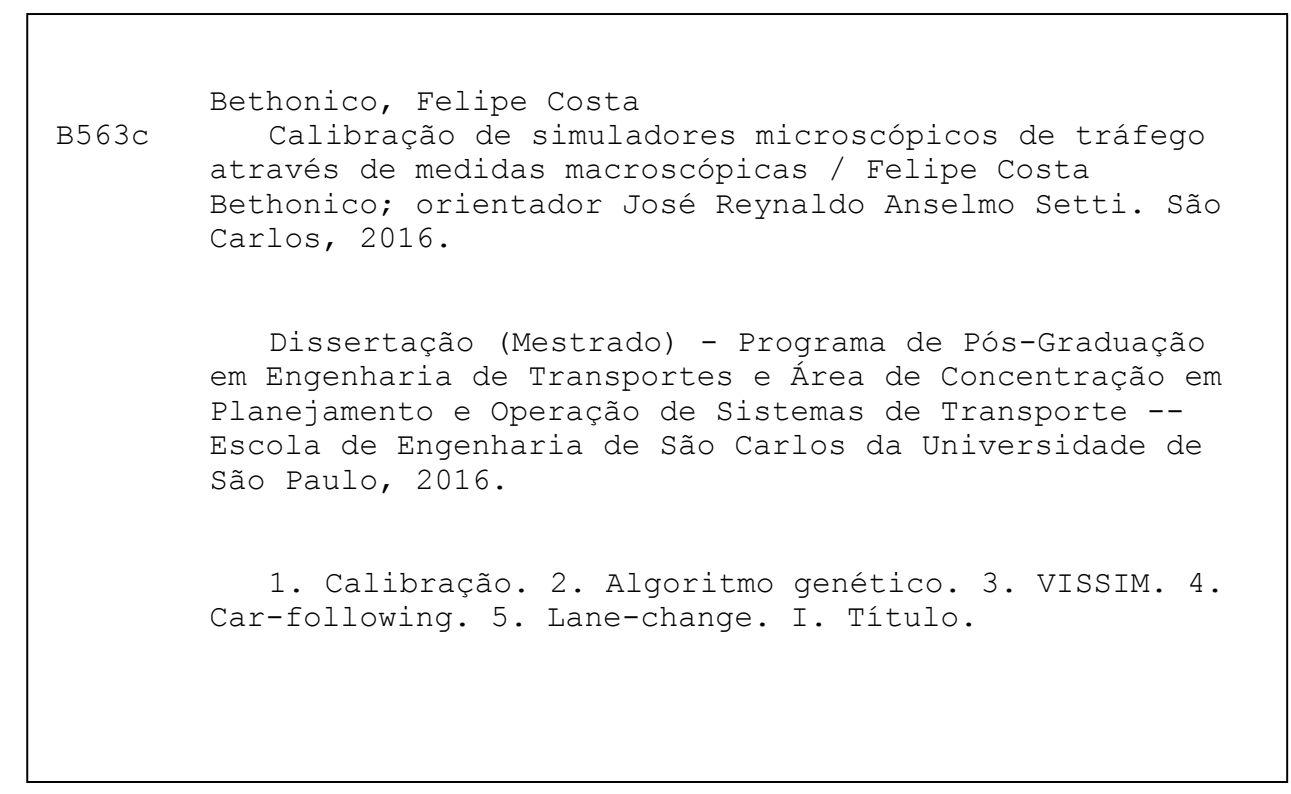


Candidato: Engenheiro FELIPE COSTA BETHONICO.

Título da dissertação: "Calibração de simuladores microscópicos de tráfego através de medidas macroscoópicas".

Data da defesa: 19/04/2016.

Comissão Julgadora:

Prof. Titular José Reynaldo Anselmo Setti (Orientador)

(Escola de Engenharia de São Carlos/EESC)

Prof. Titular André Carlos Ponce de Leon Ferreira de Carvalho (Instituto de Ciências Matemáticas e de Computação//CMC)

Profa. Dra. Cira Souza Pitombo

(Escola de Engenharia de São Carlos/EESC)

Coordenador do Programa de Pós-Graduação em Engenharia de Transportes: Prof. Associado Paulo Cesar Lima Segantine

Presidente da Comissão de Pós-Graduação:

Prof. Associado Paulo Cesar Lima Segantine
Resultado:

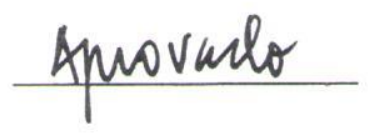

Anonado

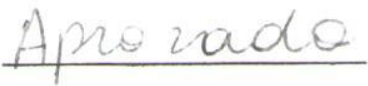



Dedico aos meus pais, Eimar (in memoriam) e Marly... 



\section{Agradecimentos}

Agradeço, em primeiro lugar, à minha família pelo apoio incondicional. À minha mãe, Marly, por todo carinho e suporte. À minha mulher, Priscilla, pelo amparo e por estar ao meu lado em todos os momentos. Aos meus irmãos, Bruno e Pablo, à minha cunhada Cátia e aos meus primos, Guilherme e Vinícius, pelo apoio e pela motivação desde sempre.

Agradeço ao Prof. Dr. José Reynaldo Setti pela orientação em todos os âmbitos deste trabalho, não apenas pelo conhecimento do assunto tratado na pesquisa, mas pelos ensinamentos que certamente contribuíram para o meu desenvolvimento pessoal e profissional.

Aos amigos e professores Dr. André Cunha e Dr. Elievam Bessa Jr., agradeço o imenso apoio dado nestes 3 anos de projeto. Ao Artur Piatti e ao Fernando Piva, meus amigos e companheiros de sala, agradeço pela agradável companhia nessa jornada e pelas experiências compartilhadas.

Agradeço à CAPES e ao CNPq pelo suporte financeiro; à ARTESP, à concessionária CCR AutoBan e ao IPMet por fornecerem os dados de tráfego e meteorológicos utilizados nesta pesquisa. Agradeço também à Prof. Dr. Ana Paula Larocca e ao colega Renaude Carneiro pelo auxílio no levantamento topográfico realizado no Rodoanel.

Agradeço à Universidade de São Paulo e ao Laboratório de Simulação de Sistemas de Transporte do Departamento de Engenharia de Transportes da Escola de Engenharia de São Carlos por oferecer as condições necessárias para a condução da pesquisa; à Universidade Federal de Minas Gerais, por formar o alicerce do conhecimento que precisei neste mestrado; ao Grupo Tectran, pelo apoio e pela experiência adquirida durante o período de estágio; Ao Rio Ônibus, por permitir que eu concluísse com sucesso este trabalho.

Por fim, agradeço a todos os amigos e colegas do departamento e de São Carlos: Alisson, Anabele, Andressa, Andrise, Angélica, Anthony, Aurenice, Bruno Brandimarte, Bruno Medeiros, Bruno Tardiole, Cíntia, Daniel, Diego, Elaine, Gláucia, Giuliana, Gustavo, Igor, Isabela, João Paulo, João Vitor, Jorge, Júlia, Karla, Leonardo, Lucas Verdade, Magaly, Marcella, Ma- 
riana, Miguel, Murilo, Ramane, Ricardo, Rosuel, Thais, Thalita, Thiago e Zezé. Obrigado por tornarem essa jornada mais leve e pela contribuição dada à pesquisa, direta ou indiretamente. 
Bethonico, F. C. Calibração de simuladores microscópicos de tráfego através de medidas macroscópicas. 116 p. Dissertação de Mestrado - Escola de Engenharia de São Carlos, Universidade de São Paulo, 2016.

Os simuladores de tráfego são programas computacionais que, através de diversos modelos, tentam simular o tráfego, o comportamento dos motoristas, o desempenho dos veículos, entre outros aspectos que envolvem uma rede viária. Estes modelos precisam ser calibrados para representar as condições de um determinado local. O objetivo da pesquisa foi propor um método de calibração de um microssimulador de tráfego através de dados coletados por estações de monitoramento. O estudo de caso foi realizado através do simulador VISSIM para um trecho do Rodoanel Mário Covas (SP-021), utilizando um algoritmo genético (AG). A calibração envolveu, além dos parâmetros comportamentais dos sub-modelos de car-following e lane-change, o ajuste das distribuições de velocidade desejada dos veículos e um método para simulação do congestionamento. A função fitness do AG foi baseada em três medidas de desempenho: uma que comparava gráficos de fluxo-velocidade simulados e observados e outras duas que comparavam a distribuição do volume de tráfego e o percentual de veículos comerciais por faixa de tráfego. Os resultados mostraram que a medida mais apropriada para a comparação dos gráficos foi a distância de Hausdorff modificada (MHD). A medida MHD também foi fundamental para garantir a eficiência do método de simulação de congestionamento de tráfego proposto. O modelo calibrado foi validado usando dados de tráfego coletados em dias diferentes, pela mesma estação de monitoramento.

Palavras-chave: Calibração; Algoritmo Genético; VISSIM; Car-following; Lane-change. 



\section{Abstract}

Bethonico, F. C. Calibration of microscopic traffic simulators using macroscopic measures. 116 p. Master Thesis - São Carlos School of Engineering, University of São Paulo, 2016.

Traffic simulators are computer programs that, through various models, try to simulate traffic, driver behavior, vehicle performance, and other aspects involved in a road network. These models need calibration to represent local conditions satisfactorily. The objective of the research was to propose a method for the calibration of a traffic microsimulator based on traffic data collected by monitoring stations. To demonstrate the feasibility of the proposed approach, a case study was performed calibrating the simulator VISSIM for a section of Rodoanel Mario Covas (SP-021) using a genetic algorithm (GA). The calibration focused on behavioral parameters for car-following and lane-change submodels, as well as on the desired speed distributions of vehicles and on a method to simulate congestion. The GA fitness function was based on three performance measures: one that compared simulated and observed speed-flow plots, and two that compared the distribution of traffic volume and truck volumes across traffic lanes, respectively. The results showed that the most appropriate measure for comparison of the graphs was the modified Hausdorff distance (MHD). MHD was also important to ensure the efficiency of the method used to simulate traffic congestion. The calibrated model was validate using traffic data collected on different days, by the same monitoring station.

Keywords: Calibration; Genetic Algorithm; VISSIM; Car-following; Lane-change. 



\section{Sumário}

1 Introdução 17

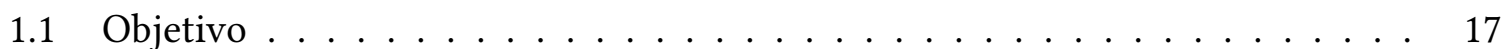

1.2 Justificativa da pesquisa $\ldots \ldots \ldots \ldots \ldots \ldots$

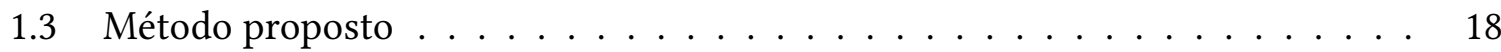

2 Revisão da literatura $\quad 21$

2.1 Simuladores de tráfego . . . . . . . . . . . . . . . . . . . . . 21

2.2 Modelos comportamentais do VISSIM . . . . . . . . . . . . . . . 22

2.2.1 Modelo de car-following . . . . . . . . . . . . . . . . . . . 22

2.2.2 Modelo de mudança de faixa do VISSIM . . . . . . . . . . . . . 25

2.3 Calibração através de algoritmo genético . . . . . . . . . . . . . 26

2.3.1 Algoritmo genético . . . . . . . . . . . . . . . . 26

2.3.2 Calibração dos modelos comportamentais do VISSIM . . . . . . . . . 27

2.3.3 Medidas de ajuste da calibração . . . . . . . . . . . . . . . 28

2.3.4 Validação da calibração . . . . . . . . . . . . . . . . . . . . . . 29

2.4 Reconhecimento de padrões . . . . . . . . . . . . . . . . . 30

2.4.1 Por medida de dissimilaridade entre conjuntos . . . . . . . . . . . 30

2.4.2 Por amostragem e quantização de imagem . . . . . . . . . . . . . 33

2.5 Considerações sobre a revisão da literatura . . . . . . . . . . . . . . . . 36

$3 \quad$ Tratamento dos dados 37 
3.1 Dados coletados . . . . . . . . . . . . . . . . . . . 37

3.1.1 Dados dos sensores de tráfego . . . . . . . . . . . . . 38

3.1.2 Dados meteorológicos . . . . . . . . . . . . . . . . 38

3.1.3 Estrutura do banco de dados . . . . . . . . . . . . . . . . . 39

3.2 Filtro de dias típicos . . . . . . . . . . . . . . . . . . 41

3.3 Filtro de dados meteorológicos f . . . . . . . . . . . . . . 42

3.4 Filtro de dados inconsistentes . . . . . . . . . . . . . . . . . . . 42

3.5 Definição do fluxo congestionado . . . . . . . . . . . . . . . . . . 43

3.6 Dias selecionados para calibração e validação . . . . . . . . . . . . . . . . . 44

3.7 Considerações finais $\ldots \ldots \ldots \ldots$. . . . . . . . . . . . . . 44

$4 \quad$ Preparação do simulador $\quad 47$

4.1 Criação da rede . . . . . . . . . . . . . . . . . . . 47

4.2 Definição do time-step . . . . . . . . . . . . . . . . . . . . . . . 48

4.3 Inserção de veículos na rede . . . . . . . . . . . . . . . . . . . . . 49

4.4 Método para obtenção de fluxo congestionado no simulador . . . . . . . . . . 51

$5 \quad$ O algoritmo genético $\quad 53$

5.1 Organização dos dados de tráfego . . . . . . . . . . . . . . . . . . 53

$5.1 .1 \quad$ Leitura dos dados de entrada . . . . . . . . . . . . . . 53

5.1 .2 Leitura dos dados de saída . . . . . . . . . . . . . . . 54

5.2 Estrutura do algoritmo . . . . . . . . . . . . . 56

5.2.1 Crossover e Seleção (Reprodução) . . . . . . . . . . . . . . . . . . . . 57

5.2 .2 Seleção natural e mutação . . . . . . . . . . . . . . . . 60

5.3 Função fitness . . . . . . . . . . . . . . . . . . . . . . . . . . . . 61

5.3.1 Medidas de desempenho . . . . . . . . . . . . . 61

5.3 .2 Coeficientes da função fitness . . . . . . . . . . . . . . . . . . 70

5.4 Determinação do mínimo de observações do gráfico de fluxo vs. velocidade . 72

5.5 Definição da duração do período de warm-up . . . . . . . . . . . . . . . 74

5.6 Definição do tamanho da população . . . . . . . . . . . . . . 75

5.7 Seleção dos parâmetros de calibração . . . . . . . . . . . . . . . . . . . 76

5.8 Definição dos parâmetros de velocidade desejada dos veículos . . . . . . . . 76 
5.9 Definição dos parâmetros de congestionamento . . . . . . . . . . . . . . . 78

5.10 Considerações finais $\ldots \ldots \ldots$. . . . . . . . . . . . . 79

$6 \quad$ Análise dos Resultados $\quad 81$

6.1 Definição da simulação default . . . . . . . . . . . . . . . . . . 81

6.2 Análise do desempenho do AG . . . . . . . . . . . . . . . . 81

6.3 Análise dos resultados . . . . . . . . . . . . . . . . . . 84

6.3.1 Análise das medidas de comparação entre conjuntos . . . . . . . . . . 84

6.3.2 Percentual de veículos comerciais e distribuição de veículos pelas faixas de tráfego . . . . . . . . . . . . . . . . . . . . . 990

6.4 Parâmetros de modelos comportamentais e de velocidade desejada . . . . . . 92

6.5 Validação da calibração . . . . . . . . . . . . . . . . . . . . . . 95

6.6 Considerações finais $\ldots \ldots \ldots \ldots$. . . . . . . . . . . . . . 96

7 Conclusões e recomendações

7.1 Recomendações . . . . . . . . . . . . . . . . . . . . . 100

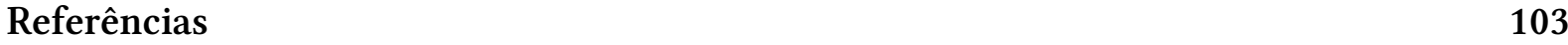

$\begin{array}{lr}\text { Apêndices } & 109\end{array}$

APÊNDICE A Tabelas da calibração do simulador $\quad 111$ 



\section{Capítulo}

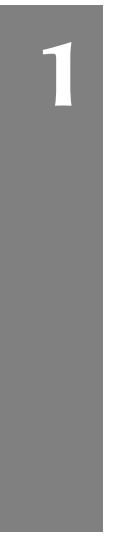

\section{Introdução}

Uma das ferramentas utilizadas para análise operacional de sistemas de transporte é o simulador de tráfego. Os simuladores de tráfego têm como objetivo a criação de modelos que se assemelham à realidade e, através da diversidade de parâmetros passíveis de ajuste, buscam obter resultados que se aproximam da melhor forma possível de um caso real. A simulação também auxilia o desenvolvimento de novas alternativas para modificações em um sistema já existente, a previsão de impactos e o estudo de situações difíceis de serem analisadas por outros métodos.

Diversos modelos são utilizados para simular o comportamento do condutor. Entre estes modelos, destacam-se o car-following, que observa a atitude do motorista diante de um veículo à sua frente, e o lane change, modelo que avalia o comportamento em relação à mudança de faixa. Devido à variedade de parâmetros e à dificuldade de se adotar valores que se enquadram em diversas situações, surge a necessidade de um método eficaz de calibração do sistema.

Para calibrar um simulador de tráfego, tem sido cada vez mais usada, desde o fim da década de 1990, uma ferramenta denominada Algoritmo Genético (AG) (MENNENI, 2008). O AG auxilia na replicação de experimentos ao variar os valores dos parâmetros passíveis de alteração baseando-se em conceitos de genética evolutiva, como crossover, mutação e seleção natural. Através de uma série extensa de simulações, o algoritmo busca os melhores ajustes de parâmetros para produzir resultados mais próximos ao que é observado em campo.

\subsection{Objetivo}

O objetivo principal desta pesquisa de mestrado é desenvolver um método para calibrar simuladores microscópicos de tráfego de um simulador, através de dados coletados por sensores de tráfego. O método propõe o ajuste do modelo por reconhecimento de padrões de gráficos de fluxo e velocidade, e por medidas de erro do percentual de veículos comerciais, além da 
distribuição do fluxo por faixa de tráfego. Como objetivos secundários, citam-se:

1. Determinar valores para os diversos parâmetros internos do algoritmo genético que minimizem o tempo de processamento sem afetar significativamente a fidedignidade dos resultados da calibração;

2. Analisar a medida mais apropriada para comparar os gráficos fluxo vs. velocidade; e

3. Propor uma forma de simular congestionamento de tráfego que reproduza, com a maior fidelidade possível, os congestionamentos observados em rodovias de pista dupla.

\subsection{Justificativa da pesquisa}

O Highway Capacity Manual (HCM), manual de capacidade de rodovias consagrado internacionalmente e principal referência na avaliação operacional (SETTI, 2009), recomenda a adaptação de seus estudos às condições locais (TRB, 2010, p. 1-6). A necessidade surge devido a diversos fatores que são diferentes em relação ao observado em rodovias americanas e canadenses, onde os dados foram obtidos para o desenvolvimento dos métodos apresentados no manual. Esses fatores podem estar relacionados à forma de condução dos motoristas (agressividade, obediência às regras de trânsito), às características dos veículos (tamanho, potência, massa) e à composição veicular (DNIT, 2006).

Assim como os diversos estudos publicados no HCM, os simuladores de tráfego também precisam ser adaptados para as redes de tráfego de diferentes regiões. A adaptação pode ser feita através da calibração dos parâmetros contidos nos modelos abordados pelos softwares, e este processo pode não ser uma tarefa tão simples de se realizar devido à dificuldade de se coletar informações que são comumente utilizadas para comparar o que é observado em campo com o resultado da simulação. Surge, então, a necessidade de se avaliar novas maneiras para adaptação dos simuladores através de métodos menos complexos e mais eficazes para ajustar o modelo de tráfego dos simuladores ao local de estudo.

\subsection{Método proposto}

O método proposto para a calibração do simulador é dividido em cinco etapas: (1) revisão da literatura; (2) análise e tratamento dos dados de sensores da rodovia; (3) preparação do simulador para a análise do trecho; (4) criação do algoritmo genético para a calibração da rede; (5) avaliação dos resultados e validação da calibração.

\section{Revisar a literatura relacionada}

A primeira etapa apresenta uma revisão da literatura dos temas que envolvem esta pesquisa. Os modelos de comportamento contidos no simulador (car-following e lane-change) foram ava- 
liados para definir quais seriam utilizados na calibração através do uso do algoritmo genético. Também foi realizada uma revisão sobre as medidas de reconhecimento de padrões utilizadas no trabalho.

\section{Analisar e tratar dados da rodovia em estudo}

Os dados dos sensores de tráfego usados no trabalho foram filtrados para que fosse considerado na pesquisa apenas o tráfego de dias típicos de operação, excluindo-se dias próximos aos fins de semana e feriados, dias em que houve ocorrência de chuva e dias de fluxo atípico, possivelmente ocasionados por incidentes ou mau funcionamento da estação. Também foi desconsiderado o fluxo de motos por não trafegarem na via da mesma forma que automóveis e veículos comerciais.

\section{Preparar o simulador para a análise do trecho}

Nesta etapa, criou-se no simulador um cenário semelhante ao trecho onde está localizado o sensor de tráfego, a partir de levantamento topográfico realizado na rodovia. As configurações do simulador também foram ajustadas para atender à necessidade da pesquisa.

Para simular dados de fluxo congestionado, foi proposto um método de simulação de congestionamento a partir de reduções temporais das velocidades desejadas dos veículos.

\section{Criar um algoritmo para calibrar o modelo}

A calibração do simulador foi feita a partir de um algoritmo baseado em conceitos de genética evolutiva. A partir da revisão da literatura sobre os modelos comportamentais do VISSIM, foram escolhidos diversos parâmetros que compõem estes modelos para serem ajustados pelo Algoritmo Genético (AG).

A etapa contemplou também as definições sobre a estrutura do AG, sobre os demais parâmetros calibrados pelo algoritmo, além das configurações necessárias para melhorar a eficiência do processo.

\section{Avaliar os resultados da calibração}

A última etapa do trabalho consistiu na avaliação dos resultados obtidos através dos métodos de calibração propostos a partir dos gráficos de fluxo-velocidade e das medidas de desempenho. Após a escolha da medida mais adequada para calibrar o simulador, foi realizada a validação da calibração para garantir a extensibilidade e a aplicabilidade do método proposto. Além disso, foram apresentadas as conclusões e recomendações para trabalhos futuros. 


\section{Capítulo}

\section{Revisão da literatura}

Este capítulo aborda uma revisão da literatura dos principais temas relacionados a esta pesquisa: o uso de simuladores de tráfego, os modelos comportamentais contidos no simulador e calibração dos parâmetros que compõem estes modelos através do uso de algoritmo genético. Por fim, a última seção trata dos métodos de reconhecimento de padrões utilizados na calibração do simulador.

\subsection{Simuladores de tráfego}

O simulador de tráfego é uma importante ferramenta para a análise operacional de sistemas de transporte. A principal vantagem do uso do simulador é oferecer ao usuário a oportunidade de avaliar estratégias alternativas de operação do sistema de transportes sem interferência no tráfego real (DEMARCHI, 2000). Ao longo dos últimos anos houve uma rápida evolução na sofisticação dos modelos de simulação, resultando em seu maior uso na engenharia de transportes (DOWLING; SKABARDONIS; ALEXIADIS, 2004).

Os modelos de simulação de tráfego podem ser classificados em:

- Macroscópicos: Consideram a corrente de tráfego como um todo, desconsiderando as interações individuais. As variáveis macroscópicas de tráfego (fluxo, velocidade média, entre outras) aplicam-se ao conjunto de veículos que trafegam em uma via ou trecho de via e apresentam valores médios associados a esses fluxos veiculares (SILVA; TYLER, 2002). Exemplos de simuladores: FREFLO, FREQ, KRONOS, KWAVES.

- Microscópicos: Os veículos na corrente de tráfego são tratados individualmente e se movem de acordo com os modelos comportamentais, tais como o car-following e lanechange (ASTARITA et al., 2001). Exemplos de simuladores: FRESIM, NETSIM, CORSIM, VISSIM, AIMSUN, TRANSIMS, TWOPAS, TRARR, INTEGRATION. 
- Mesoscópicos: Consideram que os sistemas de tráfego são compostos de elementos discretos, mas tais elementos não são unitários. É um modelo intermediário entre macroscópico e o microscópico (SILVA; TYLER, 2002). Exemplos de simuladores: DYNASMART, DYNAMIT, TRANSYT.

Nesta pesquisa, foi usado o software VISSIM (Verkehr In Stadten-SIMmulation), um programa utilizado para analisar operações de tráfego em sistemas de transporte público e privado. $\mathrm{O}$ simulador foi desenvolvido pela Universidade de Karlsruhe, na Alemanha, em 1970, e começou sua distribuição comercial em 1993 (AYALA, 2013). Dentre as funcionalidades, destaca-se a capacidade de modelar veículos de passageiros e caminhões típicos em rodovias e vias arteriais, bem como os modos de transporte, como ônibus, VLT, trens urbanos e de carga (MOEN et al., 2000).

O simulador VISSIM possui diversos parâmetros passíveis de ajuste com o objetivo de tornar as condições de tráfego da via mais semelhantes à realidade. Estes parâmetros enquadramse em quatro modelos comportamentais abordados pelo software: car-following; mudança de faixa (lane-change); aceitação de gaps (gap-acceptance); e decisão de rotas (route decision). Outro modelo contido no simulador é o de desempenho veicular, que exerce um importante papel na simulação, especialmente em trechos com aclives na rede, ao considerar a influência da potência do motor e da massa no movimento do veículo.

\subsection{Modelos comportamentais do VISSIM}

Os modelos de Wiedemann $(1974,1991)$ utilizados para simular o comportamento dos motoristas combinam aspectos psicofísicos com o desempenho dos veículos através do modelo de car-following, que rege os movimentos longitudinais de veículos, e do modelo de lane-change, que determina os movimentos transversais por um algoritmo baseado em regras (OLIVEIRA; CYBIS, 2008).

\subsubsection{Modelo de car-following}

Dois modelos de car-following podem ser usados no simulador: o modelo de Wiedemann 74 e o modelo de Wiedemann 99. O modelo de Wiedemann 74 é indicado para redes de tráfego urbanas, enquanto o modelo de Wiedemann 99 é recomendado para vias rurais (PTV, 2009), por conter parâmetros mais significativos em situações de tráfego em rodovias (fluxo contínuo).

O modelo funciona da seguinte forma: o motorista de um veículo com maior velocidade (veículo seguidor) começa a desacelerar quando encontra um veículo à sua frente, que está se deslocando com menor velocidade (veículo líder). Como o seguidor não pode determinar exatamente a velocidade do veículo líder, sua velocidade irá cair abaixo da velocidade do veículo à frente. Em seguida, o veículo seguidor começa a acelerar ligeiramente até que seja necessária 
uma nova desaceleração, a fim de evitar uma colisão. Isto resulta em um processo iterativo de aceleração e desaceleração (AYALA, 2013), simulado pelo modelo de car-following.

A Figura 2.1 ilustra o comportamento de um condutor durante o processo de car-following dos modelos de Wiedemann. O eixo das abscissas representa a diferença de velocidade $\Delta V$ entre os veículos seguidor e líder, e o eixo das coordenadas representa a distância $\Delta X$ entre eles.

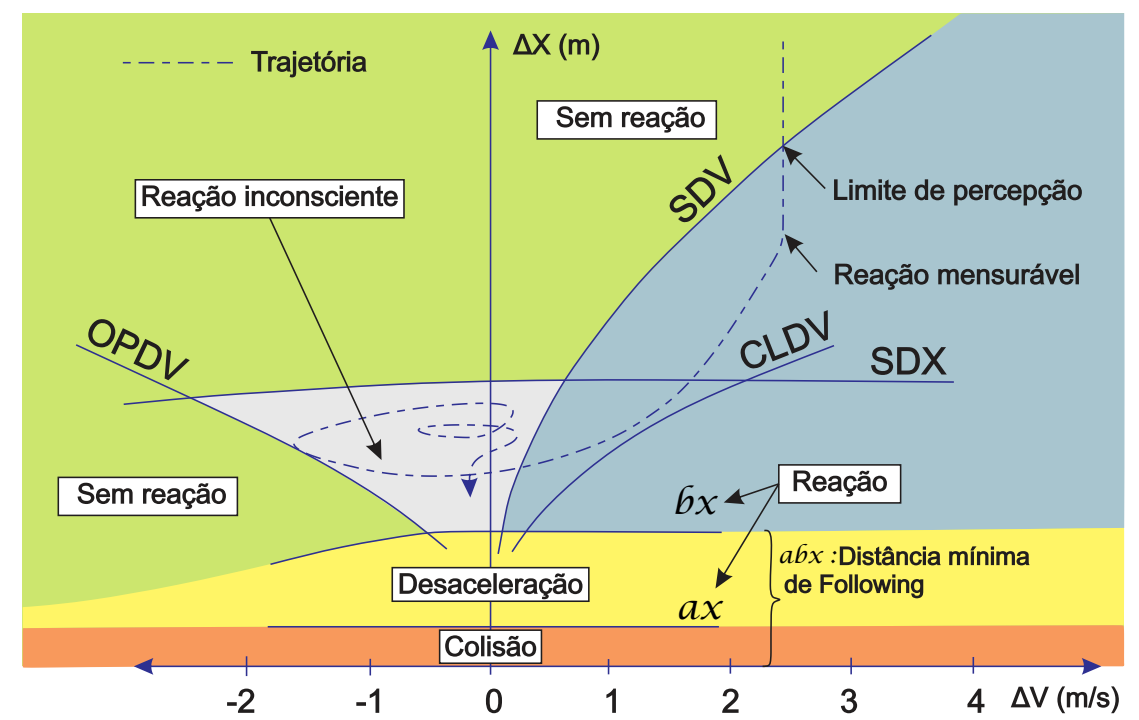

Figura 2.1 - Limiares do modelo de car-following de Wiedemann, adaptado de Wiedemann (1974)

As siglas referentes à Figura 2.1 são descritas a seguir:

- $\Delta V$ : Diferença de velocidade entre o veículo seguidor e o veículo líder. Se positiva, $\Delta V_{\text {seguidor }}>\Delta V_{\text {líder }}$; se negativa, $\Delta V_{\text {seguidor }}<\Delta V_{\text {líder }}$.

- $\Delta X$ : Distância entre o veículo seguidor e o veículo líder.

- ax: Mínima distância de headway no repouso.

- bx: Mínima distância desejada entre o veículo líder e o seguidor.

- SDX: Máxima distância desejada entre o veículo líder e o seguidor. É o limite de distância máxima para entrada ou saída do modelo de car-following, e é calculada através da soma dos parâmetros $C C 1$ e $C C 2$, definidos a seguir.

- $S D V$ : Limiar em que o motorista reconhece que está se aproximando de um veículo mais lento. É a posição em que o condutor passa a perceber que há um veículo mais lento à frente. Esse limiar é variável de acordo com a diferença entre as velocidades dos veículos.

- $O P D V$ : Limiar para a diferença de velocidade durante um afastamento na condição de car-following. É o instante em que o condutor do veículo seguidor percebe que se afastou 
do veículo líder, e passa a acelerar novamente. Esse limiar varia segundo a diferença de velocidade entre os veículos seguidor e líder.

- $C L D V$ : Limiar para a diferença de velocidade durante uma aproximação na condição de car-following. Trata-se de um limite adicional ao SDV para considerar as variações de desaceleração (FELLENDORF; VORTISCH, 2010).

O Modelo Wiedemann 74 possui três parâmetros que buscam ajustar a distância de segurança entre veículos. O modelo de Wiedemann 99 é mais complexo, contendo dez parâmetros passíveis de alteração, descritos a seguir:

- CC0: (standstill distance) (m): Distância desejada entre o veículo seguidor e o veículo líder no repouso, considerado para o cálculo da distância de segurança:

$$
a x=C C 0
$$

- CC1: (headway time) (s): Tempo desejado entre o veículo seguidor e o veículo líder, considerado para o cálculo da distância de segurança:

$$
b x=C C 0+C C 1 \times V_{\text {seguidor }}
$$

- CC2: (following variation) (m): Funciona como uma restrição da oscilação da distância de segurança:

$$
S D X=b x+C C 2
$$

- CC3: (threshold for entering following) (s): Limiar de tempo para entrada no modelo de car-following. Representa o tempo necessário para o veículo iniciar o processo de desaceleração antes de atingir a distância de segurança em relação ao veículo líder.

$$
S D V=C C 3
$$

- CC4: (negative following threshold) e CC5: (positive following threshold): Limites de following positivo e negativo. São parâmetros adimensionais que controlam a diferença de aceleração entre o veículo líder e o veículo seguidor.

- CC6: (speed dependency of oscillation): Representa a influência da distância de segurança na oscilação da velocidade durante o car-following (parâmetro adimensional).

- CC7: (oscillation acceleration): Oscilação da aceleração do veículo seguidor. Trata-se de um aumento da margem de variação da aceleração e desaceleração do veículo, enquanto este encontra-se no regime de car-following.

- CC8: (standstill acceleration): Aceleração desejada do veículo, quando este encontra-se em repouso. Esta aceleração é limitada de acordo com o modelo de desempenho do veículo. 
- CC9: (acceleration at $80 \mathrm{~km} / \mathrm{h}$ ): Aceleração desejada do veículo quando trafega em velocidade acima de $80 \mathrm{~km} / \mathrm{h}$, limitada de acordo com o modelo de desempenho do veículo.

O simulador disponibiliza parâmetros de ajuste na distância de visibilidade à jusante e à montante do condutor (look ahead distance e look back distance), definidos em metros, além do número de veículos observados OBSVEH (observed vehicles) simultaneamente para a tomada de decisões no regime de car-following. O valor padrão do parâmetro OBSVEH definido pelo VISSIM é de 2 veículos em Freeways e de 4 veículos em vias urbanas.

Há também um parâmetro relativo à probabilidade de desatenção do condutor (temporary lack of attention).

\subsubsection{Modelo de mudança de faixa do VISSIM}

O modelo de mudança de faixa no VISSIM foi originalmente desenvolvido por Sparmann (1978). Para tomar a decisão de mudar de faixa, três aspectos precisam ser avaliados (GAO, 2008): Se há a possibilidade de um veículo mudar de faixa, se a situação da faixa a qual se deseja transferir é favorável e se há a intenção de mudar de faixa. Há duas situações em que se deseja mudar de faixa: A mudança de faixa compulsória, quando há a intenção de alterar a rota e atingir um acesso; e a mudança de faixa livre, quando o veículo quer trafegar em uma via menos congestionada ou com velocidade condizente com a desejada pelo motorista.

O comportamento do condutor, quando a mudança de faixa não é compulsória, é simulado de duas maneiras: A seleção de faixa livre (free lane selection) e a regra do lado direito rightside rule. O parâmetro que faz diferenciar estes os dois modelos é o "to slower lane if collision time above", presente apenas no modo "right-side rule". Trata-se de um headway mínimo, em segundos, para que haja a mudança de faixa de um veículo na faixa rápida para a faixa lenta. Quando este parâmetro é ativado, os veículos tendem a circular nas faixas mais à direita da pista, e a mudança de faixa é regida pelo espaçamento permitido pelo headway mínimo.

Os demais parâmetros relacionados à mudança de faixa a seguir estão presentes em ambos os modelos de mudança de faixa e são passíveis de calibração:

- Necessary lane change (route): Parâmetros de desaceleração relacionados à mudança de faixa devido à rota. Não se aplica ao caso estudado devido à ausência de acessos na rede.

- Waiting time before diffusion: Tempo máximo de espera parado atrás de um veículo até ser retirado da rede (uma mensagem de erro aparecerá no fim da simulação).

- Min. Headway (front/rear): Menor distância para mudança de faixa quando o veículo está parado atrás de outro. 
- Safety distance reduction factor: O fator de redução da distância de segurança reduz a distância de segurança durante a mudança de faixa. Por exemplo, se o fator é definido como 0,6 , a distância de segurança será reduzida em $40 \%$.

- Maximum deceleration for cooperative braking: Define a desaceleração máxima de um veículo para permitir que outro veículo entre em sua faixa.

- Cooperative lane change: Modelo de troca de faixas entre veículos, em que um veículo desacelera e cede espaço a outro em sua faixa, mudando-se para a faixa em que este se encontra.

\subsection{Calibração através de algoritmo genético}

Um microssimulador de tráfego possui diversos parâmetros que estão contidos em modelos de comportamento. Muitos destes parâmetros são difíceis de medir em campo, ou pela dificuldade em isolá-los, ou pela necessidade de coletar muitos dados (HOLLANDER; LIU, 2008). Os simuladores disponibilizam valores default para os parâmetros; todavia, estes valores representam as condições de tráfego do local onde foram desenvolvidos (BESSA Jr., 2015). Estes valores podem não ser adequados a outros locais, por isso, é necessária a calibração destes parâmetros.

A calibração é um procedimento que visa determinar os valores dos parâmetros dos modelos contemplados pelo simulador para que as diferenças entre os resultados da simulação e os dados coletados em campo sejam minimizadas (HELLINGA, 1998; KIM; RILETT, 2001; EGAMI; SETTI; RILLET, 2004; SCHULTZ; RILETT, 2005; KIM; KIM; RILETT, 2005; HOLLANDER; LIU, 2008; BESSA Jr., 2009).

Caso o ajuste de parâmetros seja feito manualmente, é imprescindível que se tenham poucos parâmetros (HOLLANDER; LIU, 2008). Porém, a calibração de um conjunto maior de parâmetros aumenta a confiabilidade do simulador, mas deve ser feita através de um procedimento automático para que a probabilidade de atingir uma boa resposta seja maior (MA; DONG; ZHANG, 2007; BESSA Jr., 2009). A vantagem de se utilizar uma calibração automática é que pode-se calibrar vários parâmetros simultaneamente gastando menos tempo, além disso, a verificação dos resultados ao longo do processo também é realizada automaticamente pelo programa (EGAMI, 2006).

\subsubsection{Algoritmo genético}

Os algoritmos genéticos (AG) são algoritmos de busca baseados nos mecanismos de seleção natural e genética (GOLDBERG, 1989), criados por John Holland na Universidade de Michigan. Um algoritmo de busca é um conjunto de processos cuja saída de dados busca a resolução do problema de entrada através de sucessivas tentativas. 
O AG é um conjunto de processos iterativo que inicia com uma população gerada de maneira aleatória. Em cada iteração (geração), os indivíduos, ou seja, as soluções para um problema, são avaliados e selecionados de acordo com o grau de adaptação ao meio ambiente (BESSA Jr., 2009). Esse grau de adaptação é denominado fitness, e representa a qualidade da solução encontrada. Dessa forma, o processo mantém os indivíduos mais bem adaptados para transmitir suas características em gerações futuras, enquanto os que possuem o menor fitness tendem a desaparecer (GOLDBERG, 1989; TOMASSINI, 1995; CUNHA; SETTI, 2006).

Um AG que conduz a bons resultados em muitos problemas práticos é composto por três operadores (GOLDBERG, 1989): Reprodução (ou seleção), cruzamento (ou crossover) e mutação. A reprodução remete à seleção natural, em que um indivíduo com maior valor da função tem maior probabilidade de contribuir para a formação de um ou mais descendentes na próxima geração (GOLDBERG, 1989). Para melhorar o desempenho do algoritmo genético, pode-se utilizar uma seleção elitista, procedimento em que se preserva os melhores indivíduos da população para seguirem inalterados para a próxima geração, garantindo que o fitness da geração seguinte não seja menor que o fitness de indivíduos antecessores (ANACLETO, 1996).

O crossover é a troca de informações entre cromossomos. O procedimento consiste na combinação entre genes de dois indivíduos, escolhidos no processo de reprodução, para a formação de novos indivíduos. A mutação serve para introduzir variações aleatórias nas soluções, e dessa maneira, reduzir a probabilidade de um dos parâmetros fixar seu valor em um ótimo local. $\mathrm{Na}$ programação do algoritmo, a mutação consiste em modificar os cromossomos a partir de uma probabilidade denominada taxa de mutação (GOLDBERG, 1989; TOMASSINI, 1995; CUNHA; SETTI, 2006; BESSA Jr., 2009).

\subsubsection{Calibração dos modelos comportamentais do VISSIM}

Em âmbito nacional, Lacerda e Castro Neto (2014) discorrem sobre pontos relevantes acerca da calibração do modelo de car-following do VISSIM para a modelagem do desempenho operacional do tráfego em vias arteriais. Os autores fazem ainda uma análise de sensibilidade que indica que o modelo de Wiedemann 74 é mais adequado para modelar tempo de viagem e atraso para vias urbanas. Também são discutidos no trabalho aspectos conceituais importantes sobre a metodologia de calibração como escolha dos parâmetros e das medidas de desempenho.

Oliveira e Cybis (2008) avaliaram o modelo de car-following de Wiedemann 99 do VISSIM para ambientes rodoviários, analisando a aplicabilidade das experiências reportadas na literatura em um estudo de caso de uma autoestrada brasileira. O estudo, realizado na rodovia BR-290, indica alteração preferencial dos parâmetros de distância de parada (CC0), tempo de headway (CC1) e limites negativos e positivos (CC4 e CC5) para a calibração de trechos rodoviários. Segundo Oliveira e Cybis, estes parâmetros influenciam diretamente as velocidades e capacidades, atuando no espaçamento desejado de tráfego entre veículos.

Na literatura encontram-se trabalhos que utilizam diferentes formas de calibração dos mo- 
delos comportamentais: Através do uso de dados desagregados dos veículos (CHU et al., 2003; TOLEDO et al., 2003; DOWLING; SKABARDONIS; ALEXIADIS, 2004; SHAABAN; RADWAN, 2005; KIM; KIM; RILETT, 2005; PARK; QI, 2005) ou utilizando dados agregados de fluxo e velocidade média de veículos (MENNENI; SUN; VORTISCH, 2008; GOMES; MAY; HOROWITZ, 2004).

Menneni, Sun e Vortisch (2008) utilizaram dados agregados fluxo e velocidade média para calibrar uma rede de tráfego localizada no estado da Califórnia, Estados Unidos. Foram calibrados apenas cinco parâmetros do modelo de car-following de Wiedemann 99 no VISSIM (CC1, $\mathrm{CC} 2, \mathrm{CC} 3, \mathrm{CC} 4, \mathrm{CC} 5$ ), com base em dados obtidos por sensores. Estes parâmetros referem-se à distância de segurança entre os veículos e aos limiares de velocidade e proximidade em relação a outros veículos para enquadrar-se no modelo de perseguição.

Gomes, May e Horowitz (2004) calibraram um conjunto limitado de parâmetros (CC0, CC1, CC4 e CC5, além de parâmetros de desacelerações máximas do modelo de mudança de faixa) para redes de vias rurais, usando dados agregados do percentual de veículos comerciais. Caleffi et al. (2012) utilizaram dados de velocidade média de veículos obtidos através de laços indutivos e filmagens para calibrar apenas os parâmetros CC1, CC2, CC3, CC4 e CC5 do modelo de Wiedemann 99 em um trecho da rodovia BR-290.

A calibração através de dados desagregados é encontrada em diversos trabalhos na literatura. Como exemplo, cita-se Bham e Vallati (2011), que propuseram adaptações na geometria dos acessos de uma rodovia a partir do estudo da distribuição do espaçamento entre veículos em faixas exclusivas para caminhões. Os autores calibraram somente alguns parâmetros de car-following (CC0, CC1, CC2, CC4 e CC5), e o parâmetro de mudança de faixa relativo ao fator de redução de distância segura (Safety distance reduction factor).

Observa-se, então, a necessidade de se avaliar métodos que proponham a calibração de quantidade maior de parâmetros de modelos comportamentais, utilizando, preferencialmente, dados simples de serem obtidos em campo como medidas de desempenho.

\subsubsection{Medidas de ajuste da calibração}

A qualidade do ajuste da calibração é regida basicamente pela comparação entre a saída do simulador e os diversos dados obtidos em campo (HOLLANDER; LIU, 2008). Essa comparação é feita por parâmetros denominados "medidas de desempenho". O algoritmo, através da análise do erro das medidas de desempenho, busca selecionar o conjunto de valores dos parâmetros de calibração que fornece a melhor resposta.

Usualmente, utilizam-se funções objetivo baseadas na tendência central das medidas de desempenho, ainda que alguns trabalhos incluam a dispersão das medidas no cálculo do valor da função objetivo (HOLLANDER; LIU, 2008; BESSA Jr., 2009). Dentre estas funções objetivo, estão o erro percentual (PE), o erro quadrático (SE), o erro médio (ME), o erro médio absoluto (MAE), entre outras. A Tabela 2.1 apresenta algumas medidas de erro utilizadas para a calibração de 
simuladores.

Tabela 2.1 - Medidas de erro (Adaptado de Hollander e Liu (2008))

\begin{tabular}{lcl}
\hline Nome & Equação & Referência \\
\hline Erro percentual (PE) & $\frac{x_{i}-y_{i}}{y_{i}}$ & Park e Qi (2005) \\
Erro quadrático (SE) & $\sum_{i=1}^{N}\left(x_{i}-y_{i}\right)^{2}$ & Toledo e Koutsopoulos (2004) \\
Erro médio (ME) & $\sum_{i=1}^{N}\left(x_{i}-y_{i}\right)$ & Toledo et al. (2004) \\
Erro médio absoluto (MAE) & $\frac{1}{N} \sum_{i=1}^{N}\left|x_{i}-y_{i}\right|$ & Ma e Abdulhai (2002) \\
Erro médio normalizado (MNE) & $\frac{1}{N} \sum_{i=1}^{N}\left(x_{i}-y_{i}\right)$ & Toledo et al. (2003) \\
Erro médio absoluto normalizado (MANE) & $\frac{1}{N} \sum_{i=1}^{N} \frac{\left|x_{i}-y_{i}\right|}{y_{i}}$ & Ma e Abdulhai (2002) \\
\hline
\end{tabular}

As medidas de desempenho avaliadas na maioria das pesquisas relacionadas à calibração do simulador são: tempo de viagem (CHU et al., 2003; DOWLING; SKABARDONIS; ALEXIADIS, 2004; KIM; KIM; RILETT, 2005; PARK; QI, 2005); fluxo (HOURDAKIS; MICHALOPOULOS; KOTTOMMANNIL, 2003; KIM; RILETT, 2003; TOLEDO et al., 2004; CHU et al., 2003); velocidade (HOURDAKIS; MICHALOPOULOS; KOTTOMMANNIL, 2003; TOLEDO et al., 2004; TOLEDO; KOUTSOPOULOS, 2004; BROCKFELD; KÜHNE; WAGNER, 2004); e tamanho de filas (TOLEDO et al., 2003; SHAABAN; RADWAN, 2005). Apesar do uso de medidas macroscópicas como fluxo e velocidade média em alguns trabalhos, poucos aliam estas medidas ao uso de algoritmos genéticos.

\subsubsection{Validação da calibração}

A validação é uma etapa essencial do processo de calibração, e determina se o modelo calibrado representa de maneira correta o sistema real (HELLINGA, 1998). Esta etapa deve ser feita a partir de um conjunto de dados diferente do que foi utilizado para realizar a calibração (BESSA Jr., 2009), porém, não é necessário que esse novo conjunto de dados seja coletado no mesmo local avaliado no primeiro processo (HOLLANDER; LIU, 2008).

Há diversos métodos para validar um simulador, tais como (HOLLANDER; LIU, 2008):

- Validação visual, através de representações gráficas dos valores das medidas de desempenho observadas e simuladas;

- Validação a partir da função objetivo, que deve ser a mesma utilizada na calibração;

- Validação estatística, a partir de testes em medidas observadas e simuladas para avaliar se possuem as mesmas propriedades. 
A validação é a determinação do quão o modelo da simulação representa de forma precisa o sistema em estudo: se o modelo é válido, então as decisões tomadas pelo modelo devem ser similares às que ocorreriam em uma experimentação física com o sistema (se fosse possível) (BRACKSTONE; PUNZO, 2014). Todavia, vale ressaltar que a validação não deve ser mais rigorosa que a calibração, uma vez que as incertezas são intrínsecas aos parâmetros definidos no processo de ajuste (BESSA Jr., 2009).

Alguns trabalhos realizaram a validação através de comparação visual entre dados observados e simulados ou através de estatística descritiva (TOLEDO; KOUTSOPOULOS, 2004). Por exemplo, Abdulhai, Sheu e Recker (1999) compararam gráficos observados e simulados de distribuições de headway, de percentual de fluxo por faixa, e de curvas de fluxo-densidade, e calcularam o erro percentual relativo da média da demanda total, do fluxo e do percentual de fluxo. Fellendorf e Vortisch (2001) validaram a calibração do VISSIM pela comparação entre dados observados e simulados através de gráficos de fluxo-velocidade, de velocidade-tempo do veículo líder e do percentual de veículos por faixa.

\subsection{Reconhecimento de padrões}

Uma das principais metas da análise de imagens por computador é dotar uma máquina com a capacidade dos seres humanos de identificar padrões (GONZALEZ; WOODS, 2007). Comparar duas formas distintas é, na maioria dos casos, uma tarefa simples de se realizar visualmente. Todavia, há uma necessidade de se automatizar esse processo e de se obter uma medida comparativa para definir o quão próximo um conjunto está de outro conjunto. Este problema é recorrente em estudos para reconhecimento de padrões, que buscam soluções simples de se implementar, que consumam menos tempo e que possam produzir resultados razoáveis (ZHAO; SHI; DENG, 2005).

Neste trabalho, são testados dois métodos de reconhecimento de padrões: Por medida de dissimilaridade entre conjuntos e por quantização de imagem. Esses dois métodos são apresentados nas seções a seguir.

\subsubsection{Por medida de dissimilaridade entre conjuntos}

A distância de Hausdorff é uma medida que desempenha um papel essencial nos estudos de reconhecimento de imagens. Trata-se da determinação da maior distância que os pontos de um determinado conjunto podem ter em relação a outro conjunto de pontos. Sendo $a$ e $b$ quaisquer pontos de conjuntos distintos $A=a_{1}, a_{2}, \ldots, a_{n}$ e $B=b_{1}, b_{2}, \ldots, b_{n}$ e a distância entre os pontos

sendo definida como a distância euclidiana $d(a, b)=\sqrt{\left(x_{a}-x_{b}\right)^{2}+\left(y_{a}-y_{b}\right)^{2}}=\|a-b\|$, temos a distância de Haudorff (HUTTENLOCHER; KLANDERMAN; RUCKLIDGE, 1993) definida como:

$$
H(A, B)=\max [h(A, B), h(B, A)]
$$


em que: $\quad h(A, B)=\max _{a \in A} \min _{b \in B}\|a-b\|$;

$$
h(B, A)=\max _{b \in B} \min _{a \in A}\|b-a\| .
$$

A função $h(A, B)$, denominada distância direta de Hausdorff de $A$ para $B$, identifica o ponto $a \in A$ de maior distância ao ponto mais próximo do conjunto $B$. Intuitivamente, se $h(A, B)=d$, qualquer ponto $a$ possui distância menor ou igual a $d$, no que tange à mínima distância aos pontos do conjunto $B$ (HUTTENLOCHER; KLANDERMAN; RUCKLIDGE, 1993).

O esquema apresentado pela Figura 2.2 ilustra o passo-a-passo do cálculo da distância, que ocorre da seguinte maneira:

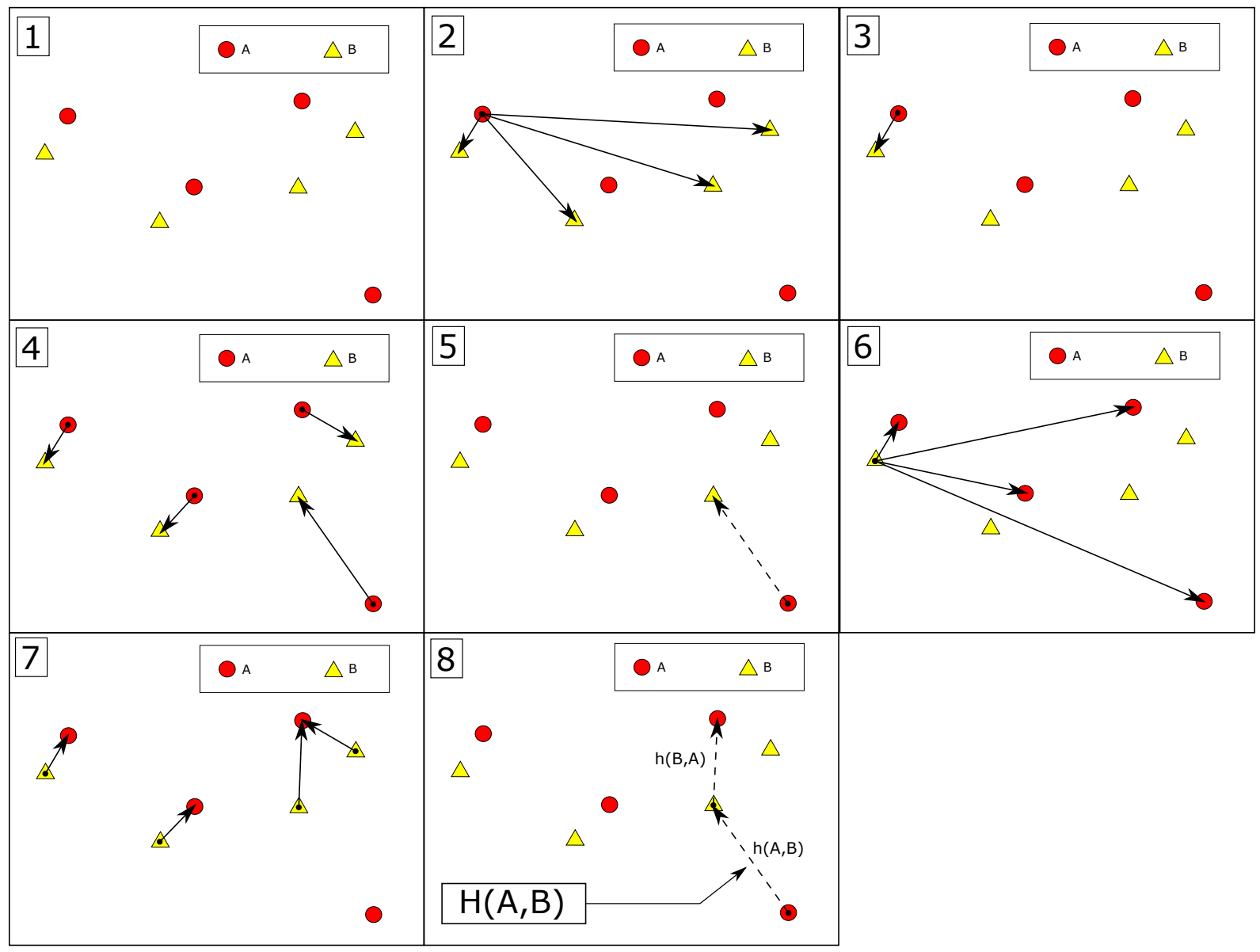

Figura 2.2 - Processo de cálculo da distância de Hausdorff

- Quadro 1 - Têm-se dois conjuntos distintos, denominados $A$ e $B$, com $n$ pontos;

- Quadro 2 - Calculam-se as distâncias $d(a, b)=\|a-b\|$ de um ponto qualquer $a$ do conjunto $A$ para todos os $n$ pontos do conjunto $B$;

- Quadro 3 - Armazena-se a menor distância daquele ponto em relação a qualquer ponto do conjunto $B ; d(a, B)=\min _{b \in B}(a, b)$; 
- Quadro 4 - Repetem-se os procedimentos 2 e 3 para todos os pontos do conjunto $A$, obtendo-se o conjunto contendo as mínimas distâncias entre cada ponto $a$ do conjunto $A$ para o conjunto $B ; d(a, B)=\min _{b \in B}(a, b)$;

- Quadro 5 - Avalia-se qual a maior distância entre as mínimas distâncias do conjunto $B$ para o conjunto $A ; h(A, B)=\max _{a \in A}\left[\min _{b \in B} d(a, B)\right]$;

- Quadro 6 - Repete-se o mesmo procedimento que ocorre no Quadro 2, porém, do conjunto $B$ em relação aos pontos do conjunto $A, \operatorname{com} d(b, a)=\|b-a\|$;

- Quadro 7 - Armazenam-se as mínimas distâncias dos pontos do conjunto $B$ em relação ao conjunto $A ; d(b, A)=\min _{a \in A}(b, a)$; A máxima distância dos pontos do conjunto $B$ em relação ao conjunto $A$ é calculada por: $h(B, A)=\max _{b \in B}\left[\min _{a \in A} d(b, A)\right]$;

- Quadro 8 - A partir dos valores das máximas-mínimas distâncias entre os conjuntos $h(A, B)$ e $h(B, A)$, define-se a distância de Hausdorff $H(A, B)=\max [h(A, B), h(B, A)]$ como o maior dos valores entre as duas distâncias.

O método, apesar de simples, é extremamente sensível a outliers (ZHAO; SHI; DENG, 2005). Se uma forma possui um ponto que diverge dos demais em grande escala, toda a dissimilaridade entre os conjuntos será definida por este ponto distante.

Algumas adaptações do método têm sido consideradas como eficazes para amenizar essas perturbações (HUTTENLOCHER; KLANDERMAN; RUCKLIDGE, 1993; DUBUISSON; JAIN, 1994; LU et al., 2001; KWON; SIM; PARK, 2001; GUO et al., 2003; LIN; LAM; SIU, 2003; ZHAO; SHI; DENG, 2005; TAN; ZHANG, 2006; VIVEK; SUDHA, 2007). Uma dessas adaptações é denominada distância de Hausdorff modificada, cuja diferença para a distância de Hausdorff é a utilização da média ao invés da máxima das mínimas distâncias entre os pontos. A Figura 2.3 ilustra a diferença entre o processo de cálculo da distância de Hausdorff e a distância de Hausdorff modificada. Dubuisson e Jain (1994) sugerem calcular a distância de Hausdorff modificada da seguinte forma:

- Quadro 1 - Sendo $n_{a}$ a quantidade de pontos do conjunto $A$, calcula-se a média das mínimas distâncias dos pontos $a$ do conjunto $A$ em relação ao conjunto $B$, para $\mathrm{i}=1, \ldots, n_{a}$ :

$$
h_{M H D}(A, B)=\frac{1}{n_{a}} \sum_{i=1}^{n_{a}} d\left(a_{i}, B\right)
$$

- Quadro 2 - Sendo $n_{b}$ a quantidade de pontos do conjunto $B$, calcula-se a média das mínimas distâncias dos pontos $b$ do conjunto $B$ em relação ao conjunto $A$, para $\mathrm{j}=1, \ldots, n_{b}$;

$$
h_{M H D}(B, A)=\frac{1}{n_{b}} \sum_{j=1}^{n_{b}} d\left(b_{j}, A\right)
$$




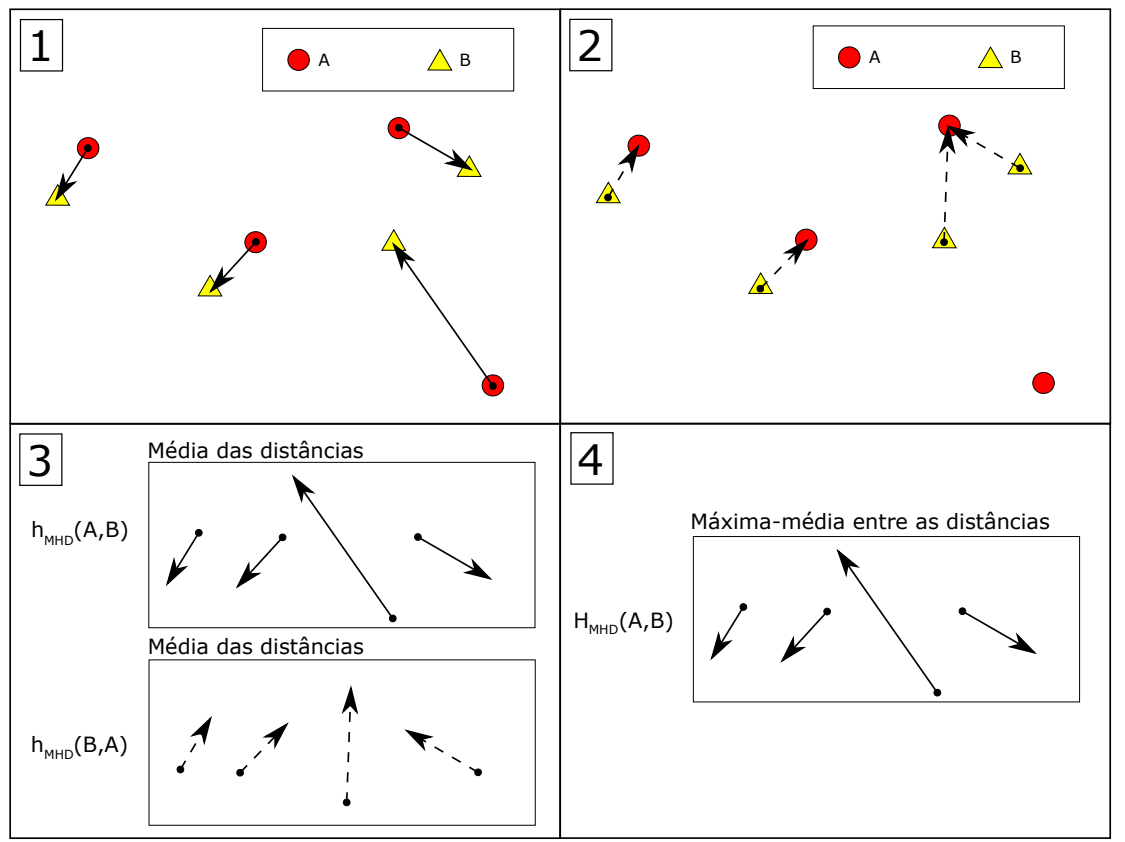

Figura 2.3 - Processo de cálculo da distância de Hausdorff modificada

- Quadro 3 - Comparam-se as duas médias $h_{M H D}(A, B)$ e $h_{M H D}(B, A)$;

- Quadro 4 - A distância de Hausdorff modificada $H_{M H D}(A, B)$ é a máxima entre as duas médias.

$$
H_{M H D}(A, B)=\max \left[h_{M H D}(A, B), h_{M H D}(B, A)\right]
$$

Pode-se avaliar pelas equações descritas nesta seção que um conjunto de pontos sobrepõe perfeitamente o outro quando $H_{M H D}(A, B)$ é igual a zero. Dessa forma, a solução do problema resume-se a minimizar a distância de Hausdorff modificada (MHD).

\subsubsection{Por amostragem e quantização de imagem}

O termo imagem digital, ou simplesmente imagem, é designado à função bidimensional de intensidade da luz $f(x, y)$, em que $x$ e $y$ são as coordenadas espaciais e o valor de $f$ em qualquer ponto $(x, y)$ refere-se à intensidade (brilho) da imagem naquele ponto (GONZALEZ; WOODS, 2007), conforme Equação 2.9 e Figura 2.4, que apresenta como é convencionado o plano cartesiano para a representação de uma imagem.

$$
f(x, y)=\left[\begin{array}{cccc}
f(0,0) & f(0,1) & \ldots & f(0, M-1) \\
f(1,0) & f(1,1) & \ldots & f(1, M-1) \\
\vdots & \vdots & \ddots & \vdots \\
f(N-1,0) & f(N-1,1) & \ldots & f(N-1, M-1)
\end{array}\right]
$$

O processo de digitalização das coordenadas espaciais $(x, y)$ em valores discretos é denominado amostragem. A amostragem representa o tamanho da imagem nos eixos $x$ e $y$, repre- 


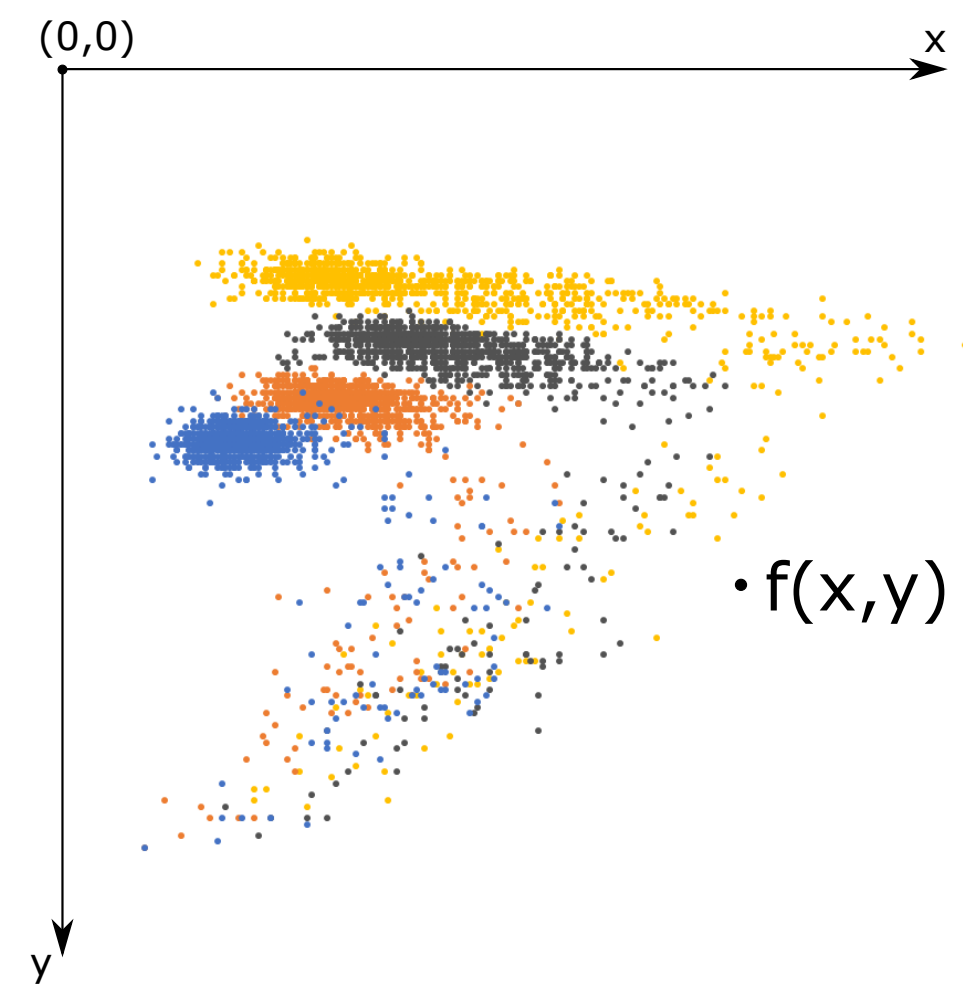

Figura 2.4 - Representação do plano cartesiano em relação à imagem

sentados por $M$ linhas e $N$ colunas. A Figura 2.5 apresenta três exemplos de amostragem de imagem: O primeiro (a) com 65.536 (256x256) pixels, o segundo (b) com 4.096 (64x64) pixels e o terceiro (c) com $256(16 \times 16)$ pixels.

(a)

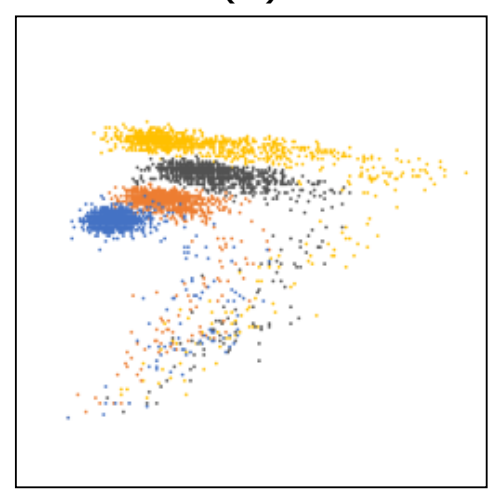

(b)

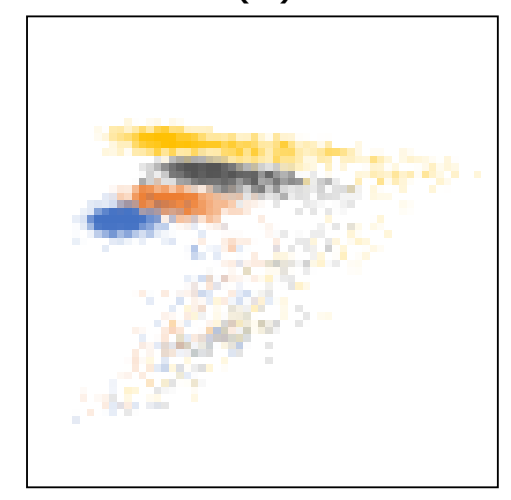

(c)

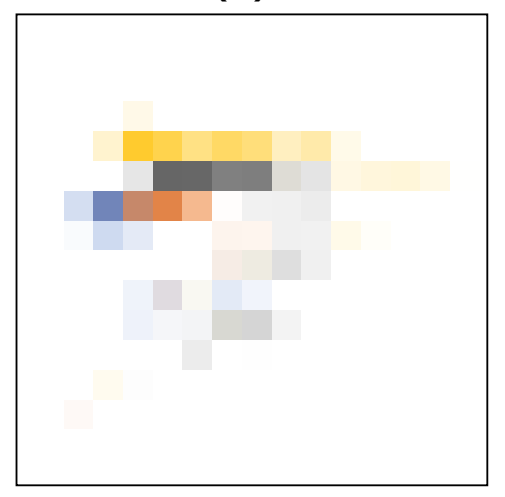

Figura 2.5 - Exemplos de amostragem de imagem

Cada ponto $(x, y)$ da matriz digital é denominado "elemento da imagem" ou pixel, uma abreviação de Picture Element. O nível de cinza $f(x, y)$ de cada pixel é quantizado em uma escala de acordo com a resolução da imagem. Por exemplo, uma imagem com 1 bit de resolução apresenta apenas dois níveis de cinza, o branco e o preto, denominada imagem binária; enquanto uma imagem com resolução de 8 bits fornece 256 níveis de cinza diferentes variando 
do branco ao preto, e a quantização em 256 níveis traz muita informação que pode ser usada para diferenciar objetos (CUNHA, 2013). A cor preta está associada ao nível 0 e a cor branca ao nível 255, enquanto os níveis intermediários de cinza assumem valores inteiros entre os dois extremos.

Em imagens coloridas, no espaço de cores RGB (red-blue-green), cada pixel armazena três valores de intensidade de luz, um para cada plano de cor representado por: $f(x, y)=(R, G, B)$. Dessa forma, imagens coloridas possuem 24 bits ( 3 planos de 8 bits), totalizando mais de 16 milhões de cores diferentes.

As informações contidas nas imagens digitais podem oferecer condições para que se realize uma etapa fundamental da análise de imagens: o reconhecimento de padrões (GONZALEZ; WOODS, 2007). O reconhecimento de padrões através da segmentação de imagens é encontrado facilmente na literatura (PAL; PAL, 1993).

Menneni, Sun e Vortisch (2008) utilizaram a representação gráfica de dados de fluxo e velocidade para calibrar uma rede no simulador VISSIM utilizando um AG. Cada elemento de imagem (pixel) continha informações sobre a ocorrência ou não de observações de tráfego. A função objetivo baseava-se na minimização do somatório dos pixels de fluxo e velocidade dos dados observados que não foram cobertos pelos dados gerados pela simulação.

Outra métrica comumente usada na literatura para verificar a detecção de objetos em imagens é a matriz de contingência (CUNHA, 2013). Assim como a medida utilizada por Menneni, Sun e Vortisch (2008) de acertos por pixel, a avaliação é feita através da imagem gerada a partir do processo de amostragem.

A associação entre as imagens com gráficos gerados por dados de fluxo e velocidade observados e simulados é feita através da matriz de contingência, apresentada na Tabela 2.2 .

Tabela 2.2 - Tabela de Contingência - Adaptada de Fawcett (2006)

\begin{tabular}{llll}
\hline Referência (sensor) & $\begin{array}{l}\text { Resultado (simulador) } \\
\text { Positivo }\end{array}$ & Negativo & Total \\
\hline Positivo & Verdadeiro Positivo (VP) & Falso Negativo (FN) & Positivos (P) \\
Negativo & Falso Positivo (FP) & Verdadeiro Negativo (VN) & Negativos (N) \\
\hline
\end{tabular}

em que $V P$ (verdadeiro positivo): Áreas em que há pontos observados e simulados; $V N$ (verdadeiro negativo): Áreas em que não há pontos observados ou simulados; FP (falso positivo): $\quad$ Áreas em que não pontos observados, mas há presença de pontos simulados;

FN (falso negativo): $\quad$ Área em que há pontos observados, mas não há pontos simulados.

Algumas métricas podem ser calculadas a partir da classificação da matriz de contingência. A taxa de verdadeiros positivos, a precisão e a exatidão são calculadas de acordo com as 
equações:

$$
\begin{aligned}
\text { Taxa de VP } & =\frac{V P}{V P+F N} \\
\text { Precisão } & =\frac{V P}{V P+F P} \\
\text { Exatidão } & =\frac{V P+V N}{V P+F P+V N+F N}
\end{aligned}
$$

A taxa de verdadeiros positivos representa o percentual de objetos relacionados corretamente $(V P)$ em relação à imagem de referência $(V P+F N)$, no caso, da imagem dos dados do sensor. A precisão expressa o percentual de acertos do objeto $(V P)$ em relação à quantidade de dados simulados $(V P+F P)$. A exatidão representa a razão dos elementos de imagem associados corretamente $(V P)$, incluindo os pixels em que não há observações e que foram relacionados adequadamente $(V N)$, a todos os pixels da imagem $(V P+F P+V N+F N)$.

\subsection{Considerações sobre a revisão da literatura}

A revisão da literatura abordou assuntos relevantes para o entendimento do método de calibração proposto. Além de uma breve revisão sobre os simuladores de tráfego, foram discutidos os modelos comportamentais de car-following e lane-change utilizados pelo VISSIM.

A calibração através de algoritmo genético foi discutida a partir de trabalhos encontrados na literatura que realizaram o procedimento, e também os métodos de reconhecimento de padrões utilizados na pesquisa.

Foi possível avaliar que grande parte dos estudos realizam a calibração a partir de uma quantidade limitada de parâmetros comportamentais, e que apenas alguns trabalhos utilizam medidas de comparação rotineiramente coletadas, como dados de fluxo e velocidade, obtidos através de estações de monitoramento.

A partir destas considerações, é apresentado, no capítulo seguinte, o tratamento dos dados de tráfego utilizados para a calibração do simulador. 


\section{Capítulo}

\section{Tratamento dos dados}

O presente capítulo apresenta o tratamento dos dados de tráfego, obtidos através de estações de monitoramento de tráfego na rodovia, e de informações das condições do tempo no local durante a coleta dos dados, obtidas por radares meteorológicos. Também são descritos no capítulo: a origem dos dados utilizados; a estruturação do banco de dados; a aplicação dos filtros e os dias selecionados para as etapas de calibração e validação. Por fim, é apresentado o procedimento para definição do fluxo congestionado.

\subsection{Dados coletados}

As coletas dos dados de tráfego que foram utilizados nesta pesquisa ocorreram no ano de 2010 através de sensores localizados entre os quilômetros 22 e 23 da rodovia SP-021, também denominada Rodoanel Mário Covas. O local foi escolhido devido às características do tráfego e aos aspectos geométricos da via.

A variabilidade do tráfego no local foi o motivo de escolha do ponto de coleta estudado. O local possui tráfego intenso de veículos em alguns períodos, e assim, pode se encontrar registros de todos os regimes de fluxo e de todos os níveis de serviço nos dados das estações de monitoramento.

Quanto às características geométricas, escolheu-se o Rodoanel por se tratar de uma típica rodovia de pista dupla do Estado de São Paulo. Além disso, o local não possui declives de grande extensão, conforme pode ser observado na Seção 4.1. Dessa forma, a influência do modelo de desempenho de veículos comerciais pode ser considerada insignificante, uma vez que a calibração do modelo de desempenho requer cenários completamente diferentes do usado nesta pesquisa (CUNHA; BESSA Jr.; SETTI, 2009). 


\subsubsection{Dados dos sensores de tráfego}

As estações de monitoramento da rodovia são compostas por laços indutivos, atualmente os sensores mais utilizados no gerenciamento do tráfego (KLEIN, 2001). O laço indutivo é formado por espiras de fio isolado, enterradas no revestimento do pavimento; e por um cabo de entrada, que liga a caixa de passagem (localizada ao lado da rodovia) ao gabinete do controlador, que armazena os dados. Quando um veículo para ou passa sobre as espiras, a indutância no fio diminui. A variação da indutância, causada pelo metal do veículo, envia pulsos ao controlador, indicando a presença ou a passagem de um veículo (KLEIN, 2001).

Os sensores das rodovias do estado de São Paulo fornecem dados agregados de fluxo e velocidade média dos veículos a cada 5 ou 6 minutos, com a informação dividida por tipo de veículo: motos, automóveis e veículos comerciais.

Os dados de fluxo de motos não foram considerados nesta pesquisa, pois a circulação das motos não ocorre da mesma forma que os outros veículos. As motocicletas eventualmente circulam entre duas faixas de tráfego, ou ocupam a faixa junto a outro veículo leve, lado a lado.

Com a eliminação dos dados de motos, fez-se uma média ponderada da velocidade dos veículos comerciais e dos automóveis com o fluxo para obter a velocidade média $u_{m}$ dos veículos considerados, conforme Equação 3.1:

$$
u_{m}=\frac{Q_{c} \times u_{c}+Q_{t} \times u_{t}}{Q_{c}+Q_{t}}
$$

Em que: $u_{m}$ : Velocidade média dos veículos;

$Q_{c}$ : Fluxo de automóveis;

$u_{c}$ : Velocidade média dos automóveis;

$Q_{t}: \quad$ Fluxo de veículos comerciais;

$u_{t}$ : Velocidade média dos veículos comerciais.

\subsubsection{Dados meteorológicos}

Foram utilizadas, nesta pesquisa, informações meteorológicas fornecidas pelo Instituto de Pesquisas Meteorológicas da UNESP (IPMet). Os dados baseiam-se em imagens de radares meteorológicos localizados na cidade de Bauru e Presidente Prudente, com intervalos de capturas a cada 30 minutos (PIZZOL; SETTI, 2013). Na Figura 3.1, o mapa fornecido pelo IPMet apresenta áreas de cor cinza, indicando tempo seco, e áreas coloridas, que indicam a presença e a intensidade da chuva.

As imagens dos radares foram processadas através do sistema de cores HSV para obter a condição do tempo através dos pixels correspondentes aos postos de coletas dos dados de tráfego para cada intervalo de tempo de captura. Para cada 30 minutos de observação, foram 


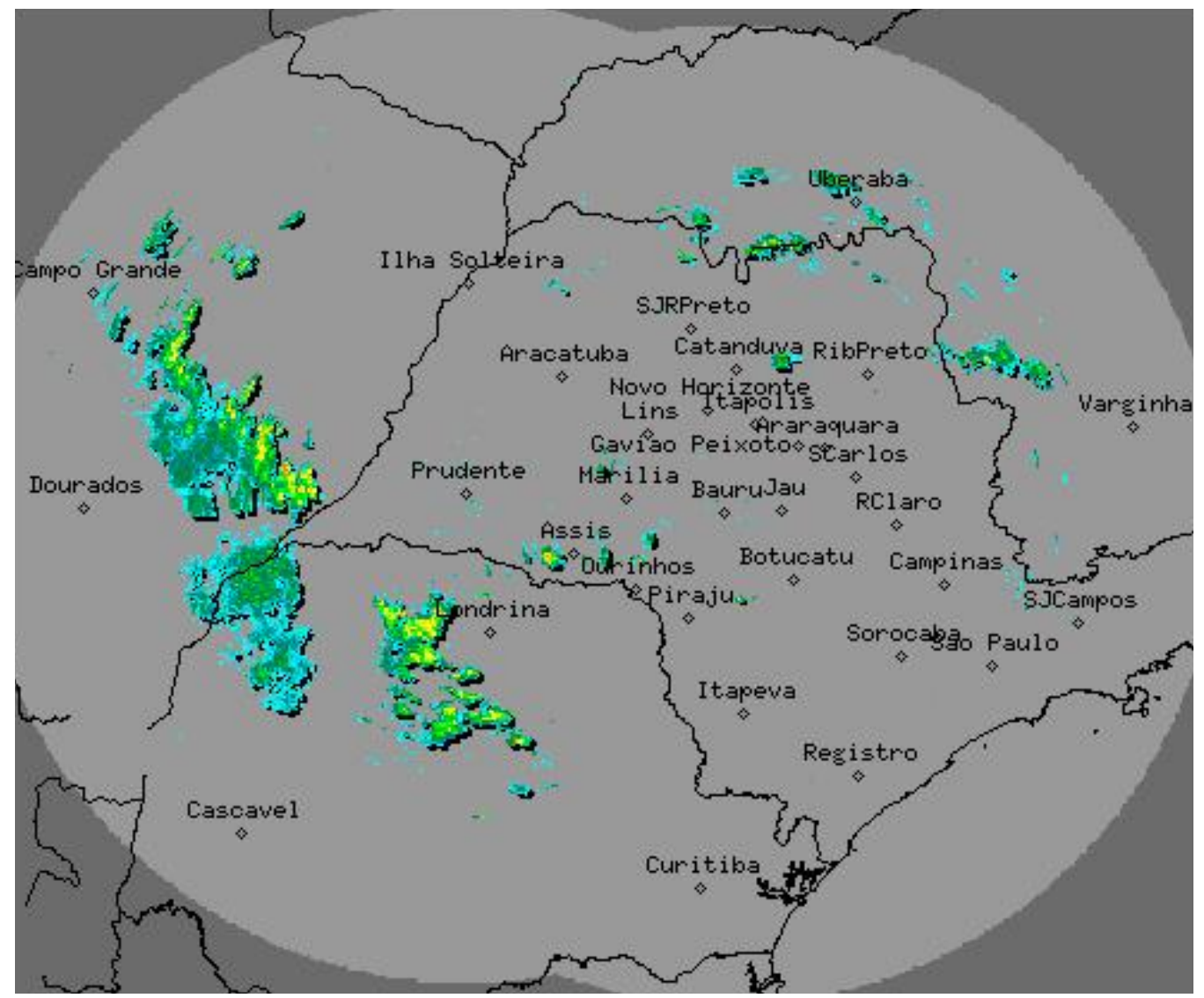

Figura 3.1 - Imagem dos radares do IPMet

atribuídas uma das três classificações das condições climáticas nos locais de coleta de dados de tráfego: sem chuva (1), com chuva (2) e indeterminado (3) (PIZZOL; SETTI, 2013).

\subsubsection{Estrutura do banco de dados}

Os dados fornecidos pela concessionária CCR-Rodoanel, através da ARTESP (Agência Reguladora de Serviços Públicos Delegados de Transporte do Estado de São Paulo), foram coletados nas estações de monitoramento da SP-021. As tabelas com as informações de contagem de veículos e velocidade média da classe veicular são identificadas através de um código com a seguinte estrutura:

- "A";

- Número da estação (3 dígitos). O código do sensor localizado próximo ao quilômetro 22 é 013;

- Código da rodovia (2 dígitos). O código da rodovia SP-021 é 01;

- $\mathrm{km}$ da estação (4 dígitos, sendo o último digito a casa decimal). O código da estação de monitoramento analisada é 0223 , que corresponde ao quilômetro 22,3. 
- Uma letra indicando o sentido da faixa (N: Norte, S: Sul, L: Leste, O: Oeste, I: Interna e E: Externa). Foram utilizadas nessa pesquisa as observações no sentido I (Interna).

- Uma letra indicando o tipo da faixa (P: Principal, A: Acesso, S: Saída, M: Marginal e E: Expressa). O Rodoanel possui faixas classificadas como "Principal".

- Número da Faixa (1 dígito, sequencial, iniciando na faixa mais próxima ao canteiro central).

Os arquivos são divididos por mês de coleta, e cada arquivo possui planilhas subdivididas pelas faixas e pelo sentido das faixas. A estação de monitoramento analisada possui uma pista por sentido e quatro faixas no local de coleta, logo, o arquivo possui 8 planilhas. Cada linha da planilha corresponde a um intervalo de 5 minutos de observação. As colunas apresentam as seguintes informações:

- Data: Data a qual se refere a informação;

- Hora: Intervalo de tempo ao qual se refere a informação, por exemplo: 10:00:00 indica que os dados referem-se ao período entre 10:00:00 e 10:04:59;

- Volume total: Quantidade de veículos (automóveis, veículos comerciais e motos) que passaram na faixa durante o intervalo de tempo de referência;

- Velocidade média $(\mathrm{km} / \mathrm{h})$ : Velocidade média da classe veicular (automóveis, veículos comerciais e motos) que passaram na faixa durante o intervalo de tempo de referência;

- Taxa de ocupação (\%): Porcentagem de duração do intervalo em que o sensor esteve acionado, arredondada para o número inteiro mais próximo;

- Volume de autos (veíc): Quantidade de veículos que passaram pela faixa durante o período especificado, com comprimento superior a 2 metros e menor ou igual a 6 metros.

- Velocidade média autos $(\mathrm{km} / \mathrm{h})$ : Velocidade média dos veículos que passaram pela faixa durante o período especificado, com comprimento superior a 2 metros e menor ou igual a 6 metros.

- Volume comerciais (veíc): Quantidade de veículos que passaram pela faixa durante o período especificado, com comprimento superior a 6 metros.

- Velocidade média comerciais $(\mathrm{km} / \mathrm{h})$ : Velocidade média dos veículos que passaram pela faixa durante o período especificado, com comprimento superior a 6 metros.

- Volume motos (veíc): Quantidade de veículos que passaram pela faixa durante o período especificado, com comprimento inferior ou igual a 2 metros. 
- Velocidade média motos $(\mathrm{km} / \mathrm{h})$ : Velocidade média dos veículos que passaram pela faixa durante o período especificado, com comprimento inferior ou igual a 2 metros.

Para auxiliar o tratamento dos dados, as informações das quatro faixas de tráfego do mesmo sentido do fluxo da estação de monitoramento analisada foram dispostas lado a lado na mesma planilha. Também criaram-se, para cada uma das faixas, colunas adicionais com o somatório dos volumes de automóveis e veículos comerciais para cada intervalo, e colunas com a velocidade média, cujo cálculo foi descrito no Item 3.1.1.

Em seguida, fez-se a fusão dos dados de tráfego aos dados meteorológicos. Os dados de tráfego foram registrados a cada 5 minutos, e os dados meteorológicos retratavam as condições do tempo a cada 30 minutos. Dessa forma, atribuiu-se as informações de 30 minutos dos dados meteorológicos aos 6 intervalos de 5 minutos referentes ao mesmo período, e criou-se uma coluna associada aos dados de tráfego com a descrição da condição de tempo no intervalo de referência.

\subsection{Filtro de dias típicos}

Para calibrar o simulador, foram utilizados somente dados de dias típicos, em horários em que o fluxo de veículos seja representativo de um dia útil, baseando-se no método proposto por Cunha (2007). A identificação do dia típico foi feita a partir de análise do fluxo de veículos por hora em todos os dias da semana. Para evitar dias de tráfego atípicos, foram desconsiderados feriados e dias próximos a feriados devido ao aumento do fluxo, conforme o esquema mostrado na Tabela 3.1. Como os dados de tráfego foram coletados no ano de 2010, foram analisados os feriados e dias próximos conforme Tabela 3.2.

Tabela 3.1 - Dias da semana eliminados

\begin{tabular}{ll}
\hline Dia do feriado & Dias da semana eliminados \\
\hline Domingo & sáb-dom-seg \\
Segunda-feira & sex-sáb-dom-seg-ter \\
Terça-feira & sex-sáb-dom-seg-ter-qua \\
Quarta-feira & ter-qua-qui \\
Quinta-feira & qua-qui-sex-sáb-dom \\
Sexta-feira & qui-sex-sáb-dom \\
Sábado & sex-sáb-dom \\
\hline
\end{tabular}

Cunha (2007) observou que, em rodovias de pista dupla do estado de São Paulo, as terças, quartas e quintas-feiras apresentam um comportamento de tráfego semelhante durante todo o dia, o que não ocorre nos demais dias da semana. Outro fator observado é que o fluxo de veículos entre 0 h e $6 \mathrm{~h}$ possui uma média inferior a 400 veículos/hora, com elevada presença de caminhões. Com base nesse estudo, definiu-se que seriam utilizados para a calibração e 
Tabela 3.2 - Feriados do ano de 2010

\begin{tabular}{lll}
\hline & & 2010 \\
\hline Data & Dia da Semana & Feriado \\
$01 /$ jan & sexta-feira & Confraternização Universal \\
$15 /$ fev & segunda-feira & Carnaval \\
$16 / f e v$ & terça-feira & Carnaval \\
$02 /$ abr & sexta-feira & Paixão de Cristo \\
21/abr & quarta-feira & Tiradentes \\
$01 /$ mai & sábado & Dia do Trabalho \\
$03 /$ jun & quinta-feira & Corpus Christi \\
07/set & terça-feira & Independência do Brasil \\
12/out & terça-feira & Nossa Sra Aparecida \\
$02 /$ nov & terça-feira & Finados \\
15/nov & segunda-feira & Proclamação da República \\
25/dez & sábado & Natal \\
\hline
\end{tabular}

validação do microssimulador somente dados de terças, quartas e quintas-feiras, excluindose feriados e dias atípicos, e horários em que o fluxo é predominantemente baixo, com alta porcentagem de veículos comerciais.

\subsection{Filtro de dados meteorológicos}

Os dados usados nesta pesquisa foram submetidos a um filtro de dados meteorológicos numa pesquisa anterior (PIZZOL; SETTI, 2013). Nessa filtragem, foram removidos os dados de tráfego nos períodos em que existia mudança nas condições do tempo. Mantiveram-se apenas os dados cuja condição de tempo se repetia por pelo menos dois intervalos de tráfego antes e um intervalo depois. Desta forma, somente as observações de tráfego realizadas sob condições de tempo que se mantiveram constantes por, no mínimo, 20 minutos foram consideradas.

Nesta pesquisa, não foram usados dados coletados em dias em que houve ocorrência de chuva, para evitar que as condições climáticas influenciassem o comportamento da corrente de tráfego (PIZZOL; SETTI, 2013). Assim sendo, após a aplicação deste filtro, restaram apenas observações realizadas em dias típicos, com tempo firme (sem chuva).

\subsection{Filtro de dados inconsistentes}

Após a aplicação, na sequência, dos filtros de dias não-típicos e dias chuvosos, foram descartados os dados inconsistentes captados pelos sensores de tráfego. Como qualquer dispositivo eletrônico, os sensores estão sujeitos a falhas de funcionamento (ANDRADE, 2012), e estas falhas podem acarretar na captação de informações que não refletem as condições de tráfego no local, tais como:

- Ausência de informações; 
- Contagem diferente de zero e velocidade zero, ou vice-versa;

- Valores negativos de contagem, velocidade ou ocupância, no caso de mau funcionamento do sensor;

Os dias de coleta que apresentaram as falhas citadas foram eliminados, bem como os dias em que a contagem de veículos destoa dos demais dias semelhantes. Isso pode ocorrer quando há uma restrição temporária na capacidade ou na velocidade ocasionada por acidentes, esquemas de operação ou fiscalização atípicos ou pela presença de obras. A Figura 3.2 ilustra o problema, apresentando um conjunto de dados de fluxo e velocidade de uma das faixas de tráfego de dois dias de coleta atípicos (26 e 31 de agosto de 2010) em contraste com dias típicos. Nos dias atípicos, há uma visível redução de velocidade e de fluxo.

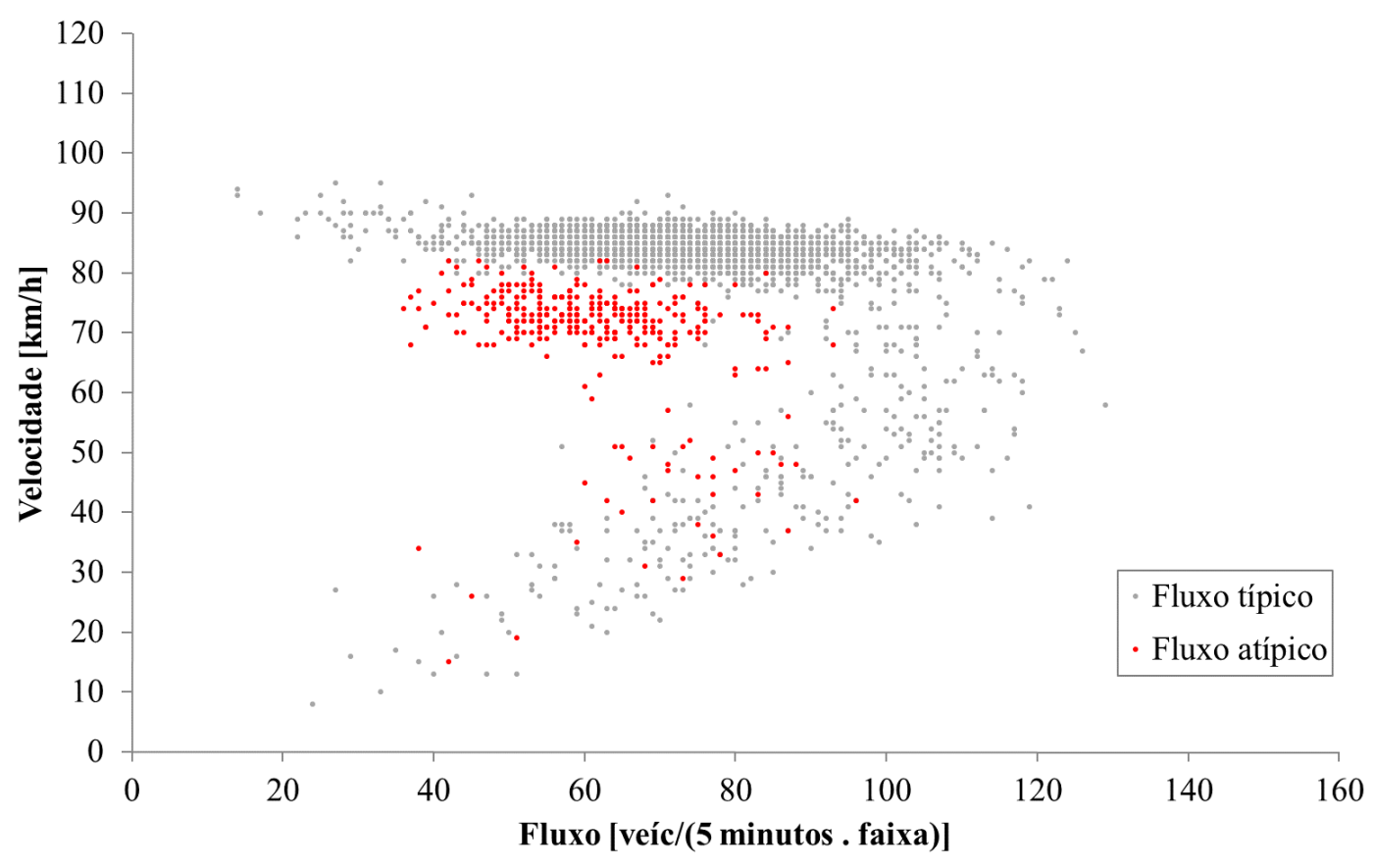

Figura 3.2 - Fluxo atípico em uma faixa de tráfego

\subsection{Definição do fluxo congestionado}

A determinação dos períodos de congestionamento foi feita numa pesquisa anterior (ANDRADE; SETTI, 2014) e baseou-se em Análise de Clusters, uma técnica estatística que permite estabelecer $n$ agrupamentos de objetos em função de critérios de similaridade, sendo o número de grupos $n$ (cluster), definido pelo analista.

Para realizar a análise de agrupamento, foram considerados dois clusters, sendo cada observação fluxo-velocidade um objeto. Somente observações com fluxo superior a $1.500 \mathrm{veíc} / \mathrm{h}$ foram usadas. Estabeleceram-se duas sementes aleatórias para representar o centroide de cada 
cluster, com coordenadas $x$ e $y$, em que $x$ representa o fluxo e $y$ a velocidade. As distâncias entre as observações de velocidade e cada centroide $k$ foram calculadas segundo a equação:

$$
d_{i k}=\sqrt{\sum_{i=1}^{N}\left(S_{i}-S_{k}\right)^{2}}
$$

Em que $d_{i k}$ : Distância entre cada observação $i$ e cada centroide $k$;

$N$ : Número total de observações;

$S_{i}$ : $\quad$ Valor de velocidade média do objeto $i$

$S_{k}$ : Valor de velocidade do centroide de cada cluster.

A partir das distâncias calculadas, cada ponto é atribuído ao centroide mais próximo. Em seguida, recalculam-se as coordenadas dos centroides como o centro de massa dos pontos atribuídos a ele. Repete-se o procedimento até que a convergência seja atingida.

O valor limite de velocidade entre os dois agrupamentos, para os dados referentes ao sensor, foi $83 \mathrm{~km} / \mathrm{h}^{1}$. Logo, definiu-se esta velocidade como determinante para a separação do regime de fluxo congestionado quando, simultaneamente, as quatro faixas de tráfego possuíssem velocidade igual ou inferior à velocidade limite.

Neste trabalho foram selecionados para a análise dias em que houve pelo menos meia hora de ocorrência de congestionamento, ou seja, ao menos 6 intervalos de 5 minutos de fluxo congestionado em um dia de observação.

\subsection{Dias selecionados para calibração e validação}

Após a aplicação dos filtros, foram considerados aptos para utilização 28 dos 201 dias disponíveis, o que representa aproximadamente $14 \%$ do total. Para as etapas de calibração e validação do simulador, foram utilizados 6 dias de observações de tráfego para cada etapa, totalizando 12 dias, apresentados na Tabela 3.3 na Figura 3.3.

\subsection{Considerações finais}

Este capítulo abordou o tratamento dos dados utilizados para calibrar o simulador de tráfego. Os capítulos a seguir apresentam os procedimentos de preparação do simulador e do algoritmo genético para a calibração do VISSIM a partir de dados macroscópicos de tráfego.

\footnotetext{
${ }^{1}$ As velocidades críticas foram fornecidas por Gustavo Riente de Andrade, tendo sido calculadas em sua pesquisa de mestrado (ANDRADE, 2012)
} 
Tabela 3.3 - Dias selecionados para calibração e validação

\begin{tabular}{lll}
\hline Dia & Dia da semana & Uso \\
\hline $07 / 04 / 2010$ & Quarta-Feira & Calibração \\
$28 / 04 / 2010$ & Quarta-Feira & Calibração \\
$06 / 05 / 2010$ & Quinta-Feira & Calibração \\
$12 / 05 / 2010$ & Quarta-Feira & Calibração \\
$20 / 05 / 2010$ & Quinta-Feira & Calibração \\
$09 / 06 / 2010$ & Quarta-Feira & Calibração \\
$15 / 04 / 2010$ & Quinta-Feira & Validação \\
$05 / 05 / 2010$ & Quarta-Feira & Validação \\
$26 / 05 / 2010$ & Quarta-Feira & Validação \\
$08 / 06 / 2010$ & Terça-Feira & Validação \\
$10 / 06 / 2010$ & Quinta-Feira & Validação \\
$12 / 08 / 2010$ & Quinta-Feira & Validação \\
\hline
\end{tabular}

(a)
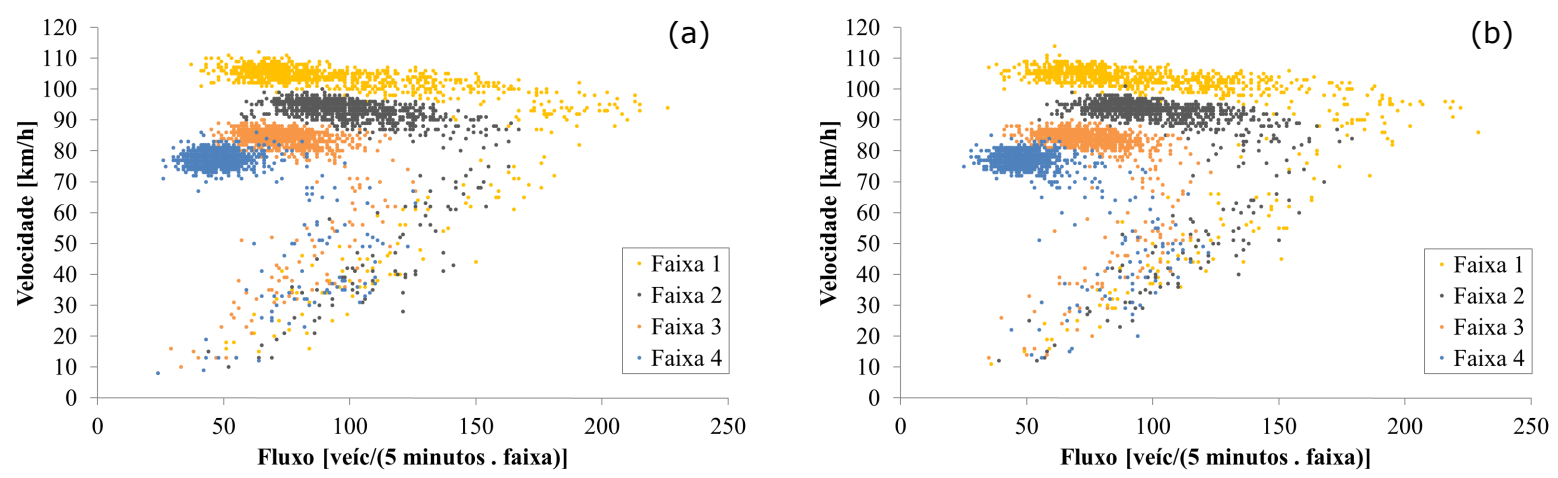

Figura 3.3 - Gráficos dos dados usados para calibração (a) e validação (b) 


\section{Capítulo}

\section{Preparação do simulador}

Neste capítulo são descritos os procedimentos de preparação do simulador necessários para a realização do trabalho. A criação da rede, incluindo a determinação do perfil horizontal e vertical do trecho estudado, a resolução da simulação, a inserção de veículos na rede e o método para simular fluxo congestionado são abordados a seguir.

\subsection{Criação da rede}

O trecho em estudo possui $2,7 \mathrm{~km}$ de extensão e localiza-se entre os quilômetros 20 e 24 do Rodoanel Mário Covas, SP-021, no trecho Oeste, na pista sentido Norte (Interna). As quatro faixas de tráfego da pista possuem largura de 3,60 m (JGP CONSULTORIA, 2009), e a estação de monitoramento está localizada no quilômetro 22,3 da Rodovia. O traçado e o perfil vertical do trecho foram obtidos através de coleta realizada no dia 1/4/2015 com o auxílio de um GPS diferencial, modelo Leica System GPS1200. O equipamento coleta dados com precisão centimétrica quando não há interferência no recebimento dos sinais dos satélites (LEICA, 2008).

Ao construir a rede de tráfego no simulador, buscou-se criar a rede mais simples possível que representasse com boa fidelidade o traçado existente. Na escolha dos nós da rede, também foram considerados pontos que representassem o perfil vertical do trecho, de acordo com os dados coletados pelo GPS, conforme Figura 4.1.

Os dados altimétricos foram corrigidos quanto à ondulação geoidal por interpolação com o auxílio do software MapGeo. A Tabela 4.1 apresenta os dados de latitude, longitude, cota altimétrica corrigida (em m), a posição relativa de cada ponto no plano cartesiano (em $\mathrm{m}$ ), as distâncias (em m) e as inclinações (\%) de cada trecho. A localização do trecho e os pontos utilizados para criar a rede no simulador são apresentados na Figura 4.2. 


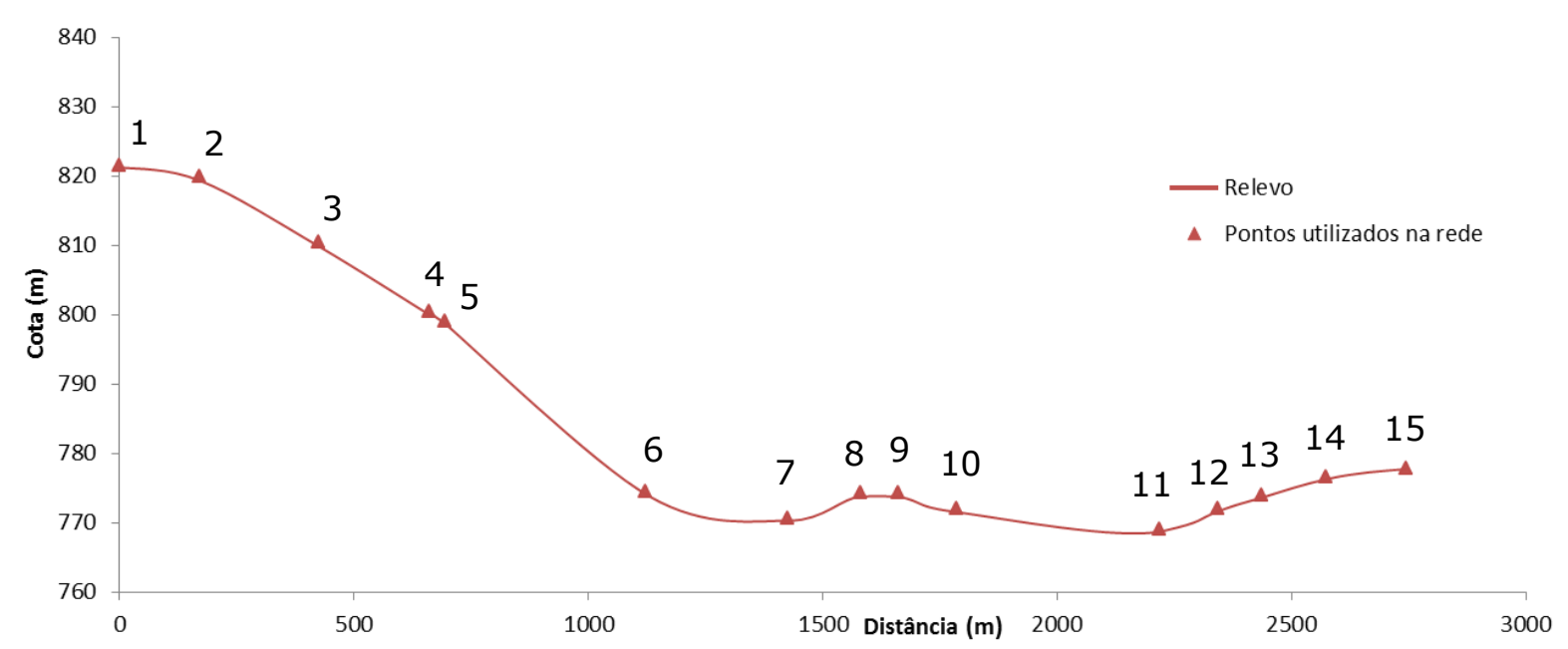

Figura 4.1 - Definição dos pontos coletados utilizados na rede do simulador

Tabela 4.1 - Dados da rede de tráfego

\begin{tabular}{|c|c|c|c|c|c|c|c|c|}
\hline Ponto & Latitude & Longitude & Cota & $\mathbf{X}$ & $\mathbf{Y}$ & Distância & Acum. & $\mathrm{i}(\%)$ \\
\hline 1 & $-23^{\circ} 35^{\prime} 01.13^{\prime \prime}$ & $-46^{\circ} 48^{\prime} 29.19^{\prime \prime}$ & 821.54 & 1208.15 & 467.48 & - & - & - \\
\hline 2 & $-23^{\circ} 34^{\prime} 55.56^{\prime \prime}$ & $-46^{\circ} 48^{\prime} 29.39^{\prime \prime}$ & 819.90 & 1202.51 & 638.67 & 171.28 & 171.28 & $-0.96 \%$ \\
\hline 3 & $-23^{\circ} 34^{\prime} 47.51^{\prime \prime}$ & $-46^{\circ} 48^{\prime} 30.89^{\prime \prime}$ & 810.39 & 1159.84 & 886.56 & 251.53 & 422.81 & $-3.78 \%$ \\
\hline 4 & $-23^{\circ} 34^{\prime} 40.19^{\prime \prime}$ & $-46^{\circ} 48^{\prime} 33.59^{\prime \prime}$ & 800.48 & 1083.21 & 1111.70 & 237.82 & 660.63 & $-4.17 \%$ \\
\hline 5 & $-23^{\circ} 34^{\prime} 39.23^{\prime \prime}$ & $-46^{\circ} 48^{\prime} 34.03^{\prime \prime}$ & 799.03 & 1070.96 & 1141.06 & 31.82 & 692.45 & $-4.56 \%$ \\
\hline 6 & $-23^{\circ} 34^{\prime} 26.47^{\prime \prime}$ & $-46^{\circ} 48^{\prime} 39.98^{\prime \prime}$ & 774.54 & 902.21 & 1533.88 & 427.53 & 1119.99 & $-5.73 \%$ \\
\hline 7 & $-23^{\circ} 34^{\prime} 17.31^{\prime \prime}$ & $-46^{\circ} 48^{\prime} 44.12^{\prime \prime}$ & 770.59 & 784.66 & 1815.60 & 305.26 & 1425.25 & $-1.29 \%$ \\
\hline 8 & $-23^{\circ} 34^{\prime} 12.70^{\prime \prime}$ & $-46^{\circ} 48^{\prime} 46.42^{\prime \prime}$ & 774.25 & 719.61 & 1957.42 & 156.03 & 1581.28 & $2.35 \%$ \\
\hline 9 & $-23^{\circ} 34^{\prime} 10.55^{\prime \prime}$ & $-46^{\circ} 48^{\prime} 47.95^{\prime \prime}$ & 774.27 & 676.19 & 2023.57 & 79.13 & 1660.40 & $0.03 \%$ \\
\hline 10 & $-23^{\circ} 34^{\prime} 07.69^{\prime \prime}$ & $-46^{\circ} 48^{\prime} 51.08^{\prime \prime}$ & 772.11 & 587.28 & 2111.54 & 125.07 & 1785.48 & $-1.73 \%$ \\
\hline 11 & $-23^{\circ} 34^{\prime} 01.12^{\prime \prime}$ & $-46^{\circ} 49^{\prime} 04.58^{\prime \prime}$ & 769.02 & 204.53 & 2313.80 & 432.90 & 2218.38 & $-0.71 \%$ \\
\hline 12 & $-23^{\circ} 33^{\prime} 58.31^{\prime \prime}$ & $-46^{\circ} 49^{\prime} 07.69^{\prime \prime}$ & 772.09 & 116.38 & 2400.38 & 123.56 & 2341.94 & $2.48 \%$ \\
\hline 13 & $-23^{\circ} 33^{\prime} 55.76^{\prime \prime}$ & $-46^{\circ} 49^{\prime} 09.54^{\prime \prime}$ & 773.98 & 63.90 & 2478.70 & 94.27 & 2436.21 & $2.00 \%$ \\
\hline 14 & $-23^{\circ} 33^{\prime} 51.65^{\prime \prime}$ & $-46^{\circ} 49^{\prime} 11.26^{\prime \prime}$ & 776.57 & 14.90 & 2605.14 & 135.60 & 2571.81 & $1.91 \%$ \\
\hline 15 & $-23^{\circ} 33^{\prime} 46.10^{\prime \prime}$ & $-46^{\circ} 49^{\prime} 11.79^{\prime \prime}$ & 777.90 & 0.00 & 2775.91 & 171.42 & 2743.23 & $0.78 \%$ \\
\hline
\end{tabular}

\subsection{Definição do time-step}

O simulador VISSIM disponibiliza a opção de aumentar ou reduzir a quantidade de atualizações da simulação (time-step) por segundo. O número de atualizações pode variar de 1 a 10, sendo 1 a simulação mais imprecisa e mais rápida, e 10 a simulação mais lenta, porém, com maior precisão quanto à representação dos veículos na rede.

Para estudar o efeito do time-step nos resultados da simulação, foram realizadas replicações da rede mantendo os mesmos dados de entrada, variando apenas o time-step do simulador, e constatou-se que o número de veículos que passam pelos sensores da rede quando é definido o intervalo de uma atualização por segundo destoa dos demais time-steps, conforme pode ser visto na Tabela 4.2. O manual do VISSIM considera a resolução de uma atualização por segundo grosseira e não recomenda utilizá-la para análise (PTV, 2009). 


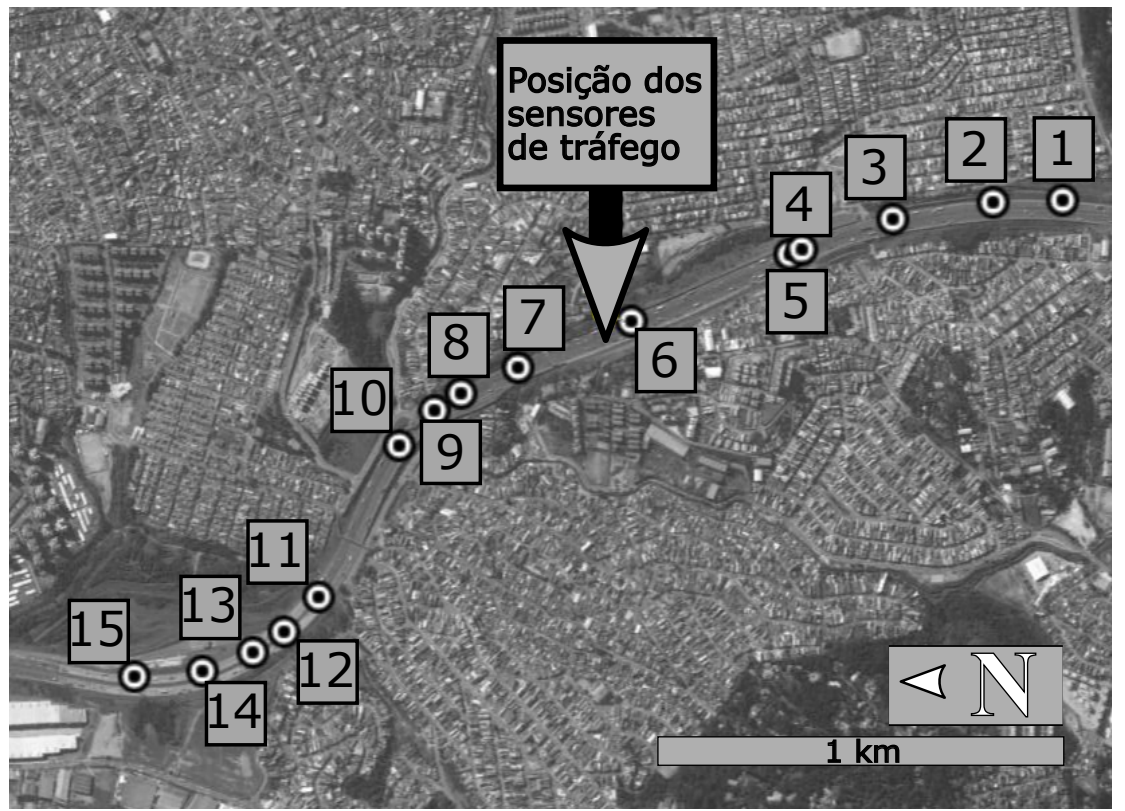

Figura 4.2 - Localização da rodovia e pontos utilizados para criação da rede no simulador

Tabela 4.2 - Quantidade de veículos contabilizados pelos sensores na rede do simulador

\begin{tabular}{lrr}
\hline Time-step & Veículos na rede & Duração da simulação \\
\hline 1 & 430921 & $267 \mathrm{~s}$ \\
2 & 432642 & $522 \mathrm{~s}$ \\
3 & 432635 & $760 \mathrm{~s}$ \\
4 & 432640 & $986 \mathrm{~s}$ \\
5 & 432637 & $1101 \mathrm{~s}$ \\
6 & 432627 & $1458 \mathrm{~s}$ \\
7 & 432634 & $1710 \mathrm{~s}$ \\
8 & 432640 & $2172 \mathrm{~s}$ \\
9 & 432646 & $2390 \mathrm{~s}$ \\
10 & 432639 & $2871 \mathrm{~s}$ \\
\hline
\end{tabular}

Como o tempo de simulação é um aspecto relevante no método de calibração, decidiu-se usar, nas simulações desta pesquisa, a configuração de 2 atualizações por segundo.

\subsection{Inserção de veículos na rede}

A entrada de dados no simulador ocorre da seguinte forma: Define-se o início e o fim de cada período, a taxa de fluxo em veículos por hora (o software distribui o fluxo proporcionalmente ao intervalo), a distribuição de veículos (percentual de veículos leves e comerciais), e o link de entrada dos veículos na rede, como pode ser visto na Figura 4.3.

Informa-se, então, a taxa de fluxo de tráfego veículos por hora de cada intervalo de 5 minutos, definido em função dos dados coletados pelo sensor de tráfego, bem como o percentual de veículos leves e comerciais do intervalo.

Os veículos são inseridos faixa por faixa para amenizar a aleatoriedade da entrada de veícu- 


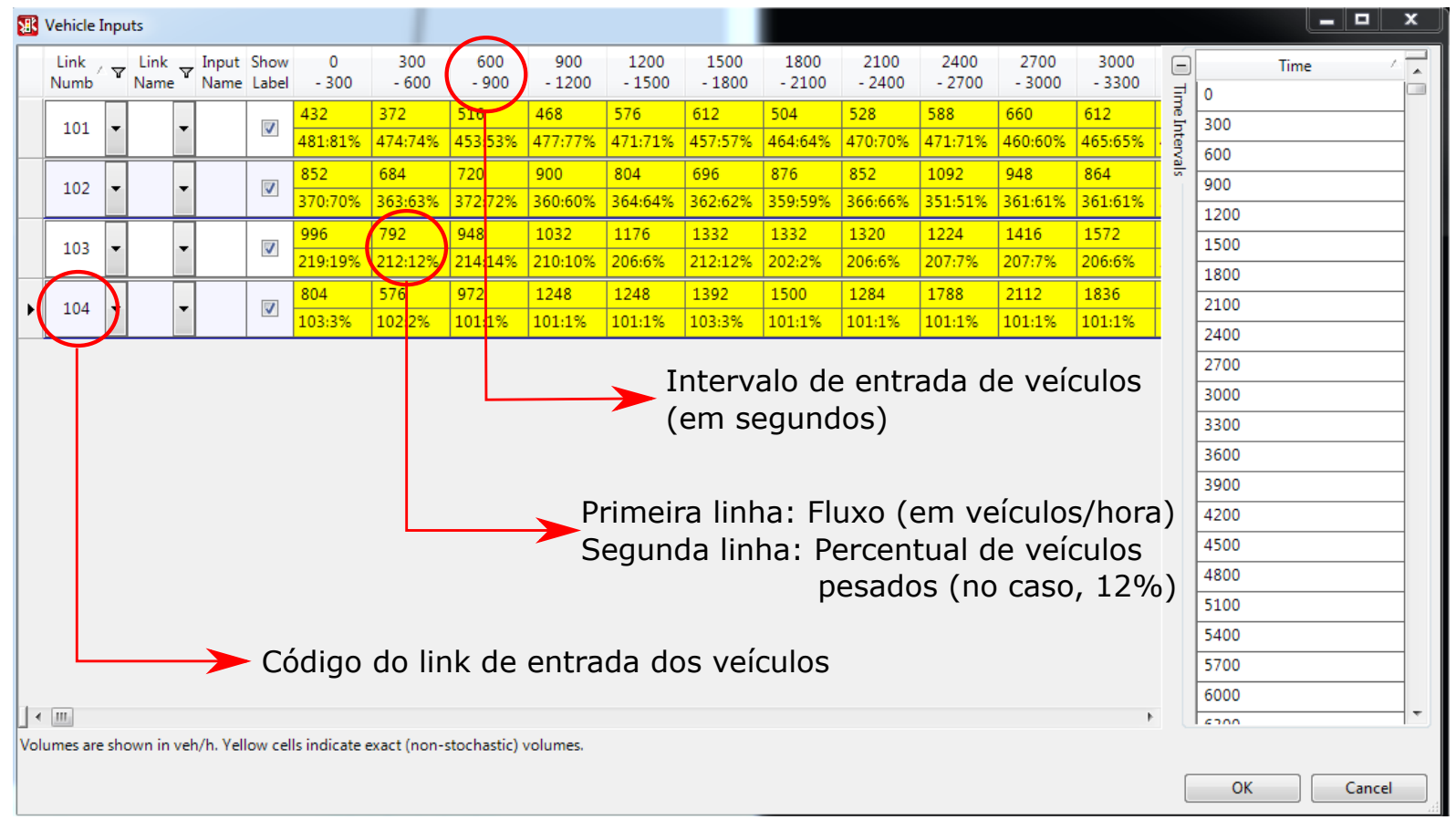

Figura 4.3 - Janela de entrada de dados de fluxo do simulador VISSIM

los na rede pelo simulador, que tende a distribuir de forma equivalente os veículos conforme a ocupação das faixas, sem levar em consideração o tipo de veículo que irá ocupá-las. Dessa forma, a rede conta com 4 acessos de aproximadamente 2 quilômetros antes do início do trecho, garantindo que todos os veículos entrem na rede a ser simulada de acordo com a sua faixa, como demonstrado na Figura 4.4. A simulação está sujeita a possíveis intervalos de longa duração de períodos de congestionamento, por isso, definiu-se uma extensão do trecho de acesso suficientemente longa para comportar a quantidade de veículos.

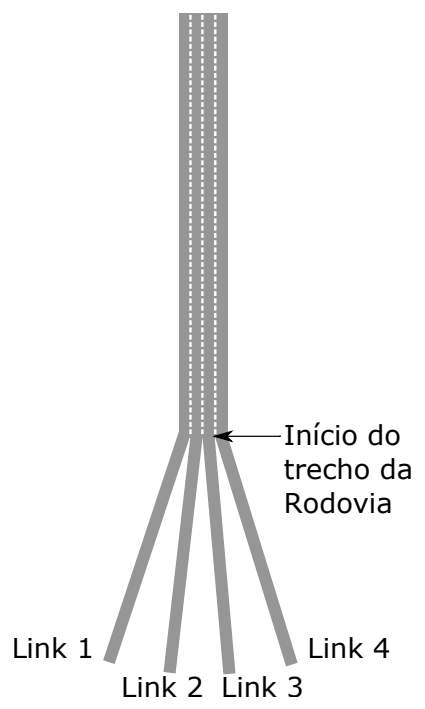

Figura 4.4 - Acesso para entrada de veículos na rede do simulador (sem escala) 


\subsection{Método para obtenção de fluxo congestionado no simulador}

Os dados obtidos através dos sensores mostram a presença de congestionamento na rodovia. O fluxo congestionado ocorre entre 7:00 e 9:00 da manhã no local do sensor, e corresponde a aproximadamente $60 \%$ deste período, em média.

O congestionamento ocorre quando a demanda de veículos é maior que a capacidade da via. A capacidade de uma via é a máxima taxa de fluxo em que veículos podem atravessar por uma seção uniforme de uma pista ou estrada durante um determinado período de tempo (TRB, 2010, p. 4-17)

Todavia, as características do simulador e os dados de entrada escolhidos impossibilitam a criação de um congestionamento sem que haja alguma impedância na rede. Os simuladores de tráfego não permitem a entrada de veículos acima do fluxo correspondente à capacidade da rede. O fluxo excedente é desconsiderado na simulação, e uma mensagem de erro é emitida pelo simulador informando a quantidade de veículos que foram eliminados para que o processo fosse concluído.

A informação obtida através dos sensores mostra a quantidade de veículos que passou pelo sensor em um determinado período de tempo. Assim, quando o tráfego é congestionado, o número de veículos contabilizados pelo sensor é reduzido. Ao definir os dados de entrada como os dados do sensor, o simulador, ao invés de aumentar a demanda de veículos quando a rede está prestes a congestionar, diminuirá.

Dadas as limitações do simulador e do modo de entrada de dados, elaborou-se um método para gerar um congestionamento semelhante ao que ocorre no local. O método consiste em inserir na rede redutores de velocidade que são ativados somente nos períodos em que se observou congestionamento. Estes redutores de velocidade são uma ferramenta do próprio software para forçar uma redução compulsória da velocidade dos veículos.

Os redutores visam criar ondas de choque na corrente de tráfego para simular a ocorrência de congestionamentos. Sem as ondas de choque, não há congestionamento na simulação, uma vez que o simulador não permite a entrada de veículos com headways menores que o headway de saturação. A Figura 4.5 apresenta a janela para configuração dos redutores de velocidade no simulador.

Para configurar os redutores de velocidade, define-se:

- o código da redução;

- o comprimento do trecho de redução;

- o trecho (link) em que haverá uma área de redução;

- a faixa de tráfego; 


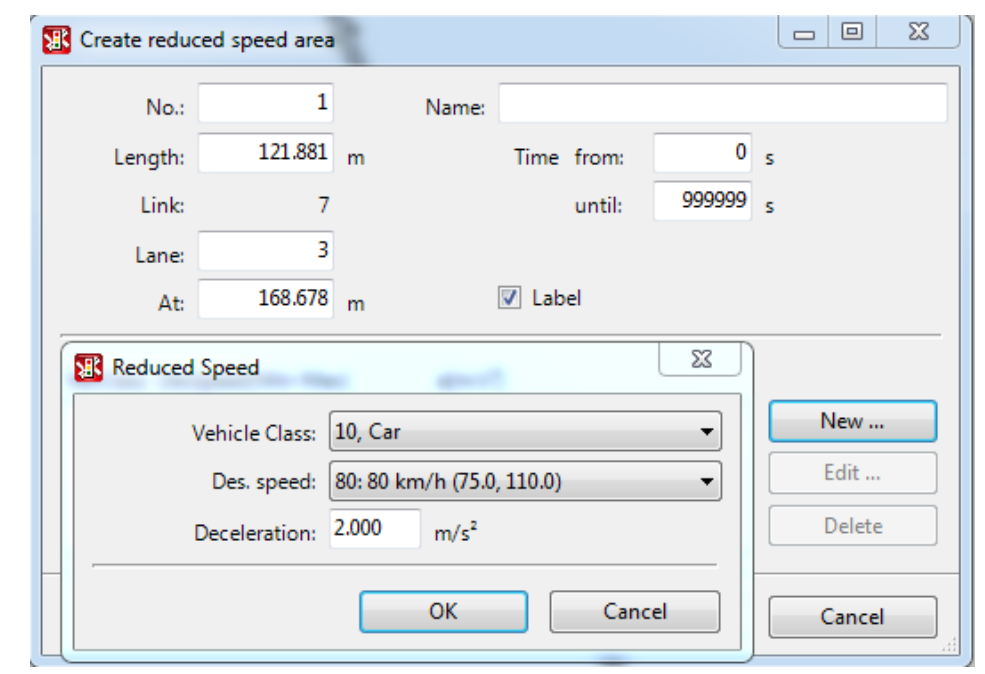

Figura 4.5 - Janela para configuração dos redutores de velocidade no simulador

- o início do trecho de redução;

- o tipo de veículo, a distribuição de velocidade desejada durante a redução e a desaceleração ao entrar na área.

Os redutores de velocidade foram inseridos nas quatro faixas de tráfego nos intervalos de 5 minutos em que há congestionamento, em um trecho fixo de 150 metros, localizado a 300 metros à jusante dos sensores da rede. A desaceleração dos veículos ao entrar no trecho de redução foi mantida em $2 \mathrm{~m} / \mathrm{s}$.

\section{Considerações finais}

Apresentou-se neste capítulo a preparação do simulador VISSIM para as demais etapas de estudo, e também o método utilizado na pesquisa para simular o fluxo congestionado. A seguir, são descritos os procedimentos de preparação do algoritmo genético. 


\section{Capítulo}

\section{O algoritmo genético}

Este capítulo pode ser considerado como o cerne da pesquisa. Nele são descritos todos os procedimentos usados na criação do AG para a calibração do simulador. A estrutura do algoritmo, a função fitness e suas medidas de desempenho, bem como as definições sobre os parâmetros são abordados nas seções a seguir.

\subsection{Organização dos dados de tráfego}

Diversas rotinas são realizadas pelo AG para que ocorram os processos de cálculo. Dentre elas, destacam-se duas rotinas essenciais para entender a estruturação dos arquivos de entrada e saída do algoritmo.

Estas rotinas agregam os dados de tráfego em vetores, armazenados em dois níveis: o primeiro nível do vetor corresponde à faixa de tráfego; o segundo nível corresponde a cada intervalo de 5 minutos, por ordem cronológica. Dentro deste segundo nível, são armazenadas informações em 3 subníveis ou colunas. Os 3 subníveis são: fluxo, velocidade média e percentual de veículos comerciais. Por exemplo:

vetor_simulador [i] [j] [1] = Refere-se ao fluxo de veículos do $j$-ésimo intervalo da $i$ ésima faixa de rolamento do trecho simulado;

vetor_sensor [i] [j] [2] = Refere-se à velocidade média dos veículos [2] do $j$-ésimo intervalo da $i$-ésima faixa de rolamento do trecho simulado;

vetor_sensor $[i][j][3]=$ Refere-se ao percentual de veículos comerciais do $j$-ésimo intervalo da $i$-ésima faixa de rolamento do trecho simulado.

\subsubsection{Leitura dos dados de entrada}

Os dados de entrada são relativamente mais simples de se trabalhar devido ao maior controle das informações. Todavia, é necessário que essa informação esteja inserida no AG, e a inserção 
é feita apenas uma vez durante a calibração. Os dados são extraídos de um arquivo denominado dados_sensor, sendo o número total de registros do arquivo definido como nlinhas. Cada linha do arquivo dados_sensor possui um registro de 5 minutos de observação de tráfego em ordem cronológica, com 4 colunas, que informam: a faixa de tráfego, o fluxo durante o intervalo, a velocidade média e o percentual de veículos comerciais. As informações extraídas do arquivo são agrupadas em vetores de acordo com a faixa de tráfego de referência, conforme o pseudocódigo a seguir:

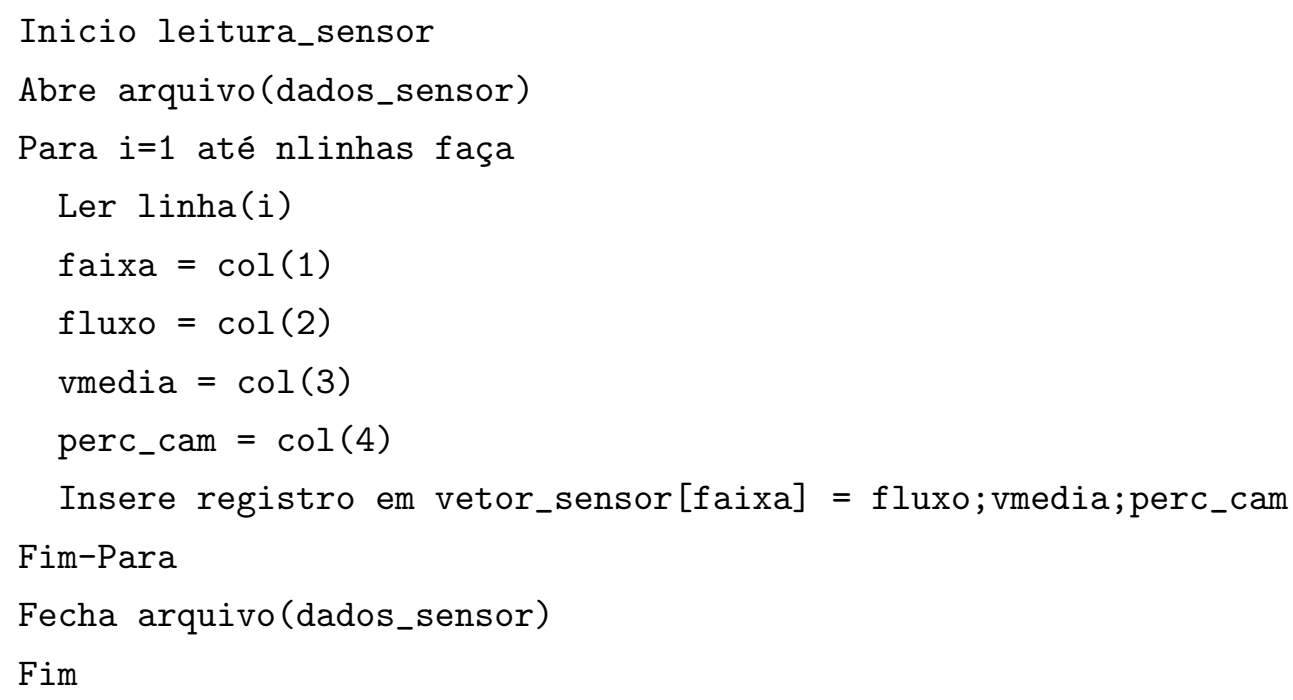

\subsubsection{Leitura dos dados de saída}

A leitura das informações de tráfego da simulação ocorre a partir do arquivo de extensão .mer do VISSIM, que contém informações desagregadas do tráfego de veículos. O arquivo possui um cabeçalho com informações gerais da replicação e das estações de monitoramento antes de registrar a informação de entrada e/ou saída de um veículo do sensor. Eventualmente, o registro de um veículo ocorre duplicado, sendo um registro para a entrada e outro para a saída da área correspondente à estação de monitoramento. A rotina que realiza a leitura das informações retira esses dados duplicados ao verificar se o tempo de entrada no sensor t_entrada é igual a -1. Considera-se ainda uma defasagem em relação ao período de entrada do veículo no simulador e de chegada ao sensor, definida como 140 segundos. O tempo de defasagem foi calculado através do tempo médio dos veículos para percorrer o trajeto entre a entrada da rede e o sensor de tráfego.

$\mathrm{O}$ arquivo de saída contém as seguintes informações: número da faixa; instante de entrada no sensor $(s)$; instante de saída $(s)$; número do veículo; tipo de veículo; velocidade $(\mathrm{m} / \mathrm{s})$; aceleração $\left(\mathrm{m} / \mathrm{s}^{2}\right)$; ocupância $(\%)$; tempo de atraso $(\mathrm{s})$; tamanho do veículo $(\mathrm{m})$. O processo de cálculo ocorre da seguinte forma:

1. Ao final de cada simulação, o algoritmo realiza a leitura do arquivo de saída; 
2. O AG identifica se a linha que está sendo lida contém informação sobre a passagem de um veículo;

3. Verifica se o tempo de entrada é diferente de -1 ou maior que o tempo de warm-up;

4. Soma os veículos de passeio e os veículos comerciais e soma as velocidades individuais de acordo com a faixa de tráfego;

5. Repete o procedimento até que o resultado da divisão do tempo de entrada (menos a defasagem) de um veículo por 300 (o que representa 300 segundos ou 5 minutos) seja maior que o resultado da divisão do tempo de entrada do veículo anterior.

6. Para o intervalo anterior, soma o número de veículos leves aos comerciais, calcula a média das velocidades e a proporção de veículos comerciais sobre o total e guarda as informações nos vetores de cada faixa;

7. Os valores agregados são zerados e inicia-se a contagem de um novo intervalo.

8. O processo descrito ocorre até a última linha do arquivo.

9. Fecha o arquivo.

O pseudocódigo a seguir apresenta o algoritmo utilizado para identificar e agregar os dados gerados pelo simulador.

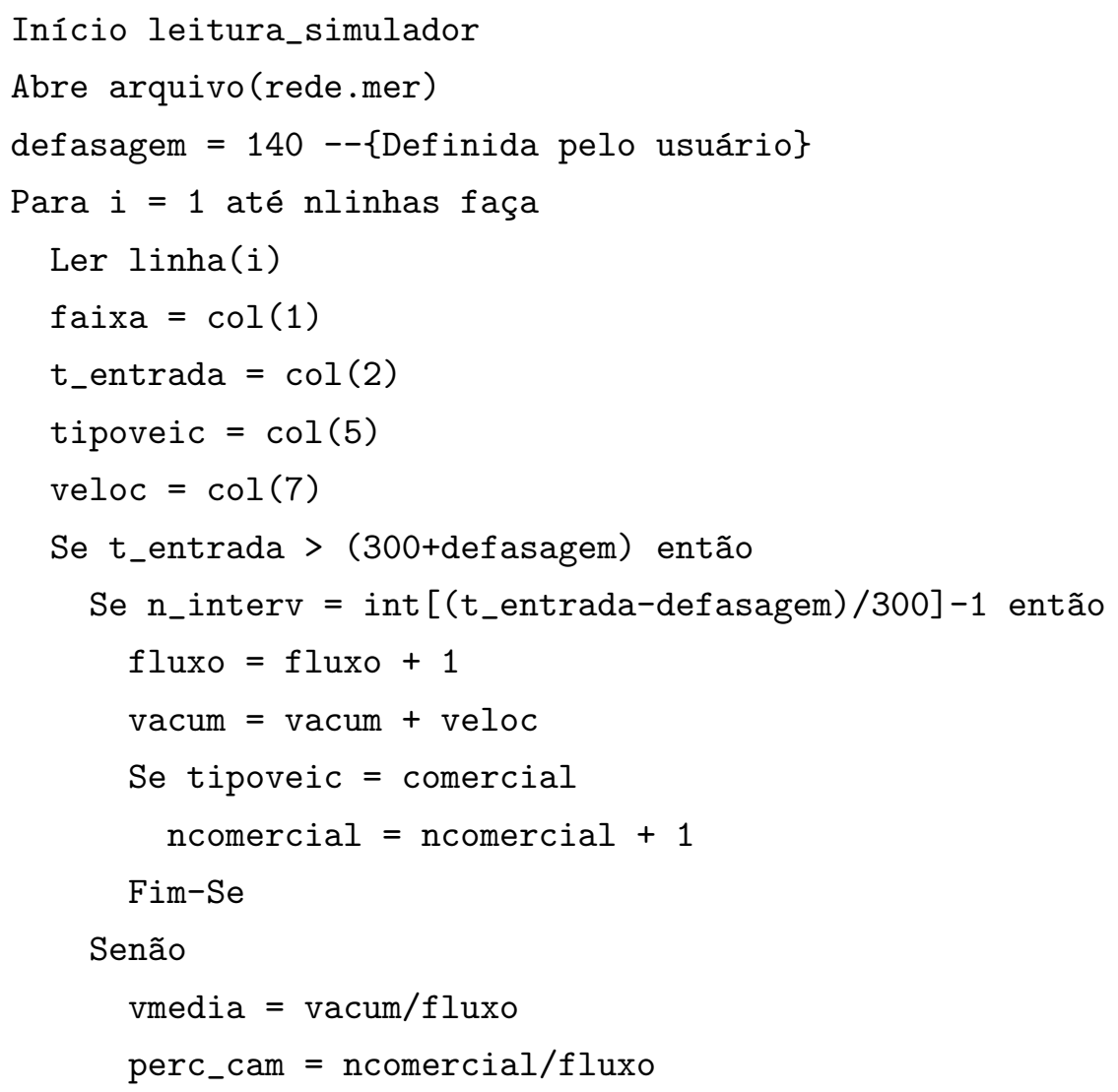




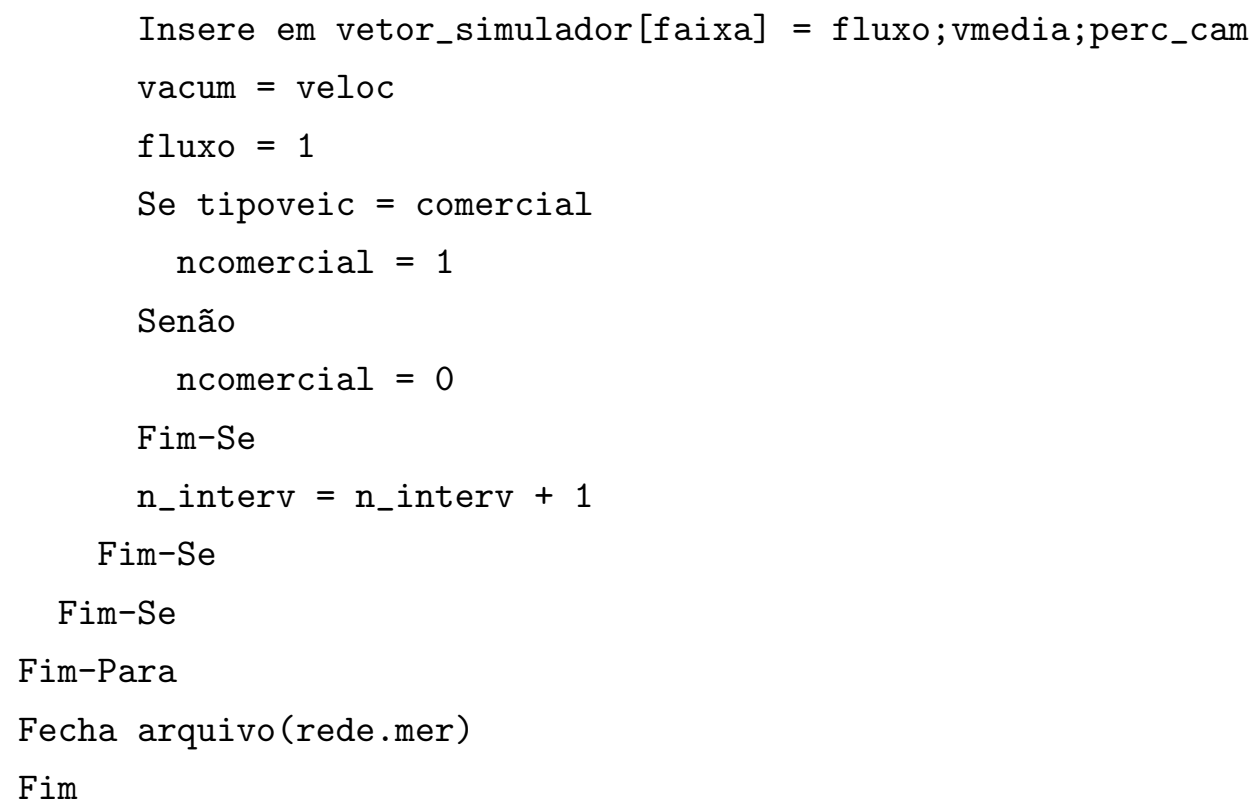

\subsection{Estrutura do algoritmo}

O Algoritmo Genético usado nesta pesquisa foi desenvolvido a partir de uma versão inicial criada por José Elievam Bessa Jr. em março de 2013 no Laboratório de Simulação de Sistemas de Transportes (LST) da Escola de Engenharia de São Carlos - USP. O algoritmo foi codificado em Lua, uma linguagem de programação criada em 1993 na Pontifícia Universidade Católica do Rio de Janeiro (PUC-RJ).

Foram feitas inúmeras adaptações no algoritmo inicial para atender às necessidades do projeto, mantendo-se apenas as rotinas relacionadas à inicialização, alterações nos arquivos de rede e encerramento do software.

A estrutura do algoritmo pode ser explicada de forma simplificada pela Figura 5.1 e pelo seguinte processo:

- Definem-se o número de indivíduos e de gerações.

- Definem-se as taxas de mutação e de eliminação de indivíduos por seleção natural e o período de ocorrência destes eventos.

- Na primeira geração, os indivíduos são criados de maneira aleatória. Cada gene criado aleatoriamente recebe um valor escolhido aleatoriamente dentro do espaço de busca predefinido para cada um dos parâmetros.

- A cada geração, uma nova população é criada a partir do cruzamento de genes de dois indivíduos distintos. A chance de um descendente herdar um gene de um dos dois indivíduos geradores (seus pais) é a mesma: $50 \%$. 


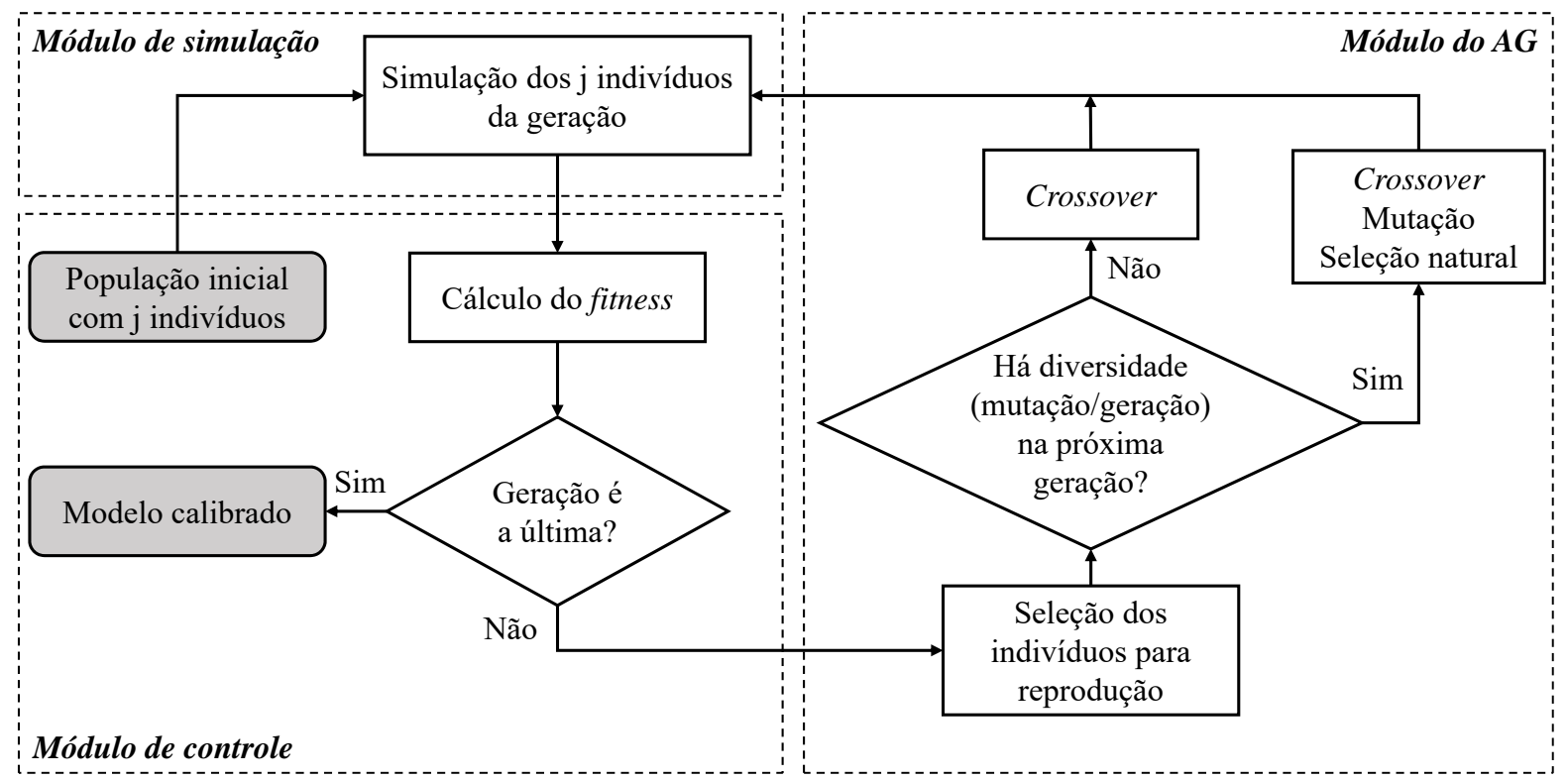

Figura 5.1 - Fluxograma da estrutura simplificada do Algoritmo Genético utilizado

- Na geração em que houver diversidade (mutação e seleção natural), cada gene tem a probabilidade de ser alterado de forma aleatória, de acordo com a taxa de mutação. A eliminação de indivíduos por seleção natural ocorre nos indivíduos que apresentarem os menores valores da função fitness de acordo com a probabilidade representada pela taxa de seleção natural. Os indivíduos eliminados pelo processo são substituídos por outros, criados aleatoriamente;

- A recombinação genética pode, ocasionalmente, gerar indivíduos idênticos ao atual melhor indivíduo. Caso isto ocorra, este indivíduo é substituído por outro, de características aleatórias.

\subsubsection{Crossover e Seleção (Reprodução)}

O crossover é o operador genético do algoritmo responsável pelo cruzamento entre partes dos cromossomos (genes) de dois indivíduos, produzindo uma nova geração, composta por indivíduos com características distintas. No algoritmo genético utilizado, os genes que compõem o novo indivíduo são escolhidos aleatoriamente entre os genes correspondentes dos dois pais. Se os pais são representados pelas sequências de genes $G_{1} G_{2} \cdots G_{n}$ e $H_{1} H_{2} \cdots H_{n}$, o primeiro gene do filho pode ser $G_{1}$ ou $H_{1}$; o segundo, $G_{2}$ ou $H_{2}$; e assim sucessivamente até o $n$-ésimo gene, que pode ser $G_{n}$ ou $H_{n}$. Para cada gene, o novo indivíduo tem a mesma possibilidade de herdar a característica de qualquer um dos seus pais.

A seleção ou reprodução é a escolha dos indivíduos que irão dar origem a um descendente através do processo de crossover. Um dos métodos de seleção é denominado elitismo, no qual o indivíduo com o maior valor da função fitness é escolhido para realizar o crossover com 
os demais indivíduos da população. Outra maneira de realizar o cruzamento é sortear dois indivíduos para trocarem informações a partir de uma probabilidade, com base no seu grau de adaptação fitness.

\subsubsection{Seleção por elitismo}

O método elitista de reprodução foi considerado com o objetivo de priorizar as características do indivíduo de melhor desempenho (indivíduo-pai) ao selecioná-lo como um dos genitores de todos os indivíduos da geração seguinte. Além disso, o indivíduo-pai automaticamente faz parte da geração seguinte, para garantir que a melhor solução encontrada até aquela geração não seja perdida por causa da aplicação dos operadores genéticos.

A chance de cada gene receber a herança genética do melhor indivíduo no cruzamento é de $50 \%$. Se for criado um outro indivíduo que produzir um valor de fitness maior do que o do indivíduo-pai, este novo indivíduo se tornará o indivíduo-pai e transmitirá seus genes para a geração seguinte.

Quando um indivíduo-pai não é substituído por um descendente mais bem adaptado, as gerações subsequentes tornam-se cada vez mais semelhantes ao indivíduo-pai, até que os eventos de mutação e seleção natural introduzam diversidade aleatória na população. Por isso, esses dois operadores genéticos desempenham um papel importante quando a seleção por elitismo é usada no algoritmo genético.

\subsubsection{Seleção por sorteio}

O operador de seleção probabilística pode ser implementado de diversas maneiras no algoritmo. A mais simples é criar um sorteio em que a probabilidade de um indivíduo ser selecionado para reprodução é proporcional ao seu grau de adaptação (fitness) (GOLDBERG, 1989, p. 11).

O modelo funciona da seguinte forma: cada indivíduo tem uma probabilidade de ser escolhido para reprodução que é proporcional ao valor do seu fitness. Dessa forma, quanto maior o fitness, maior a chance de ser sorteado. A Tabela 5.1 mostra uma situação hipotética de uma geração com 5 indivíduos, a probabilidade de escolha de cada um e o intervalo de sorteio referente àquele indivíduo. A probabilidade $p(i)$ de ser sorteado para reprodução é calculada segundo a função:

$$
p(i)=\frac{F i t(i)}{\sum_{i=1}^{i_{\max }} F i t(i)}
$$

Em que Fit(i): Fitness do indivíduo $i$;

$i_{\text {max }}$ : Total de indivíduos da população;

$p(i)$ : Probabilidade de seleção do indivíduo $i$. 
Tabela 5.1 - Intervalo de sorteio de indivíduos para cruzamento

\begin{tabular}{ccccc}
\hline Indivíduo & Fitness & Probabilidade & Prob. Acumulada & Intervalo de Sorteio \\
\hline 1 & 10.00 & $5 \%$ & $5 \%$ & $0-5$ \\
2 & 20.00 & $10 \%$ & $15 \%$ & $6-15$ \\
3 & 30.00 & $15 \%$ & $30 \%$ & $16-30$ \\
4 & 50.00 & $25 \%$ & $55 \%$ & $31-55$ \\
5 & 90.00 & $45 \%$ & $100 \%$ & $56-100$ \\
\hline
\end{tabular}

São sorteados dois números aleatórios entre 0 e 100 para definir os dois indivíduos que irão realizar a troca de genes. Por exemplo: considerando a situação hipotética, se os dois números sorteados fossem 3 e 79, o cruzamento iria ocorrer entre os indivíduos 1 e 5 . Caso os números fossem 79 e 98, o segundo número seria sorteado novamente para permitir o cruzamento com outro indivíduo. Caso o melhor indivíduo seja proveniente de gerações anteriores, este será considerado no sorteio junto aos indivíduos da geração atual para formar a próxima geração.

\subsubsection{Análise dos métodos propostos}

Um experimento foi realizado para comparar e avaliar os dois métodos de seleção para o cruzamento. Considerou-se uma população de 25 indivíduos e 50 gerações e manteve-se a mesma função fitness e a semente para os dois modelos avaliados. As taxas de mutação e seleção natural foram definidas em $30 \%$ e $50 \%$, respectivamente, e estes eventos ocorrendo a cada 4 gerações.

A Tabela 5.2 apresenta a progressão dos melhores resultados das simulações e a geração em que houve o aumento do valor do fitness máximo. Cada linha representa o registro de um novo indivíduo mais bem adaptado em relação aos anteriores, ou seja, o indivíduo com fitness máximo até o momento.

Tabela 5.2 - Parâmetros dos melhores indivíduos - seleção por elitismo

\begin{tabular}{ccccccccccccc}
\hline \multirow{2}{*}{ Geração } & & \multicolumn{1}{c}{ Parâmetros comportamentais do simulador } \\
& OBSVEH & CC0 & CC1 & CC2 & CC3 & CC4 & CC5 & MH & SD & MD & TSL & Fitness \\
\hline 1 & 1 & 0.61 & 1.29 & 3.07 & -7.37 & -0.55 & 0.69 & 1.59 & 0.16 & -5.98 & 7.93 & 46.95 \\
2 & 1 & 0.61 & 1.29 & 3.07 & -7.37 & -0.55 & 0.69 & 1.59 & 0.16 & -5.98 & 2.92 & 46.98 \\
3 & 1 & 0.61 & 1.29 & 3.07 & -7.37 & -1.23 & 0.69 & 1.59 & 0.16 & -5.98 & 7.93 & 47.02 \\
5 & 1 & 2.93 & 0.92 & 7.68 & -2.56 & -0.22 & 1.80 & 0.69 & 0.16 & -1.81 & 9.87 & 47.18 \\
6 & 1 & 0.61 & 0.92 & 7.68 & -8.79 & -0.22 & 0.69 & 0.69 & 0.16 & -5.98 & 9.44 & 48.35 \\
7 & 1 & 0.61 & 0.92 & 7.68 & -8.79 & -0.22 & 0.69 & 1.59 & 0.16 & -5.98 & 9.87 & 48.38 \\
10 & 1 & 0.61 & 0.92 & 7.68 & -8.79 & -0.22 & 0.69 & 1.59 & 0.16 & -5.98 & 9.87 & 48.40 \\
11 & 1 & 0.61 & 0.92 & 7.68 & -8.79 & -0.22 & 0.69 & 2.00 & 0.16 & -5.98 & 9.87 & 48.50 \\
15 & 1 & 0.61 & 0.92 & 7.68 & -8.79 & -0.22 & 0.69 & 2.00 & 0.16 & -5.98 & 9.87 & 48.59 \\
22 & 1 & 0.61 & 0.92 & 7.68 & -8.79 & -0.22 & 0.69 & 2.00 & 0.16 & -5.98 & 9.87 & 48.59 \\
23 & 1 & 0.61 & 0.92 & 7.68 & -8.79 & -0.22 & 0.69 & 2.00 & 0.16 & -5.98 & 9.87 & 48.61 \\
27 & 1 & 0.61 & 0.92 & 7.68 & -8.79 & -0.22 & 0.72 & 2.00 & 0.16 & -5.98 & 9.87 & 48.66 \\
34 & 1 & 0.61 & 0.92 & 7.68 & -8.79 & -0.22 & 0.72 & 2.00 & 0.16 & -5.98 & 9.87 & 48.68 \\
35 & 1 & 0.61 & 0.92 & 7.68 & -8.79 & -0.22 & 0.72 & 2.00 & 0.16 & -5.98 & 9.87 & 48.72 \\
38 & 1 & 0.61 & 0.92 & 7.68 & -8.79 & -0.22 & 0.72 & 2.00 & 0.16 & -5.54 & 9.87 & 48.74 \\
42 & 1 & 0.61 & 0.92 & 7.68 & -8.79 & -0.22 & 0.72 & 2.00 & 0.16 & -5.98 & 9.87 & 48.77 \\
\hline
\end{tabular}


Tabela 5.3 - Parâmetros dos melhores indivíduos - seleção por probabilidade de cruzamento

\begin{tabular}{ccccccccccccc}
\hline \multirow{2}{*}{ Geração } & OBSVEH & CC0 & CC1 & CC2 & CC3 & CC4 & CC5 & MH & SD & MD & TSL & Fitness \\
\hline 1 & 1 & 0.54 & 0.85 & 7.24 & -4.60 & -0.75 & 1.01 & 1.53 & 0.60 & -1.38 & 9.39 & 44.64 \\
4 & 3 & 1.65 & 0.96 & 4.74 & -8.28 & -0.50 & 0.64 & 1.16 & 0.48 & -2.53 & 1.38 & 46.61 \\
5 & 2 & 0.87 & 1.22 & 7.27 & -9.15 & -0.24 & 0.36 & 1.64 & 0.13 & -8.77 & 9.75 & 47.02 \\
6 & 5 & 0.87 & 1.22 & 4.04 & -7.46 & -1.27 & 0.50 & 1.88 & 0.26 & -5.15 & 9.75 & 47.02 \\
7 & 5 & 0.87 & 1.22 & 4.04 & -7.46 & -1.27 & 0.50 & 1.88 & 0.26 & -5.15 & 9.75 & 47.02 \\
8 & 1 & 2.46 & 0.68 & 6.30 & -14.16 & -0.39 & 1.96 & 1.01 & 0.56 & -9.00 & 6.71 & 47.02 \\
12 & 1 & 2.80 & 1.05 & 1.72 & -12.94 & -1.23 & 0.93 & 1.42 & 0.13 & -1.15 & 2.40 & 48.10 \\
39 & 6 & 1.22 & 1.05 & 1.72 & -8.15 & -1.23 & 0.93 & 1.42 & 0.54 & -1.15 & 8.03 & 50.02 \\
\hline
\end{tabular}

Percebe-se que no método de seleção por elitismo não houve muitas alterações nos parâmetros comportamentais com o avanço das gerações, pois o cruzamento de todos os indivíduos da geração com o indivíduo-pai limitou o espaço de busca dos parâmetros. Observa-se, por exemplo, que em nenhum dos melhores indivíduos o parâmetro SD sofreu alteração, e que a melhoria da função de adaptação na maior parte dos casos ocorreu devido a mudança em parâmetros não-comportamentais, apresentados nas Seções 5.8 e 5.9 .

Em contra-partida, o crossover com seleção por sorteio apresentou uma variabilidade maior nos valores dos parâmetros, e manteve alguns genes dos melhores indivíduos anteriores, como pode ser observado na Tabela 5.3. Essa maior variabilidade corrobora a hipótese de que o método de seleção por sorteio consegue cobrir melhor o espaço de busca para os parâmetros de calibração, mantendo os valores que podem definir os melhores resultados.

O AG faz a seleção para o crossover usando o método do sorteio e, ao mesmo tempo, mantém o indíviduo mais bem adaptado na geração subsequente, garantindo que o valor do fitness do indivíduo mais bem adaptado em cada geração nunca seja menor que o máximo encontrado nas gerações anteriores.

\subsubsection{Seleção natural e mutação}

O AG possui parâmetros de entrada que devem ser definidos no início da simulação: taxa de eliminação por seleção natural, taxa de mutação e a periodicidade com que os operadores mutação e seleção natural são aplicados. A taxa de seleção natural representa o percentual da população que será substituída por novos indivíduos. A escolha dos indivíduos que são eliminados é feita através do valor do seu fitness. A taxa de mutação define a probabilidade que cada gene tem de ser modificado de maneira aleatória. A quantidade de gerações para inserir diversidade é a periodicidade em que a mutação e a seleção natural irão ocorrer. Baseando-se nos estudos de Kim e Rilett (2001), foi definida a taxa de mutação como 30\%, e a taxa de indivíduos eliminados por seleção natural é de $50 \%$, com aplicação desses operadores genéticos a cada quatro gerações. A periodicidade foi definida de modo a permitir que se insiram sistematicamente novas características e, ao mesmo tempo, permitir que estas novas características sejam disseminadas entre os indivíduos durante o processo de crossover. 


\subsection{Função fitness}

Os algoritmos genéticos baseiam-se numa analogia com os sistemas naturais, em que os indivíduos da população têm seu grau de adaptação ao meio ambiente medido através de uma função de adaptação (fitness) (EGAMI, 2006). Os indivíduos com maior fitness, ou seja, melhor adaptados ao meio, possuem maior probabilidade de transmitir suas características para as gerações futuras.

O fitness é calculado para cada medida de desempenho segundo a Equação 5.2, usada por Kim e Rilett (2001). A função de adaptação do indivíduo é composta pela associação de três medidas de desempenho: (1) a distribuição de veículos por faixa; (2) o percentual de veículos comerciais; (3) por uma das medidas de comparação entre os gráficos de fluxo e velocidade. A intenção de se associar as medidas é pautada na hipótese de que a calibração conjunta poderia auxiliar no ajuste simultâneo de modelos distintos.

$$
\text { Fitness }=\sum_{j=1}^{3} A_{j} e^{-B_{j} x_{j}}
$$

Em que $x_{j}$ : $\quad$ Valor da $j$-ésima medida de desempenho;

$A_{j}$ e $B_{j}$ : Constantes da função de adaptação da $j$-ésima medida de desempenho;

Fitness: Valor da função de adaptação do indivíduo.

\subsubsection{Medidas de desempenho}

A escolha da medida de desempenho apropriada é essencial para uma análise segura dos resultados do simulador. Nesta etapa, são descritas as medidas que compõem a função fitness.

O objetivo de se utilizar as medidas combinadas é que a medida de comparação entre os conjuntos não é temporal, ou seja, não avalia se os intervalos de ocorrência dos dados observados e simulados são equivalentes ou não. Além disso, considerou-se que as demais medidas poderiam aprimorar a calibração de parâmetros de mudança de faixa.

\subsubsection{Percentual de veículos comerciais}

Como no Brasil os caminhões tendem a trafegar primordialmente pelas faixas mais à direita, o percentual de veículos comerciais foi adotado como medida de desempenho nesta pesquisa para auxiliar na calibração dos parâmetros relativos ao modelo de lane-change. O ajuste é feito a partir do cálculo do erro médio absoluto (MAE) entre o percentual de veículos comerciais observado em campo e o percentual de veículos comerciais obtido através da simulação, comparados intervalo por intervalo, conforme equação:

$$
\text { MAEcomerciais }=\sum_{j=1}^{n} \frac{1}{i_{\max _{j}}} \sum_{i=1}^{i_{\max _{j}}} \mid \% \text { observado }_{i_{j}}-\% \text { simulado }_{i_{j}} \mid
$$




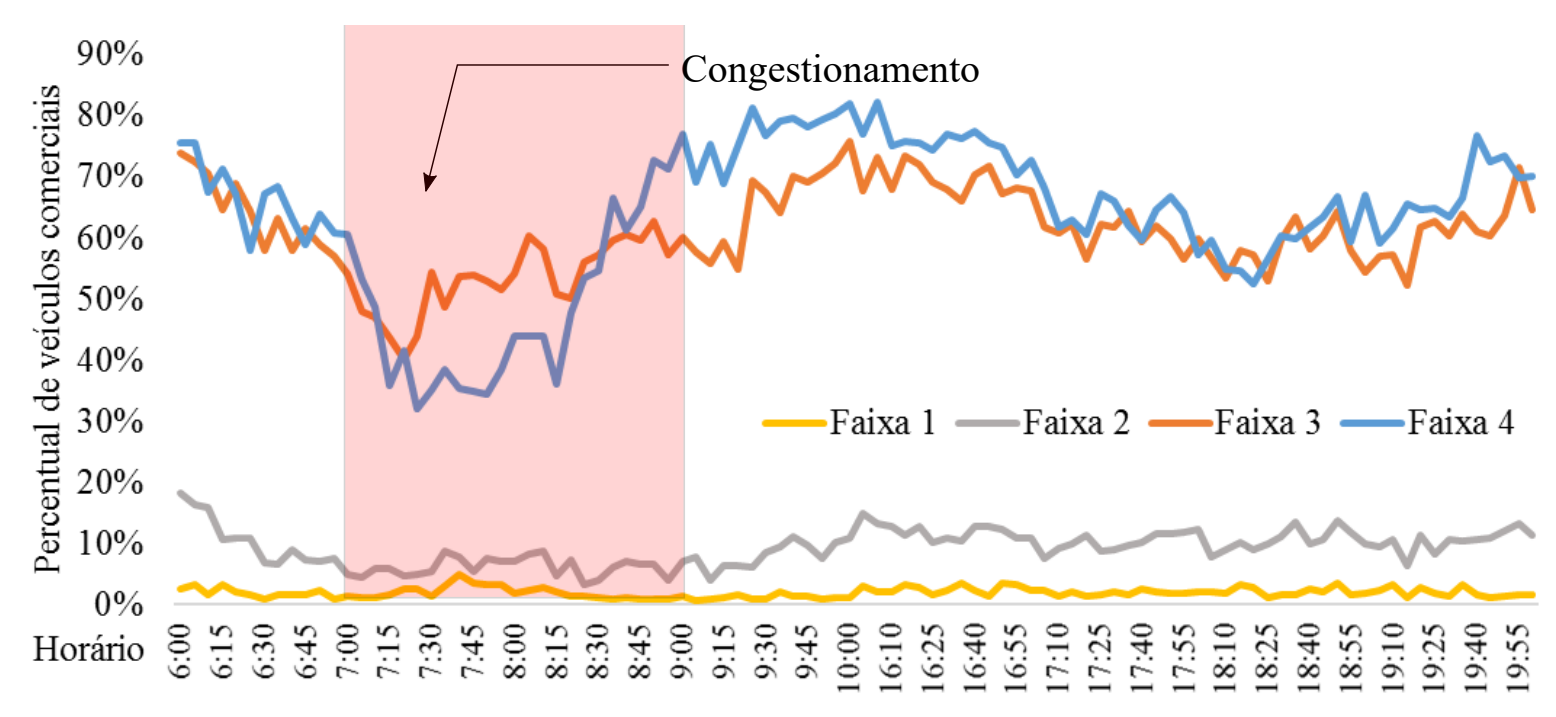

Figura 5.2 - Percentual médio de veículos comerciais de 6 dias de tráfego entre 6:00 e 10:00 e entre 16:00 e 20:00

Em que MAEcomerciais: Erro do percentual de veículos comerciais;

\begin{tabular}{|c|c|}
\hline$i_{\max _{j}}:$ & Total de intervalos de dados da simulação de tráfego da faixa $j$; \\
\hline$\% o b s e r v a d o_{i_{j}}$ : & $\begin{array}{l}\text { Percentual de veículos comerciais no intervalo } i \text { referente à faixa } \\
j \text { de } 5 \text { minutos de dados dos sensores de tráfego; }\end{array}$ \\
\hline$\%$ simulado $_{i_{j}}$ : & $\begin{array}{l}\text { Percentual de veículos comerciais no intervalo } i \text { referente à faixa } \\
j \text { de } 5 \text { minutos de dados da simulação de tráfego; }\end{array}$ \\
\hline & Número total de faixas (4 faixas nesta pesquisa). \\
\hline
\end{tabular}

O cálculo do erro médio absoluto é realizado no algoritmo conforme o pseudocódigo:

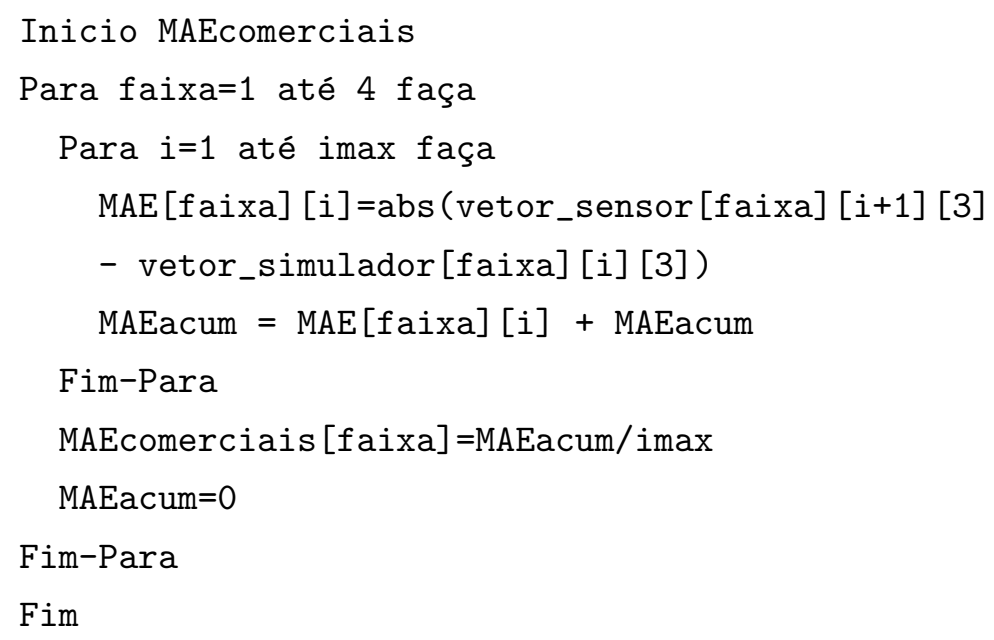

A Figura 5.2 apresenta o percentual médio de veículos comerciais dos 6 dias de tráfego utilizados na calibração, por intervalo, para cada faixa de tráfego. Observa-se que a maior variação na distribuição de veículos comerciais ocorre nas faixas próximas ao acostamento, principalmente no período em que há congestionamento (entre 7:00 e 9:00, em média). 


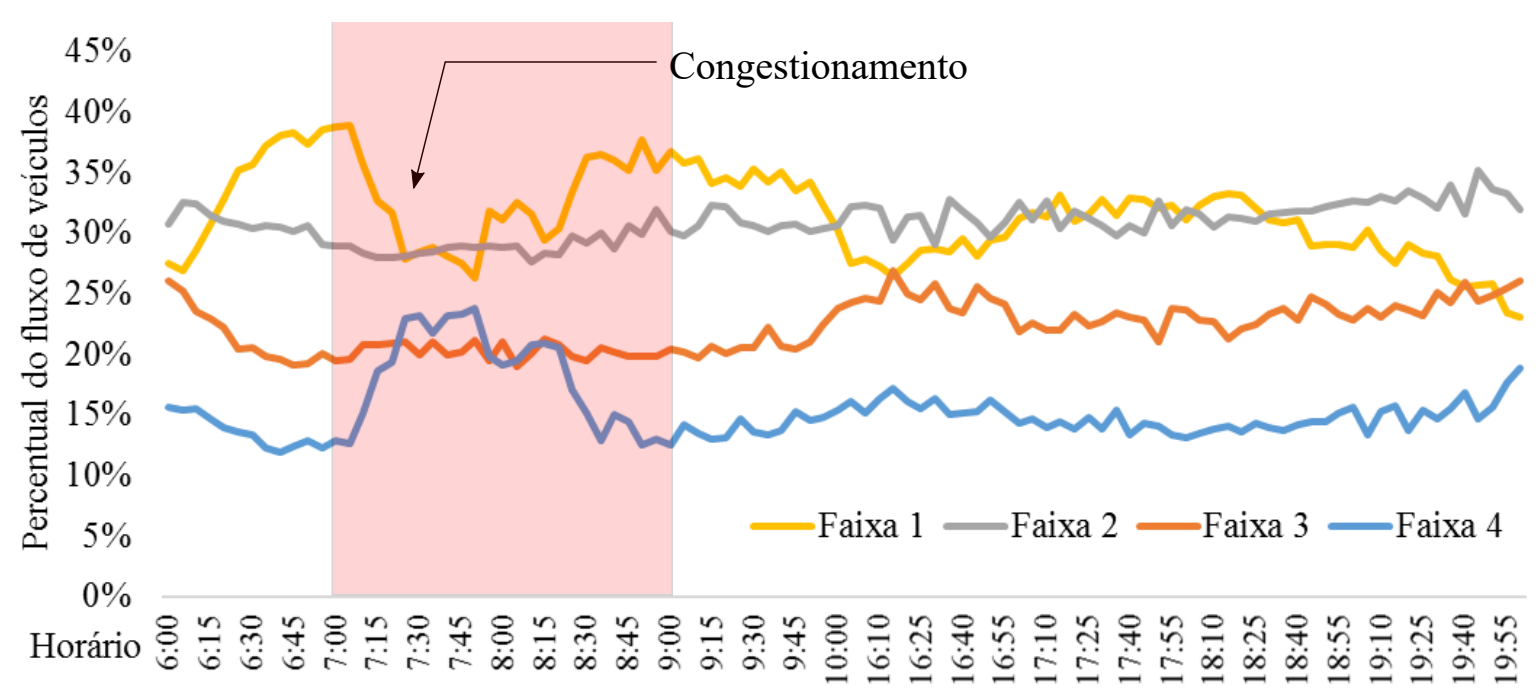

Figura 5.3 - Percentual médio de veículos por faixa de 6 dias de tráfego entre 6:00 e 10:00 e entre 16:00 e 20:00

\subsubsection{Distribuição do fluxo de veículos}

Assim como o percentual de veículos comerciais, considerou-se como medida de desempenho o erro médio absoluto da distribuição do fluxo de veículos por faixa com o objetivo de calibrar os parâmetros comportamentais do modelo de lane-change. Nota-se pela Figura 5.3 que o fluxo de veículos é maior nas faixas 1 e 2, mas no período de congestionamento a distribuição entre as faixas tende a se igualar, observando-se um aumento do fluxo na faixa 4 e uma redução na faixa 1.

O erro médio absoluto do percentual de veículos por faixa é calculado conforme equação:

$$
\text { MAEfluxo }=\sum_{j=1}^{n} \frac{1}{i_{\max _{j}}} \sum_{i=1}^{i_{\max _{j}}} \mid \% \text { observado } i_{i_{j}}-\% \text { simulado }_{i_{j}} \mid
$$

Em que MAEfluxo: Erro do percentual do fluxo de tráfego;

$i_{\text {max }_{j}}: \quad \quad \quad$ Total de intervalos de dados da simulação de tráfego da faixa $j$;

$\%$ observado $i_{i}$ : Percentual do fluxo de tráfego no intervalo $i$ referente à faixa $j$

de 5 minutos de dados dos sensores de tráfego;

$\%$ simulado $_{i_{j}}$ : Percentual do fluxo de tráfego no intervalo $i$ referente à faixa $j$

de 5 minutos de dados da simulação de tráfego;

$n$ : $\quad$ Número total de faixas (4 faixas nesta pesquisa).

O pseudocódigo a seguir apresenta o processo de cálculo do erro médio absoluto do percentual de fluxo por faixa:

Inicio MAEfluxo

Para faixa=1 até 4 faça

Para $i=1$ até imax faça 


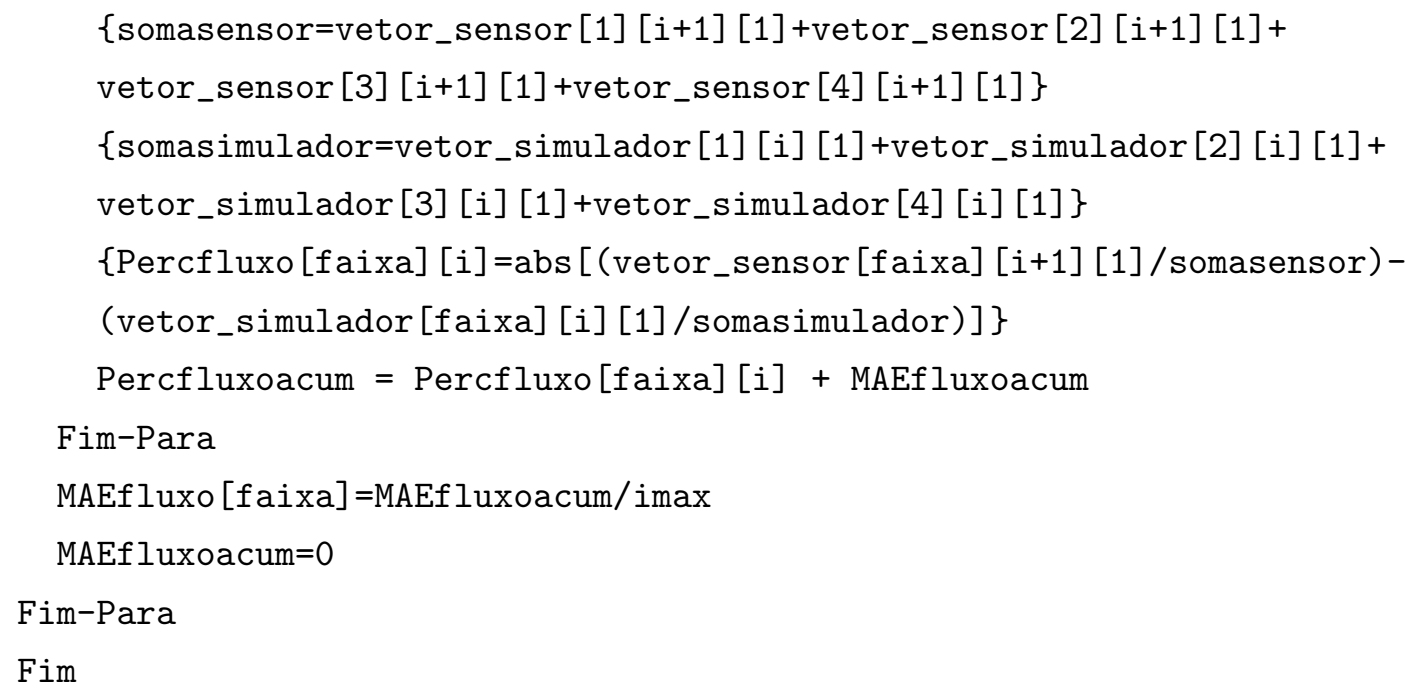

\subsubsection{Distância de Hausdorff modificada}

A dissimilaridade entre conjuntos é analisada neste trabalho de três formas. A primeira consiste na análise da distância de Hausdorff modificada (DUBUISSON; JAIN, 1994), através do conjunto de informações de fluxo e velocidade, dispostas em gráfico no plano cartesiano $x y$, cujo eixo das abscissas $(x)$ é representado pelo fluxo de veículos, em veic/(h.faixa), observados em intervalos de 5 minutos, e o eixo das ordenadas $(y)$, a velocidade média dos veículos, em $\mathrm{m} / \mathrm{s}$.

A distância de Hausdorff modificada $\left(H_{M H D}\right)$ é calculada para dois conjuntos. O primeiro conjunto, contendo dados coletados pelos sensores de tráfego, é comparado ao conjunto de dados gerados pela simulação do tráfego. Se os dois gráficos (observado e simulado) forem perfeitamente iguais, $H_{M H D}=0$; quanto mais diferirem entre si os gráficos, maior é o valor de $H_{H M D}$.

\section{Cálculo da $H_{M H D}$}

Após inserir os dados observados e simulados em vetores no AG, inicia-se o processo de cálculo das medidas de desempenho. Define-se: $A$ o conjunto dos pontos observados; $A_{i}$ os pontos do conjunto $A$; $B$ o conjunto de pontos simulados; $B_{i}$ os pontos do conjunto $B$. A distância de Hausdorff modificada é calculada da seguinte forma:

1. Define-se inicialmente um alto valor para as mínimas distâncias $d_{\min }(A ; B)$ dos pontos do conjunto A em relação aos pontos do conjunto B;

2. Calcula-se a distância euclidiana de um ponto do conjunto $A$ para todos os pontos do conjunto $B$, desde que sejam referentes à mesma faixa;

3. Verifica-se qual é a menor distância deste ponto para o conjunto $B$;

4. Repetem-se os processos anteriores para todos os pontos do conjunto $A$ em relação ao conjunto $B$; 
5. Repetem-se os processos anteriores para todas as faixas;

6. Repetem-se os processos anteriores para os pontos do conjunto $B$ em relação ao conjunto $A$;

7. Calcula-se a média das menores distâncias $\left(d_{\min }\right)$ de todos os pontos de $A$ em relação ao conjunto $B$, e de $B$ em relação ao conjunto $A$, para cada faixa;

8. Determina-se qual é a máxima das médias para cada faixa (Há duas informações por faixa: do conjunto $A$ em relação ao $B$ e do $B$ em relação ao $A$ ). A máxima das médias é a $H_{M H D}$.

A Figura 5.4 apresenta um fluxograma que representa o cálculo das mínimas distâncias, correspondente às etapas 1, 2, 3 e 4 do processo. As etapas 7 e 8 são descritas pelo pseudocódigo:

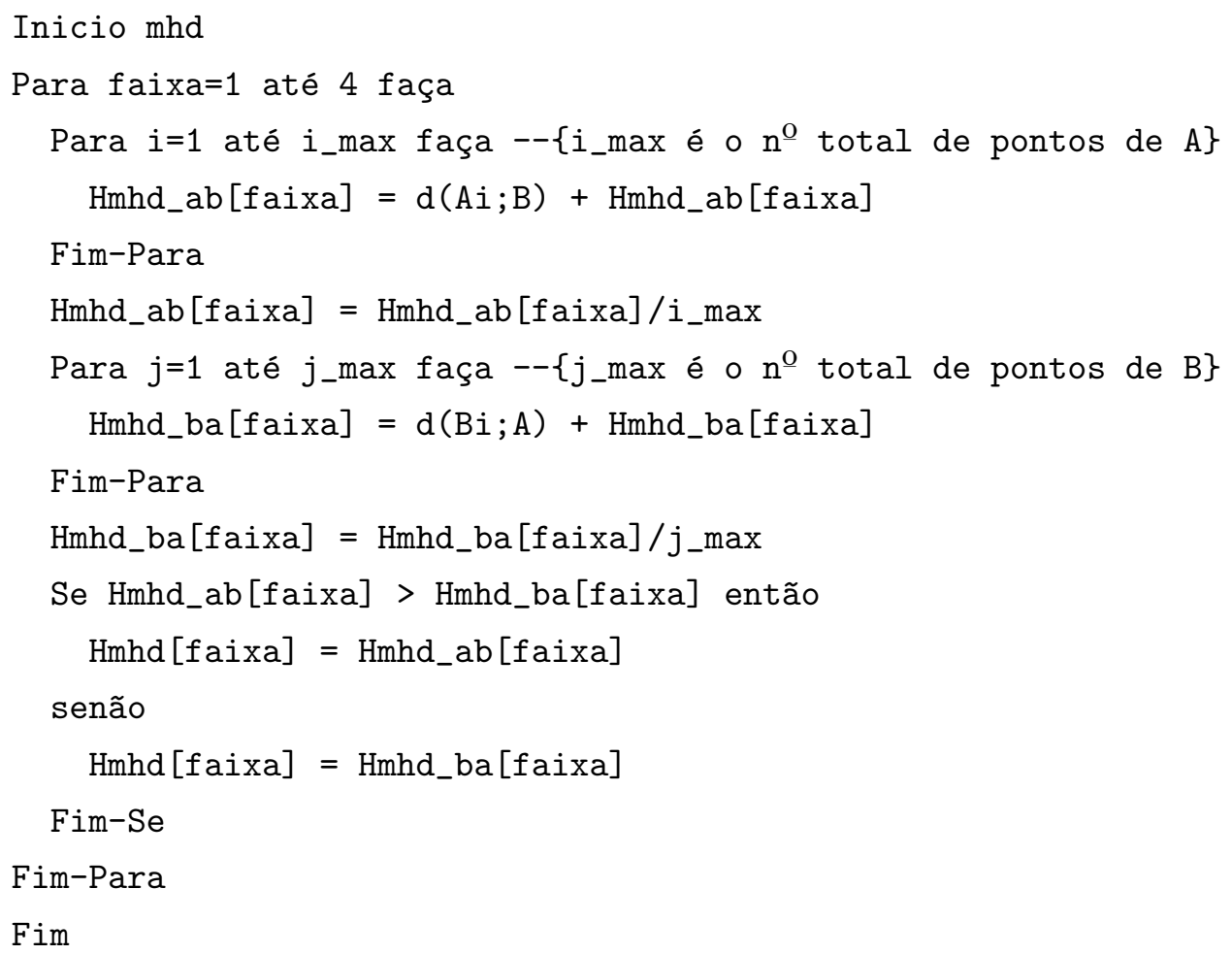

A medida de distância de Hausdorff modificada é calculada segundo a equação:

$$
M H D=\frac{1}{n} \sum_{j=1}^{n} M H D_{j}
$$

Em que $M H D_{j}$ : Distância de Hausdorff modificada da faixa j;

MHD: $\quad$ Distância de Hausdorff modificada;

$n$ : $\quad$ Número total de faixas (4 faixas nesta pesquisa). 


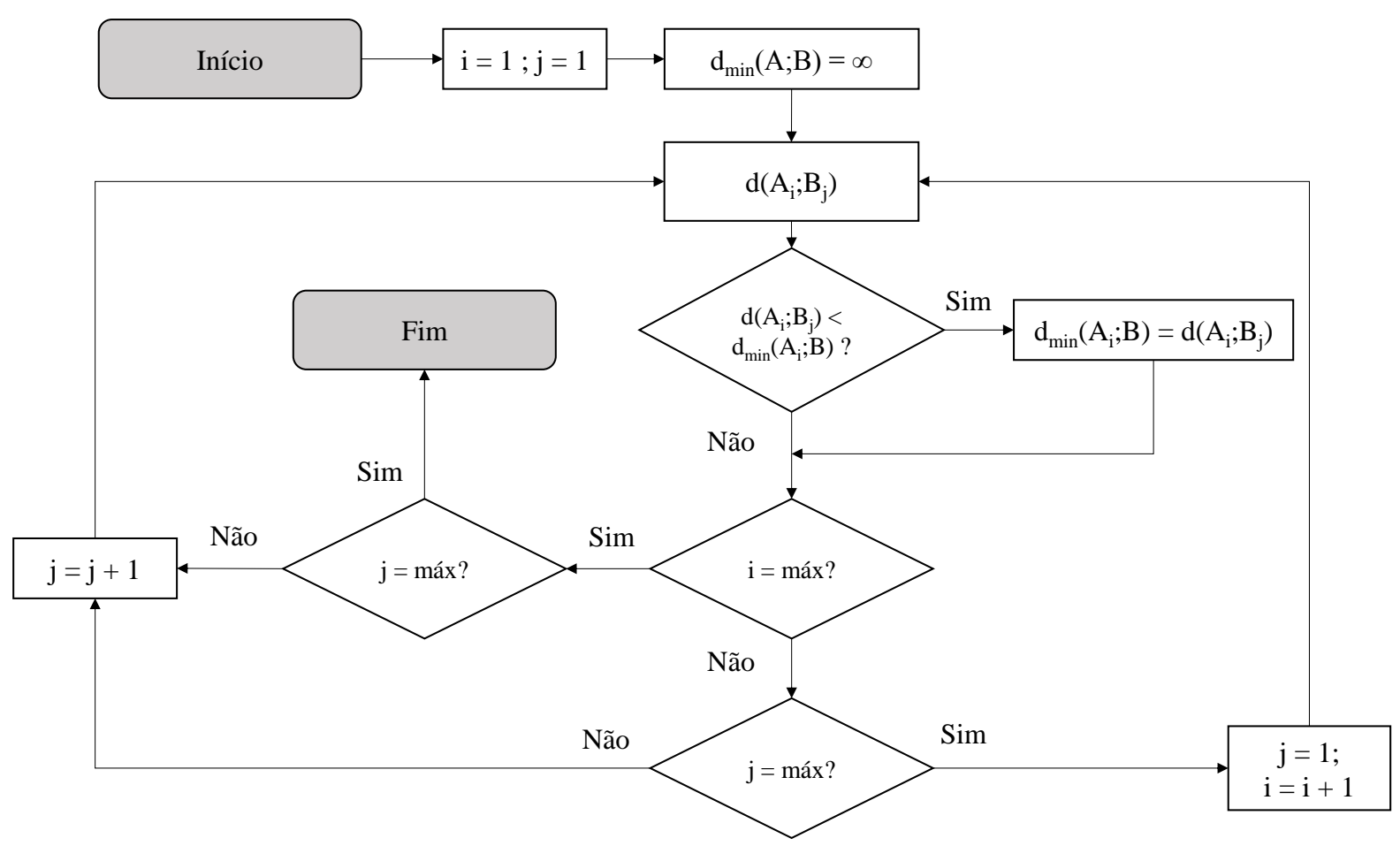

Figura 5.4 - Fluxograma do cálculo das distâncias entre pontos de dois conjuntos

\subsubsection{Densidade de pontos por pixels}

Foram testadas medidas de dissimilaridade entre conjuntos obtidas após o processo de amostragem e quantização dos dados. As medidas são calculadas através da quantidade acertos de pontos por pixel da imagem gerada pelos dados simulados em comparação à imagem-base, composta pelos dados observados.

\section{Amostragem e quantização}

A amostragem é realizada para transformar o gráfico que representa o conjunto de pontos de fluxo e velocidade em imagem, como ilustrado na Figura 5.5. Cada elemento de imagem (pixel) agrupou informações em intervalos de $1,0 \mathrm{~m} / \mathrm{s}(3,6 \mathrm{~km} / \mathrm{h})$ de velocidade e de 24 veic/(hora.faixa). Cada pixel armazena a quantidade de pontos do conjunto que fazem parte do intervalo correspondente. Este procedimento equivale à quantização, que consiste na digitalização da escala de variação de intensidade luminosa (amplitude), através de valores reais e positivos (GONZALEZ; WOODS, 2007).

Os dados dos sensores e do simulador são extraídos dos vetores criados nas rotinas de cálculo descritas na Seção 5.1.1. Os processos de amostragem e quantização são descritos no pseudocódigo: 

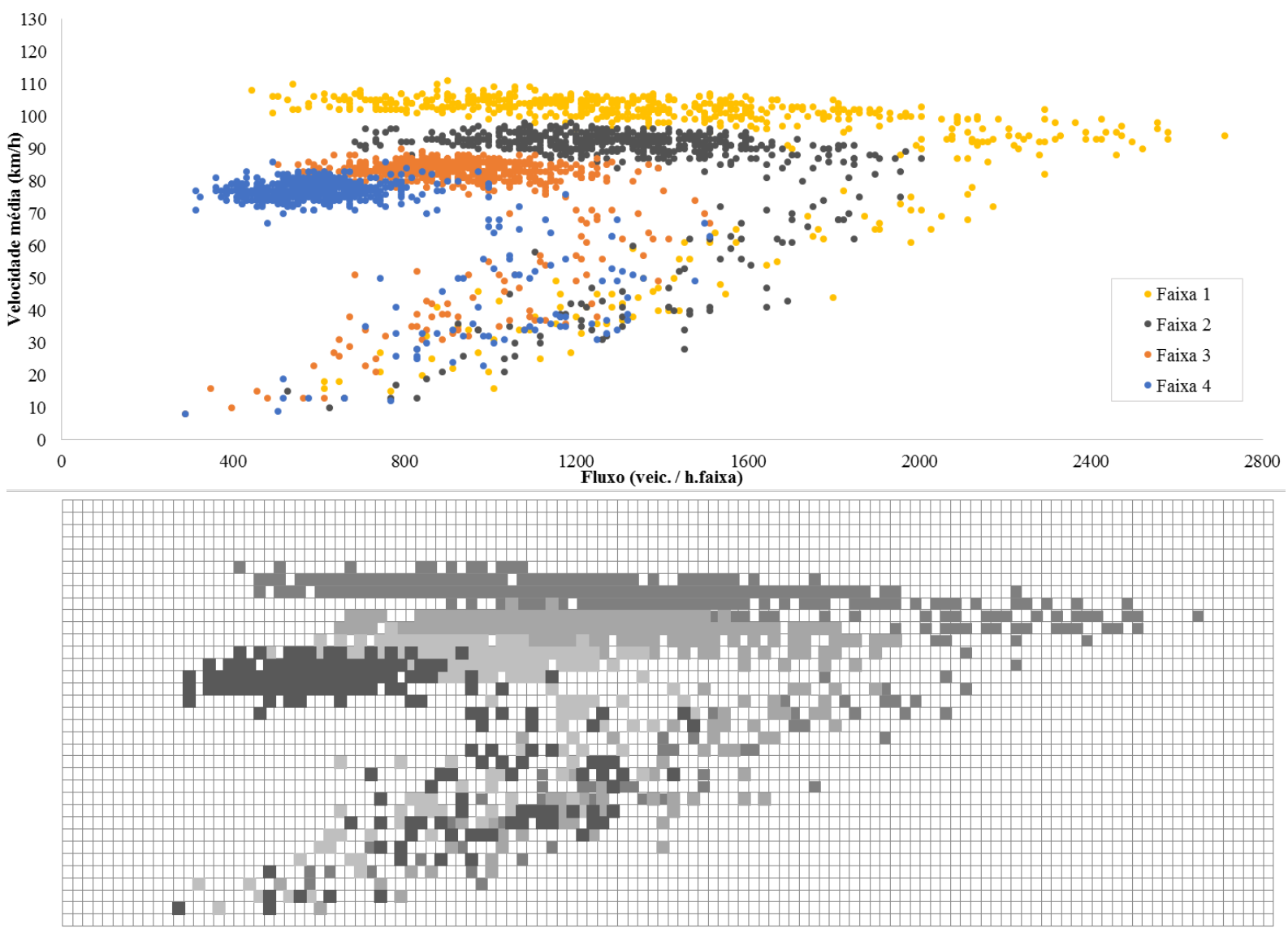

- Faixa 1

Faixa 2

Faixa 3

- Faixa 4

Figura 5.5 - Amostragem dos dados dos sensores de tráfego

Para $n=1$ até i_max faça

fluxo=int (vetor_sensor [faixa] [n] [1]/2)

veloc=int (vetor_sensor [faixa] [n] [2] )

Se dados_obs[faixa] [fluxo] [veloc] é nulo então

dados_obs [faixa] [fluxo] [veloc] $=1$

Senão

dados_obs[faixa] [fluxo] [veloc]=1+dados_obs[faixa] [fluxo] [veloc]

Fim-Se

Fim-Para

Para $n=1$ até j_max faça

fluxo=int (vetor_simulador [faixa] [n] [1]/2)

veloc=int (vetor_simulador [faixa] [n] [2])

Se dados_sim[faixa][fluxo] [veloc] é nulo então

dados_sim[faixa] [fluxo] [veloc] $=1$

Senão

dados_sim[faixa] [fluxo] [veloc]=1+dados_sim[faixa] [fluxo] [veloc]

Fim-Se

Fim-Para 
Fim-Para

Fim amostragem

Foram testados dois métodos de comparação entre padrões para os conjuntos, transformando o conjunto de pontos em uma imagem, cuja amplitude (intensidade) era proporcional à quantidade de pontos daquele pixel. O primeiro comparou a quantidade de pontos por pixel do gráfico dos dados observados com a quantidade de pontos que o simulador gerou para o pixel de referência. O segundo método utilizou medidas da matriz de contingência para avaliar a similaridade entre os conjuntos de pontos observados e simulados.

\section{Quantidade de acertos por pixel}

Considerou-se como medida de desempenho a taxa de acertos da quantidade de observações por pixel nesta análise, sendo a quantidade de pontos observados (qtde_obs [faixa]) como o maior número de acertos possíveis, por faixa de tráfego.

Menneni, Sun e Vortisch (2008) propuseram um método semelhante, porém, sem contemplar a amplitude de cada elemento de imagem. Pelo fato de se utilizar outras medidas de dissimilaridade que também não a consideram, através das medidas da matriz de contingência, e por considerar que a informação poderia ser relevante na calibração, optou-se por avaliar a amplitude dos pixels no cálculo da medida de desempenho.

Observou-se, em cada pixel, o total de pontos observados e simulados: cada dado coincidente do simulador foi descontado do vetor areadescoberta até o total de pontos observados para o pixel de referência, por exemplo:

- Se, para um determinado pixel, a quantidade de pontos observados é 10, e a quantidade de pontos simulados é 8 , contam-se 8 acertos no pixel.

- Se, para um determinado pixel, a quantidade de pontos observados é 10, e a quantidade de pontos simulados é 12 , contam-se 10 acertos no pixel.

Para cada faixa, calculou-se o percentual de acertos através da relação entre o número de acertos pelo total de observações. O pseudocódigo a seguir apresenta o processo de cálculo:

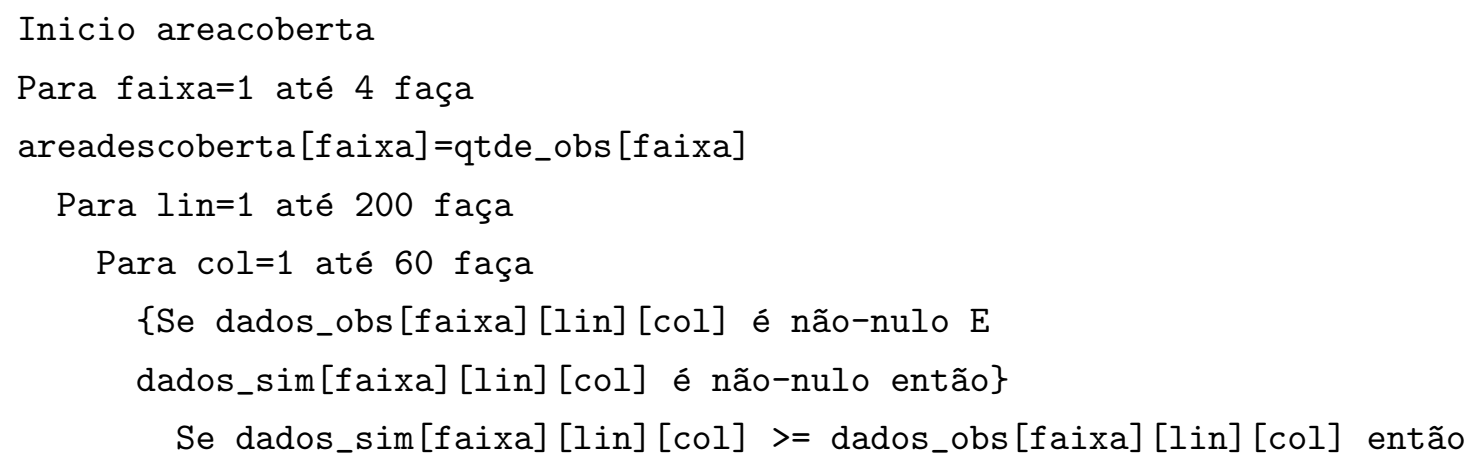




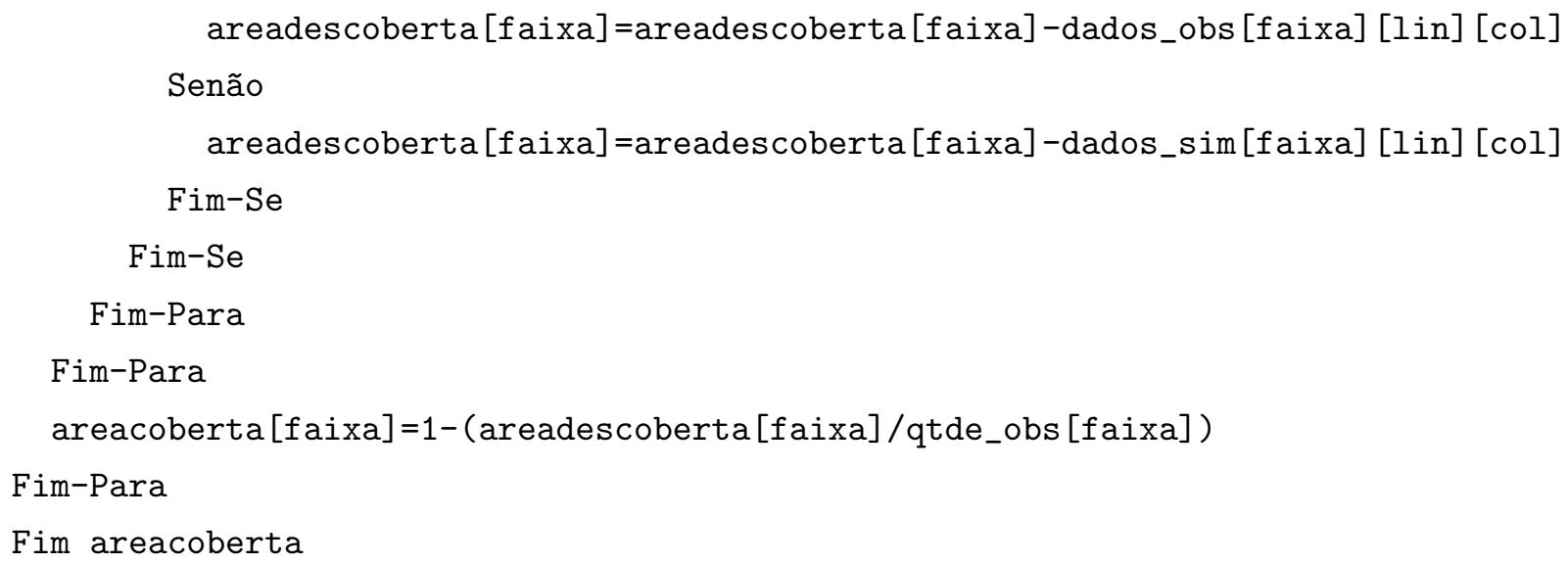

Para fins de cálculo, será utilizado o vetor areadescoberta, que representa o complemento da área dos dados observados coberta pelos dados simulados. A medida de desempenho denominada Raster é calculada através da equação:

$$
\text { Raster }=\frac{1}{n}\left(\sum_{j=1}^{n} \text { Areatotal }_{j}-\sum_{i=1}^{n_{\max _{j}}} \text { qtde_acertos }_{i_{j}}\right)
$$

Em que Raster: Percentual médio das áreas descobertas dos dados observados, de todas as faixas de tráfego;

Areatotal $_{j}$ : Quantidade de dados observados da faixa $j$;

qtde_acertos $i_{j}$ : Quantidade de acertos do $n$-ésimo elemento de imagem dos dados observados da faixa $j$;

$n_{\text {max }_{j}}$ : Quantidade de elementos de imagem com informações de tráfego dos dados observados de cada faixa $j$;

$n$ : $\quad$ Número total de faixas (4 faixas nesta pesquisa).

\subsubsection{Métricas da matriz de contingência}

A terceira, a quarta e a quinta medidas de desempenho relacionadas à comparação entre conjuntos são obtidas através das métricas de precisão, exatidão e taxa de verdadeiros positivos da matriz de contingência, apresentadas na Seção 2.4.2. As métricas são calculadas como representa o seguinte pseudocódigo:

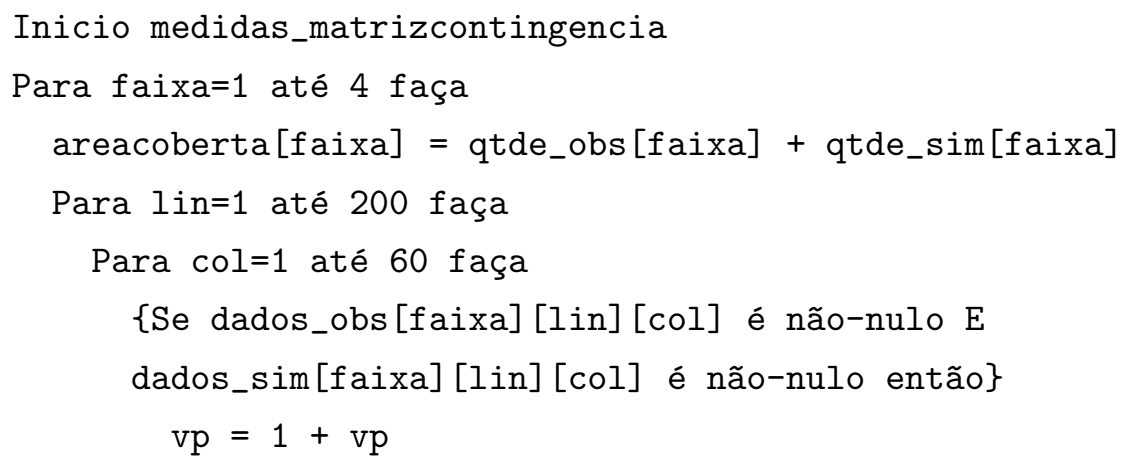




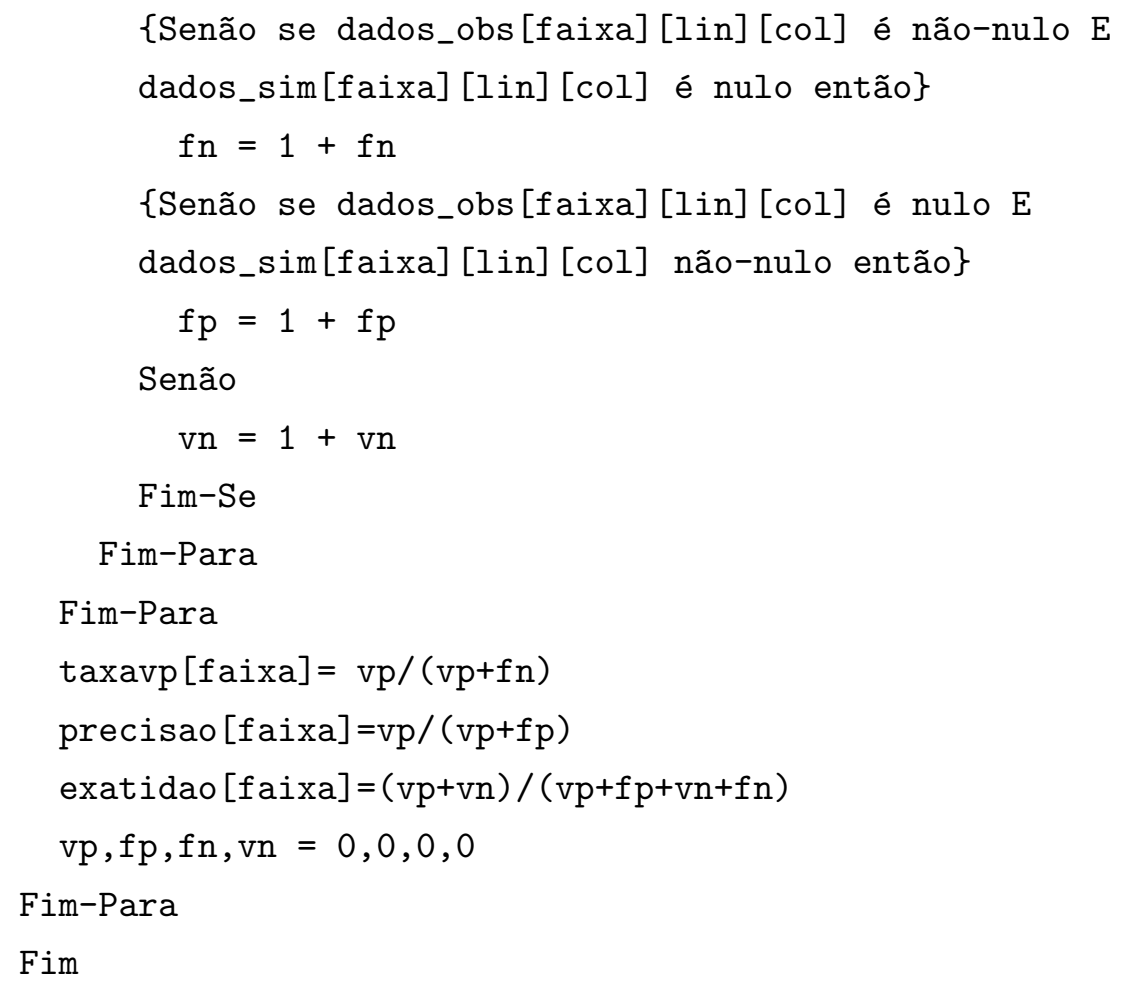

Fim

Sendo $V P$ a quantidade de verdadeiros positivos, $F P$ a quantidade de falsos positivos, $V N$ a quantidade de verdadeiros negativos, $F N$ a quantidade de falsos negativos e $n$ a quantidade de faixas de tráfego, a medida de desempenho de precisão ${ }^{1}$, é calculada pela equação:

$$
\text { Precisão }=\frac{1}{n} \sum_{j=1}^{n}\left(1-\frac{V P_{j}}{V P_{j}+F N_{j}}\right)
$$

A medida de desempenho de exatidão ${ }^{1}$ é calculada pela equação:

$$
\text { Exatidão }=\frac{1}{n} \sum_{j=1}^{n}\left(1-\frac{V P_{j}}{V P_{j}+F P_{j}}\right)
$$

A medida de desempenho de taxa de verdadeiros positivos (TaxaVP $)^{1}$ é calculada pela equação:

$$
\operatorname{TaxaVP}=\frac{1}{n} \sum_{j=1}^{n}\left(1-\frac{V P_{j}+V N_{j}}{V P_{j}+F P_{j}+V N_{j}+F N_{j}}\right)
$$

\subsubsection{Coeficientes da função fitness}

A associação entre as medidas de desempenho no processo de calibração é feita a partir do ajuste das constantes $A$ e $B$ da Equação 5.2. As medidas de desempenho possuem métricas diferentes, logo, a função precisa ser ajustada para que uma eventual melhoria seja relevante em todas as medidas de desempenho.

\footnotetext{
${ }^{1}$ As medidas de precisão, exatidão e taxa de verdadeiros positivos são calculadas pelo seu complemento, pois a função fitness considera como melhores resultados os menores valores das medidas de desempenho
} 
A constante $A$ representa o limite superior do valor da função fitness: quando a medida de desempenho é zero, o valor da função é máximo, ou seja, $A$; quando o valor da medida de desempenho tende a infinito, o valor da função é mínimo, ou seja, zero. Para as medidas em que o valor mais alto representa o melhor resultado (precisão, exatidão e taxa de VP), foi considerado no processo de cálculo o complemento da medida $x, 1-x$.

Adotou-se, para as medidas de comparação entre os gráficos, o valor da constante $A$ igual a 60. Para as medidas de distribuição de veículos por faixa e percentual de veículos comerciais, o valor estipulado foi de 20. Tem-se, então, o valor máximo da função fitness composta pelas três medidas de desempenho igual a 100 .

Os valores das constantes $A$ foram escolhidos dessa forma a fim de priorizar a calibração das medidas de comparação dos gráficos. A escolha dos valores das constantes $B$ baseou-se na definição de uma função capaz de amplificar as variações do valor da medida de desempenho ao longo de toda a gama em que podem variar.

Para isso, utilizou-se o valor máximo e o valor mínimo de cada medida de desempenho na função, e através da maximização da diferença entre os valores de fitness para as duas situações, determinou-se o coeficiente $B$ da seguinte forma:

$$
\begin{aligned}
f(B) & =A\left(e^{-B x_{2}}-e^{-B x_{1}}\right) \\
f^{\prime}(B) & =A\left(x_{1} e^{-B x_{1}}-x_{2} e^{-B x_{2}}\right)=0 \\
x_{1} e^{-B x_{1}} & =x_{2} e^{-B x_{2}} \\
\ln \left(x_{1} e^{-B x_{1}}\right) & =\ln \left(x_{2} e^{-B x_{2}}\right) \\
\ln x_{1}+\ln e^{-B x_{1}} & =\ln x_{2}+\ln e^{-B x_{2}} \\
B x_{2}-B x_{1} & =\ln x_{2}-\ln x_{1} \\
B & =\frac{\ln x_{2}-\ln x_{1}}{x_{2}-x_{1}}
\end{aligned}
$$

Em que $x_{1}$ : Máximo valor da medida de desempenho;

$x_{2}$ : $\quad$ Mínimo valor da medida de desempenho;

$A$ e $B$ : Coeficientes da função.

A Tabela 5.4 apresenta os valores adotados para as constantes $A$ e $B$ para cada medida de desempenho, e os valores máximos e mínimos das medidas adotados para a da constante $B$. 
Tabela 5.4 - Coeficientes da Função Fitness

\begin{tabular}{|c|c|c|c|c|}
\hline Medida de desempenho & Mínimo & Máximo & A & B \\
\hline Distribuição do fluxo por faixa & $0,130^{1}$ & $0,250^{1}$ & 20 & 5,50 \\
\hline Percentual de veículos comerciais & $0,380^{1}$ & $0,760^{1}$ & 20 & 1,90 \\
\hline MHD & $0,868^{2}$ & $3,000^{4,2}$ & 60 & 0.60 \\
\hline Precisão & $0,437^{2,3}$ & $0,991^{2,3}$ & 60 & 1,50 \\
\hline Exatidão & $0,017^{2,3}$ & $0,035^{2,3}$ & 60 & 40,00 \\
\hline TaxaVP & $0,513^{2,3}$ & $0,994^{2,3}$ & 60 & 1,35 \\
\hline Raster & $0,504^{2,3}$ & $0,994^{2,3}$ & 60 & 1,35 \\
\hline
\end{tabular}

\subsection{Determinação do mínimo de observações do gráfico de fluxo vs. velocidade}

Esta análise teve como objetivo avaliar uma quantidade mínima de pontos que devem ser simulados para representar a curva fluxo-velocidade típica do local de estudo para poder reduzir o tempo de processamento do AG.

Testaram-se duas propostas: Utilizar 84,5 h (169 intervalos para cada um dos 6 dias de observação) de dados ou 49 h (98 intervalos por dia) de dados de fluxo e velocidade média da corrente em intervalos de 5 minutos. As 84,5 horas de dados correspondem a 1014 intervalos por faixa, ao todo, 4056 intervalos. Para as 49 horas de dados, têm-se 588 intervalos por faixa (2352 no total). As simulações com $84,5 \mathrm{~h}$ implicam em um tempo de processamento de aproximadamente 7 minutos em um microcomputador com 8 GB de memória RAM e CPU Intel Core i7 (Ivy Bridge), e as simulações com $49 \mathrm{~h}$ requerem cerca de 4 minutos para o processamento.

Pode-se observar, através das Figuras 5.6 e 5.7, que o fluxo médio dos 6 dias de coleta e a velocidade média dos veículos não sofrem variações significativas durante o período entre 10:00 e 16:00. Por isso, considerou-se a possibilidade de excluir estes intervalos da análise, pois isso propicia uma redução de $42 \%$ no tempo de simulação.

Além disso, a exclusão dessas observações não altera o gráfico fluxo-velocidade, como pode ser visto comparando a Figura 5.8, que apresenta um gráfico com dados de tráfego de 6 dias de coleta entre 6:00 e 20:00, e a Figura 5.9, que apresenta o gráfico com os dados dos sensores após a exclusão do período de 6 horas.

Para verificar o efeito da exclusão de dados, foi feita uma avaliação através da medida de desempenho MHD, a partir da simulação de 30 indivíduos, mantendo-se os parâmetros e a semente, alterando apenas a quantidade de dados.

Foram obtidas 120 medidas para cada simulação, sendo 4 para cada indivíduo, correspondentes às faixas de tráfego. Em seguida, compararam-se as medidas através do coeficiente 


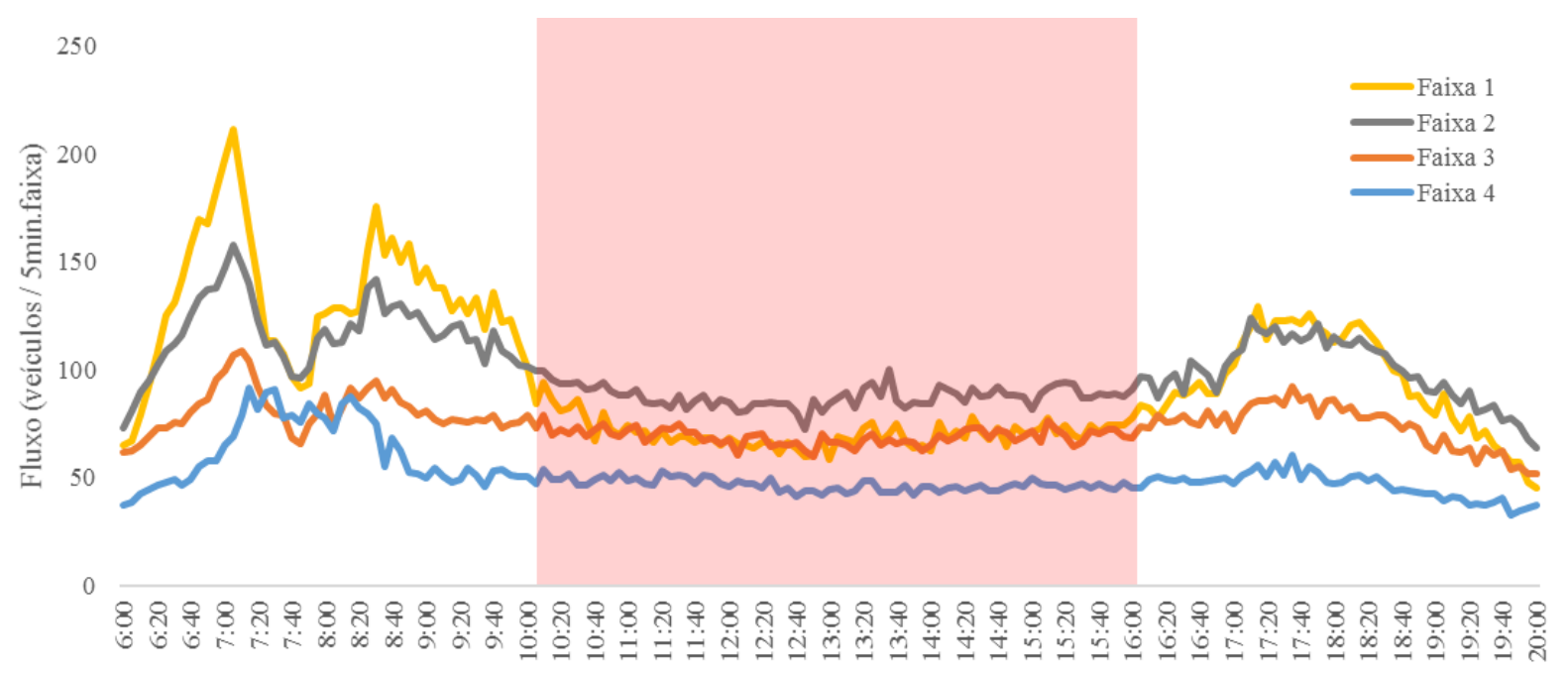

Figura 5.6 - Fluxo médio de veículos por faixa entre 6:00 e 20:00

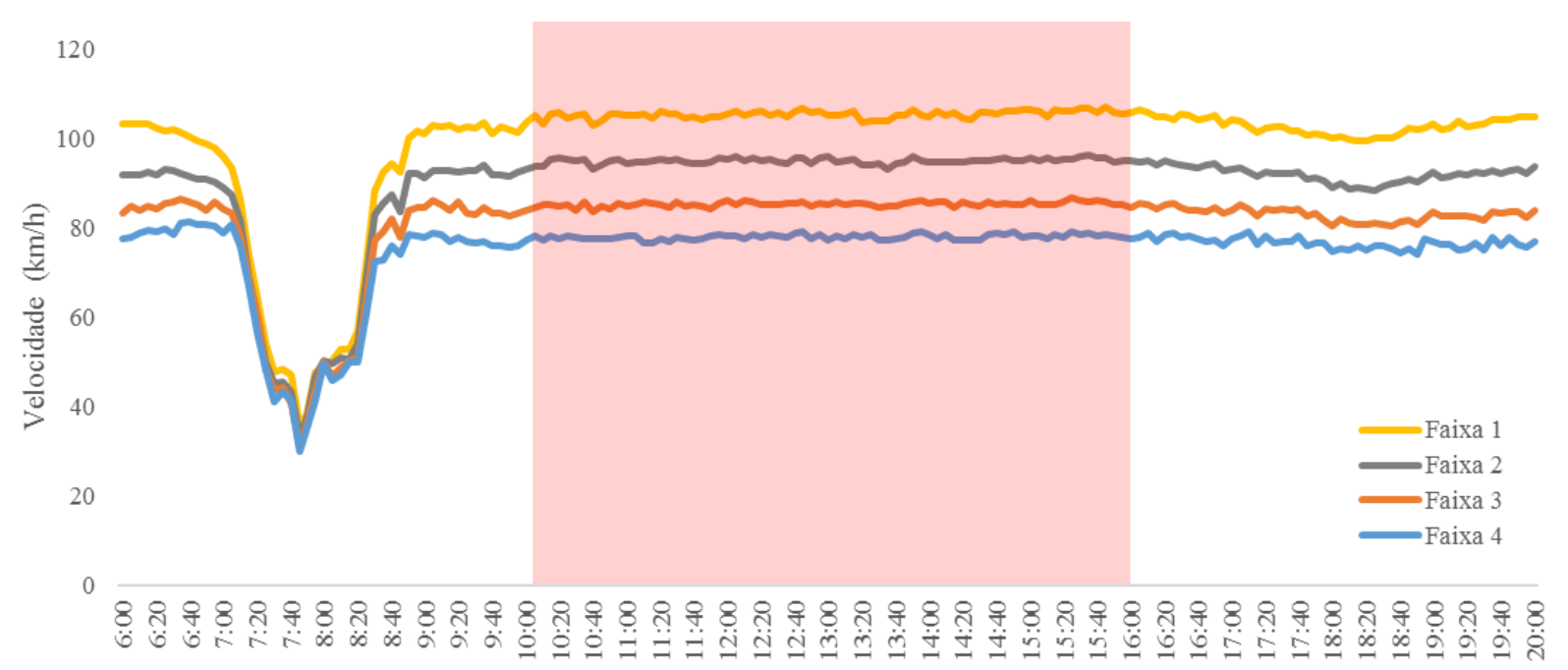

Figura 5.7 - Velocidade média de veículos por faixa entre 6:00 e 20:00

de correlação linear para avaliar se a alteração da quantidade de dados promove alterações significativas na MHD.

A Figura 5.10 apresenta as medidas obtidas através das simulações com $84 \mathrm{~h}$ de dados dos sensores no eixo das abscissas e das simulações com $49 \mathrm{~h}$ de dados no eixo das ordenadas. $\mathrm{O}$ coeficiente de correlação linear calculado para as duas variáveis apresentou um valor de 0,984, o que demonstra uma correlação alta entre dados obtidos nas duas situações analisadas.

O valor do coeficiente de Pearson encontrado $(0,984)$ é suficiente para garantir a correlação entre os dois casos, para qualquer nível de significância. A partir desta análise, decidiu-se usar $49 \mathrm{~h}$ de dados de tráfego nas análises posteriores, devido à redução do tempo de simulação. 


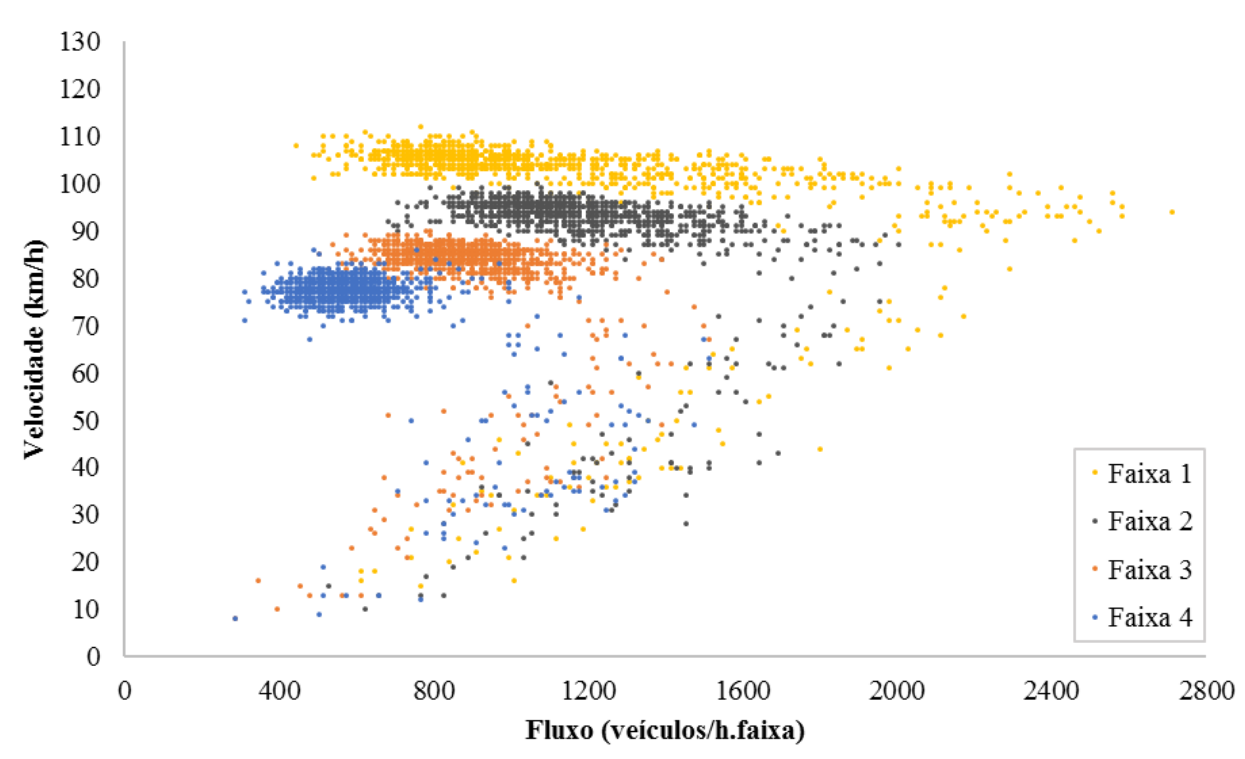

Figura 5.8 - Dados de fluxo e velocidade de 6 dias de coleta (84 horas)

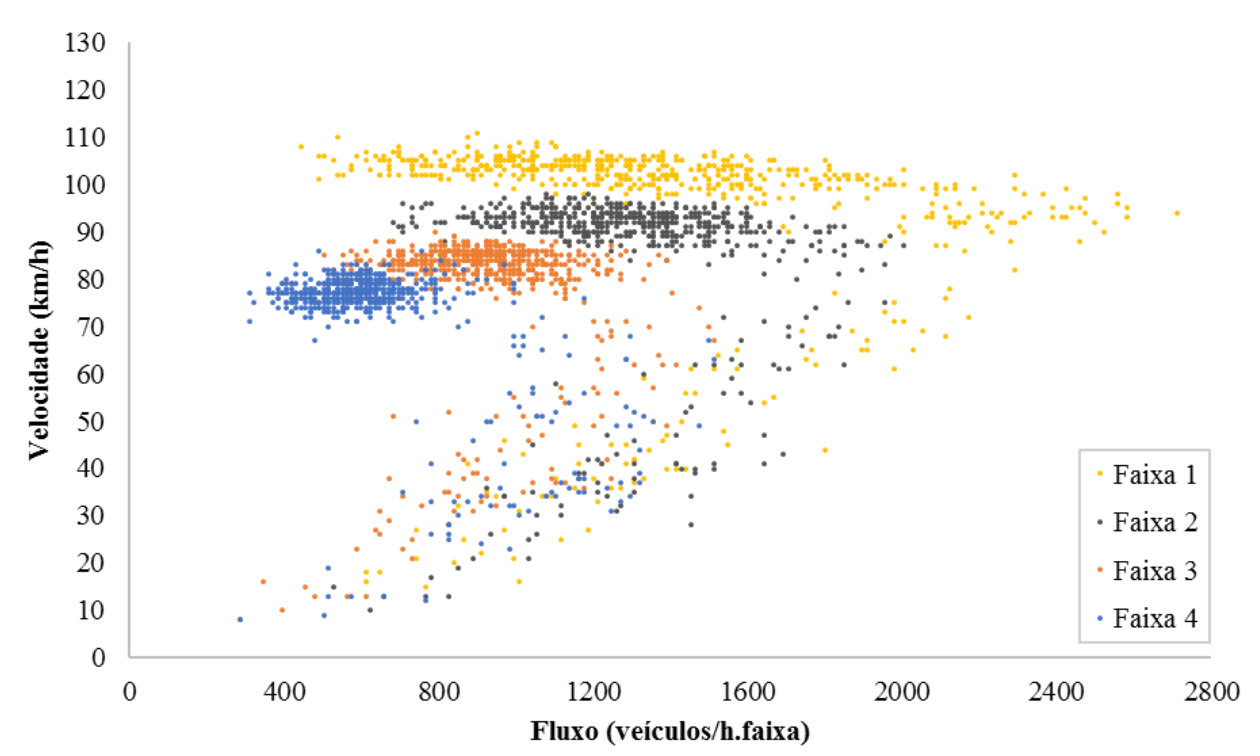

Figura 5.9 - Dados de fluxo e velocidade de 6 dias de coleta (48 horas)

\subsection{Definição da duração do período de warm-up}

O tempo de warm-up é o intervalo inicial desconsiderado com o intuito de eliminar os erros de contagem de veículos quando a rede está vazia. Segundo Brackstone e Punzo (2014), recomenda-se um warm-up que seja o dobro do tempo da viagem mais longa da rede.

O percurso total na rede é de 4,7 km (2,0 km da extensão do trecho inicial + 2,7 km da rede), e a velocidade média dos veículos é de $93 \mathrm{~km} / \mathrm{h}$, conforme os dados utilizados para a calibração. Logo, o tempo médio de percurso é de 180 segundos, então, é recomendado que o warm-up seja maior do que 360 segundos de simulação.

O tempo médio, considerando a velocidade média de $93 \mathrm{~km} / \mathrm{h}$, que o veículo leva para passar 


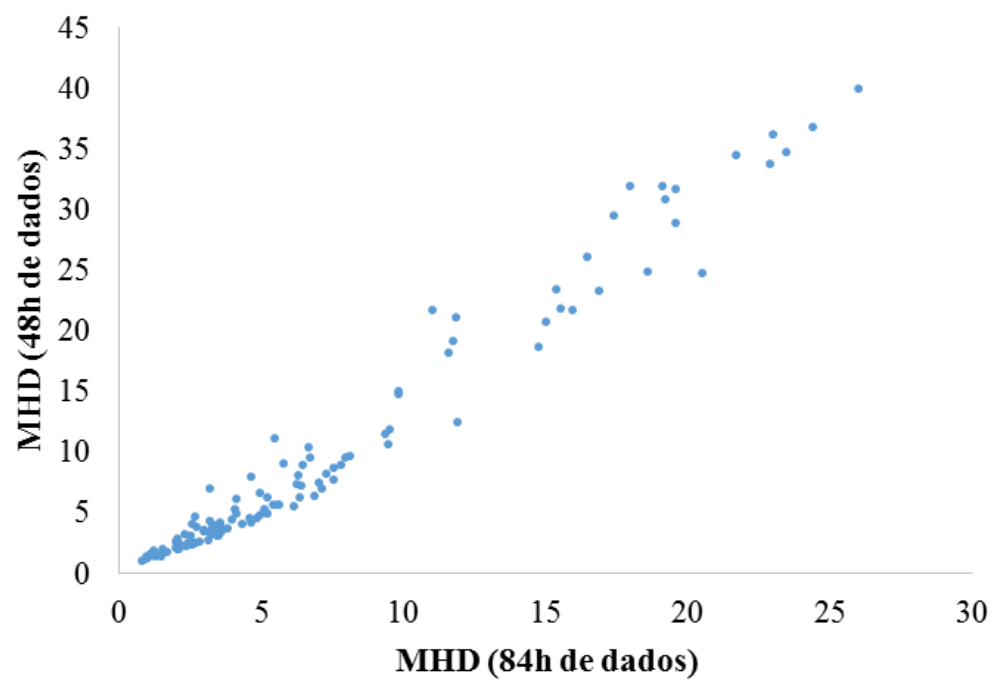

Figura 5.10 - Comparação entre as medidas obtidas nas simulações de $84 \mathrm{~h}$ e $49 \mathrm{~h}$ de dados

pelo sensor de tráfego após entrar na rede é de aproximadamente 140 segundos, logo, definiuse que para a rede em estudo, serão desconsiderados nos primeiros 300 segundos de simulação e os 140 segundos de defasagem, portanto, o warm-up foi definido em 440 segundos.

\subsection{Definição do tamanho da população}

O número de simulações durante o processo de calibração estará condicionado a diversos fatores. A maior limitação deve-se ao tempo disponível para que ocorram todas as fases do algoritmo e que a calibração consiga convergir em um valor de erro aceitável. A partir de certo momento, é necessário um grande esforço para pequenas melhorias. Assim, o analista precisa saber definir o ponto de parada da simulação (DOWLING; SKABARDONIS; ALEXIADIS, 2004).

Kim e Rilett (2001) calibraram o TRANSIMS com uma população de 20 indivíduos e o CORSIM com 30 indivíduos, ambos com um máximo de 40 gerações, e a simulação poderia ser interrompida caso fosse alcançado o erro mínimo estimado para a função.

Definiu-se, para todas as simulações, que seriam simulados 10 indivíduos para cada geração. Recomenda-se para pesquisas futuras variar essa quantidade, a fim de testar a influência da variação desta quantidade na eficiência da calibração. Porém, ressalta-se que uma quantidade maior de indivíduos poderia fazer com que a probabilidade dos mais bem adaptados serem cruzados fosse menor, considerando uma seleção dos indivíduos por probabilidade de cruzamento. Uma quantidade menor poderia diminuir a chance de criar indivíduos com características distintas ao reduzir o número de cruzamentos.

O número de gerações foi estimado inicialmente em 250, e considerando os 10 indivíduos por geração, uma análise com tal configuração dura entre 7 e 8 dias para ser concluída. 


\subsection{Seleção dos parâmetros de calibração}

A escolha dos parâmetros dos modelos comportamentais que serão utilizados na calibração baseou-se nos estudos encontrados na literatura. Em termos gerais, os parâmetros mais comuns são CC0, CC1, CC4 e CC5 (OLIVEIRA; CYBIS, 2008). Como um dos objetivos do trabalho é avaliar uma calibração simultânea de uma quantidade maior de parâmetros, definiu-se que o algoritmo deveria calibrar os parâmetros CC0, CC1, CC2, CC3, CC4, CC5 e Observed Vehicles, relativos ao modelo de car-following. Também foram incluídos no algoritmo genético os parâmetros de Minimum headway (front/rear), Safety distance reduction factor, Maximum deceleration for cooperative braking e To slower lane if collision time above do modelo de lane-change.

O comportamento dos motoristas de automóveis foi calibrado de acordo com o modelo "Free lane selection" e dos veículos comerciais foi calibrado de acordo com o modelo "Right-side rule", conforme descrito na Seção 2.2.2, pois os dados dos sensores sugerem que os motoristas de veículos comerciais apresentam uma tendência maior a circular pelas faixas mais próximas ao acostamento.

O espaço de busca dos parâmetros é apresentado na Tabela 5.5. Os limites máximos e mínimos foram estipulados considerando uma margem aceitável em torno dos valores default do VISSIM.

Tabela 5.5 - Parâmetros utilizados na calibração preliminar do AG

\begin{tabular}{lllrrr}
\hline Sigla & Descrição do parâmetro & Modelo & Default & Min. & Máx \\
\hline OBSVEH & Observed Vehicles & Car following & 2 & 1 & 6 \\
CC0 & Standstill distance & Car following & 1,50 & 0,50 & 3,00 \\
CC1 & Headway time & Car following & 0,90 & 0,20 & 1,50 \\
CC2 & Following variation & Car following & 4,00 & 1,50 & 8,00 \\
CC3 & Threshold for entering following & Car following & $-8,00$ & $-15,00$ & $-2,00$ \\
CC4 & Negative following threshold & Car following & $-0,35$ & $-2,00$ & $-0,10$ \\
CC5 & Positive following threshold & Car following & 0,35 & 0,10 & 2,00 \\
MH & Min. headway - front/rear & Lane change & 0,50 & 0,50 & 2,00 \\
SD & Safety distance reduction factor & Lane change & 0,60 & 0,10 & 0,60 \\
MD & Max. decel. for cooperative braking & Lane change & $-3,00$ & $-9,00$ & $-1,00$ \\
TSL & To slower lane if collision time above & Lane change & 0,00 & 0,00 & 10,00 \\
\hline
\end{tabular}

*Valor estabelecido para o perfil padrão Freeway, definido pelo VISSIM

\subsection{Definição dos parâmetros de velocidade desejada dos veículos}

A velocidade desejada é um importante parâmetro na microssimulação de tráfego. Trata-se da velocidade que o condutor quer impor ao seu veículo, mas que nem sempre é mantida devido à interferência de outros veículos. Essa velocidade, então, só pode ser medida diretamente para os veículos desimpedidos (GEISTEFELDT, 2015). 
Geistefeldt (2015) aplicou uma técnica de estimação das velocidades desejadas em duas seções de uma autoestrada na Alemanha com base em dados de tráfego empíricos. O método oferece distribuições de velocidade desejada consistentes que permitem uma representação realista do comportamento velocidade do motorista dentro de modelos de simulação de tráfego microscópicas. Todavia, a ausência de dados desagregados dos veículos inviabiliza o uso do método nesta pesquisa.

A velocidade desejada no VISSIM é definida através de uma distribuição acumulada. Definemse dois ou mais pontos que representam, cada um, a velocidade e o percentual acumulado referente ao valor daquela velocidade. As distribuições são divididas por tipo de veículo e o simulador possui alguns valores predefinidos para cada média de velocidade, por exemplo: Sendo a média da velocidade desejada dos automóveis $80 \mathrm{~km} / \mathrm{h}$, tem-se que a velocidade de $75 \mathrm{~km} / \mathrm{h}$ representa $0 \%$ da distribuição; $80 \mathrm{~km} / \mathrm{h}$ representa $50 \%$, o que significa que metade dos veículos trafegam em velocidade de até $80 \mathrm{~km} / \mathrm{h} ; 90 \mathrm{~km} / \mathrm{h}$ representa $80 \% ; 100 \mathrm{~km} / \mathrm{h}$ engloba $95 \%$ da distribuição; e $110 \mathrm{~km} / \mathrm{h}$ representa $100 \%$, sendo a velocidade máxima dentro da distribuição de velocidades adotada.

A Figura 5.11 apresenta algumas das curvas predefinidas de velocidade desejada propostas pelo simulador. As velocidades máximas permitidas para automóveis e caminhões no trecho em estudo são de $100 \mathrm{~km} / \mathrm{h}$ e $80 \mathrm{~km} / \mathrm{h}$, respectivamente. O VISSIM define como $50 \mathrm{~km} / \mathrm{h}$ a velocidade média padrão para automóveis e veículos comerciais, se o usuário não realizar nenhuma alteração na escolha da distribuição de velocidade.

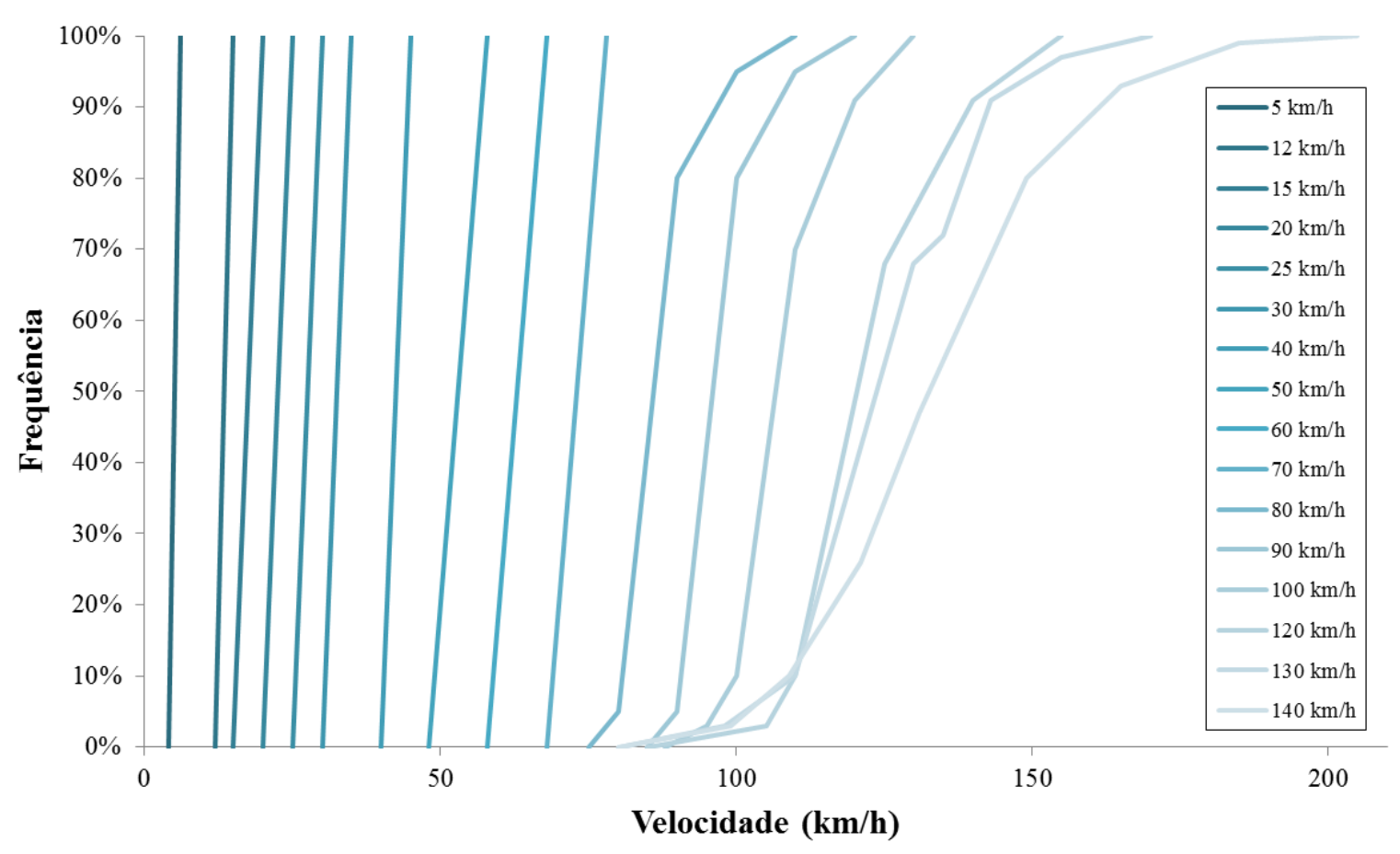

Figura 5.11 - Distribuição de velocidade desejada 
Para calibrar a distribuição de velocidade desejada no simulador, definiu-se que cada faixa de tráfego teria sua própria curva de velocidade para representar a corrente de tráfego. Não houve distinção entre o tipo do veículo, pois observou-se pelos dados coletados que, nos períodos do dia selecionados, a velocidade média de automóveis e veículos comerciais que trafegam na mesma faixa é muito parecida.

O método usado para a calibração baseou-se em selecionar uma das curvas propostas (velocidade média de $120 \mathrm{~km} / \mathrm{h}$ ) pelo simulador como base, e aplicar um fator multiplicador a essa curva para representar a distribuição de velocidade em cada faixa de tráfego do trecho estudado. Dessa forma, o AG define, dentro de um espaço de busca pré-estabelecido, os escalares que melhor representam as distribuições de velocidade desejada nas quatro faixas de tráfego.

A Tabela 5.6 apresenta os pontos que definem a curva do simulador adotado como base e também os novos valores dos pontos com a aplicação dos escalares. O espaço de busca dos parâmetros que definem a velocidade desejada para cada uma das faixas é apresentado na Tabela 5.7.

Tabela 5.6 - Velocidade desejada após aplicação do escalar

\begin{tabular}{lrrrrrr}
\hline \multicolumn{1}{c}{ Escalar } & \multicolumn{7}{c}{ Velocidade } \\
\hline 0.60 & 51.00 & 63.00 & 66.00 & 75.00 & 84.00 & 93.00 \\
0.70 & 59.50 & 73.50 & 77.00 & 87.50 & 98.00 & 108.50 \\
0.80 & 68.00 & 84.00 & 88.00 & 100.00 & 112.00 & 124.00 \\
0.90 & 76.50 & 94.50 & 99.00 & 112.50 & 126.00 & 139.50 \\
0.95 & 80.75 & 99.75 & 104.50 & 118.75 & 133.00 & 147.25 \\
$1.00^{*}$ & 85.00 & 105.00 & 110.00 & 125.00 & 140.00 & 155.00 \\
1.10 & 93.50 & 115.50 & 121.00 & 137.50 & 154.00 & 170.50 \\
\hline Frequência & 0.000 & 0.030 & 0.100 & 0.680 & 0.910 & 1.000 \\
\hline *Representa a curva do simulador adotada como base
\end{tabular}

* Representa a curva do simulador adotada como base

Tabela 5.7 - Espaço de busca dos parâmetros de velocidade desejada

\begin{tabular}{llrr}
\hline Faixa & Parâmetro & Mínimo & Máximo \\
\hline 1 & DESIRED_1 & 0.90 & 1.20 \\
2 & DESIRED_2 & 0.80 & 1.10 \\
3 & DESIRED_3 & 0.70 & 1.00 \\
4 & DESIRED_4 & 0.60 & 0.90 \\
\hline
\end{tabular}

\subsection{Definição dos parâmetros de congestionamento}

Além dos parâmetros comportamentais e de velocidade desejada, também foram incluídos na calibração parâmetros para simular o congestionamento e obter dados do simulador nos regimes de fluxo congestionado e de descarga.

A partir da escolha da velocidade que separa o fluxo do congestionado, conforme explicado na Seção 3.5, foram considerados períodos de congestionamento todos os intervalos em que 
as velocidades médias nas faixas fossem menores ou iguais a $83 \mathrm{~km} / \mathrm{h}$. Dessa forma, para os dados selecionados para calibração do simulador, ocorreram 82 intervalos de 5 minutos de congestionamento, e 83 intervalos nos dados de validação.

A reprodução do congestionamento foi feita através da inserção de redutores, conforme descrito na Seção 4.4. Para cada intervalo, foi definida uma distribuição de velocidade "congestionada" em um trecho de $150 \mathrm{~m}$ de extensão, localizado aproximadamente $300 \mathrm{~m}$ à jusante dos sensores de tráfego. Após o redutor de velocidade, o comportamento dos veículos volta a ser regido pelos parâmetros de velocidade desejada.

Foram definidas 14 distribuições de velocidade reduzida, conforme mostra a Tabela 5.8, e estas distribuições compõem o espaço de busca dos parâmetros de congestionamento. Cada 5 minutos de observação de fluxo congestionado corresponde a um parâmetro. O AG define um valor inteiro do espaço de busca (entre 1 e 14) para cada parâmetro de congestionamento. Assim, para as 82 observações de fluxo congestionado na calibração, foram definidos 82 parâmetros, e cada um destes parâmetros contemplou uma das 14 distribuições de velocidade.

Tabela 5.8 - Velocidade desejada nos períodos de congestionamento

\begin{tabular}{lrrrrrrrrr}
\hline Redução & & \multicolumn{8}{c}{ Velocidade $\mathbf{( k m / h )}$} \\
\hline 1 & 3.45 & 4.00 & 4.45 & 4.73 & 5.00 & 5.27 & 5.63 & 6.27 & 7.45 \\
2 & 6.91 & 8.00 & 8.91 & 9.45 & 10.00 & 10.54 & 11.27 & 12.54 & 14.90 \\
3 & 10.36 & 12.00 & 13.36 & 14.18 & 14.99 & 15.81 & 16.90 & 18.81 & 22.36 \\
4 & 13.81 & 15.99 & 17.81 & 18.90 & 19.99 & 21.08 & 22.54 & 25.08 & 29.81 \\
5 & 17.27 & 19.99 & 22.26 & 23.63 & 24.99 & 26.35 & 28.17 & 31.35 & 37.26 \\
6 & 20.72 & 23.99 & 26.72 & 28.35 & 29.99 & 31.62 & 33.81 & 37.62 & 44.71 \\
7 & 24.17 & 27.99 & 31.17 & 33.08 & 34.99 & 36.90 & 39.44 & 43.89 & 52.16 \\
8 & 27.63 & 31.99 & 35.62 & 37.80 & 39.98 & 42.17 & 45.07 & 50.16 & 59.61 \\
9 & 31.08 & 35.99 & 40.08 & 42.53 & 44.98 & 47.44 & 50.71 & 56.43 & 67.07 \\
10 & 34.53 & 39.98 & 44.53 & 47.25 & 49.98 & 52.71 & 56.34 & 62.70 & 74.52 \\
11 & 37.99 & 43.98 & 48.98 & 51.98 & 54.98 & 57.98 & 61.98 & 68.97 & 81.97 \\
12 & 41.44 & 47.98 & 53.43 & 56.71 & 59.98 & 63.25 & 67.61 & 75.24 & 89.42 \\
13 & 44.89 & 51.98 & 57.89 & 61.43 & 64.98 & 68.52 & 73.24 & 81.51 & 96.87 \\
14 & 48.35 & 55.98 & 62.34 & 66.16 & 69.97 & 73.79 & 78.88 & 87.78 & 104.32 \\
\hline Frequência & 0.000 & 0.064 & 0.105 & 0.355 & 0.704 & 0.882 & 0.967 & 0.990 & 1.000 \\
\hline
\end{tabular}

\subsection{Considerações finais}

Este capítulo apresentou as etapas de preparação do AG para a calibração do simulador VISSIM a partir de dados obtidos através de sensores de tráfego. As etapas seguintes apresentam a análise e escolha da medida de desempenho de comparação entre gráficos de fluxo e velocidade, os resultados da calibração, a validação da calibração e discussão acerca dos parâmetros e seus resultados. 


\section{Capítulo}

\section{Análise dos Resultados}

Este capítulo apresenta a discussão dos resultados obtidos através dos métodos de calibração propostos e define a simulação default para comparar com os dados dos sensores e com a resposta da simulação. Também são analisados o desempenho do algoritmo e a validação da calibração.

\subsection{Definição da simulação default}

Os resultados da calibração do simulador através do AG foram avaliados a partir da comparação com os dados dos sensores de tráfego, e com uma simulação cujos parâmetros relativos aos modelos de desempenho veicular não foram modificados (valores default do VISSIM).

Considerou-se que, na simulação default, as distribuições de velocidade desejada seriam definidas como a velocidade máxima permitida para o trecho, segundo as distribuições sugeridas pelo VISSIM. A definição das distribuições partiu do princípio de que esta é uma prática comum de usuários de softwares de tráfego: definir uma das curvas pré-definidas pelo simulador sem avaliar se a distribuição representa a distribuição de velocidades observadas no trecho. Dessa forma, a velocidade dos veículos leves foi regida pela distribuição de velocidade de média $100 \mathrm{~km} / \mathrm{h}$ e dos veículos comerciais pela distribuição de velocidade de média $80 \mathrm{~km} / \mathrm{h}$.

A Figura 6.1 apresenta o resultado desta simulação, que foi considerada como a base para comparação com os resultados da calibração.

\subsection{Análise do desempenho do AG}

Alguns fatores foram relevantes para avaliar se o AG atendeu à proposta de calibração do simulador, e se a estrutura do algoritmo (operadores genéticos, número de gerações, função fitness) foi adequada. 

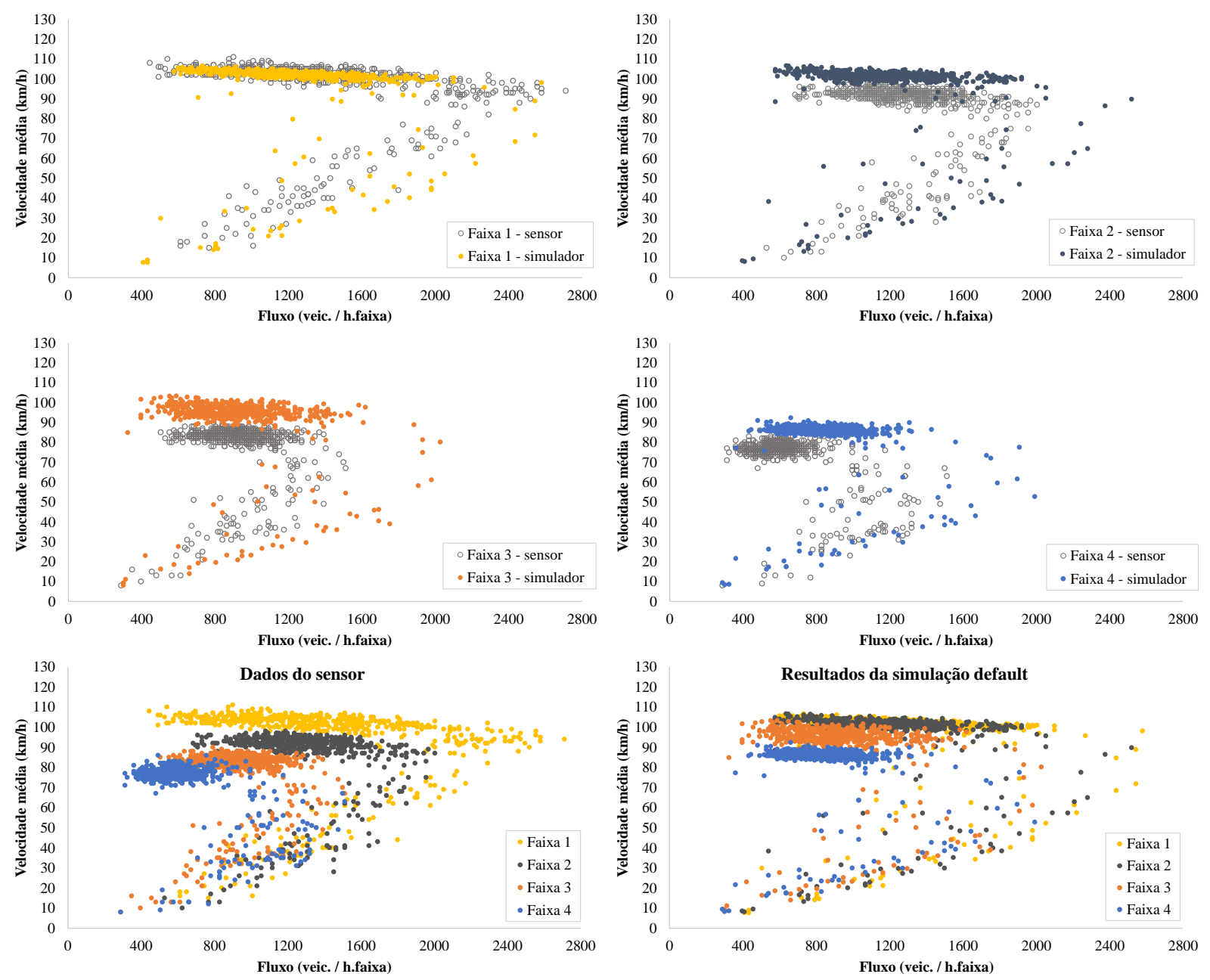

Figura 6.1 - Simulação com parâmetros default e velocidade desejada de $100 \mathrm{~km} / \mathrm{h}$ e $80 \mathrm{~km} / \mathrm{h}$ para automóveis e veículos comerciais, respectivamente

Observa-se, pela Figura 6.2, que todas as funções fitness apresentam um aspecto semelhante a uma curva logarítmica, sendo a função fitness 1 a que apresenta maior variação entre o valor inicial e final. Essa função, que se baseia na medida de distância de Hausdorff (MHD), reflete melhor a dissemelhança entre os conjuntos e tem melhor sensibilidade no grau de adaptação do melhor indivíduo em cada geração.

Outro aspecto relevante é que todas as funções fitness testadas se estabilizam em algum ponto no intervalo entre 100 e 150 gerações. A partir deste ponto, a melhoria no grau de adaptação é praticamente nenhuma. Assim, dada a necessidade de minimizar o tempo de processamento da calibração, sugere-se que uma simulação com 10 indivíduos e 150 gerações tem uma probabilidade razoável de convergir em uma solução satisfatória, pois o ganho marginal a partir dessa quantidade de gerações não é relevante. O processamento de um AG com 10 indivíduos e 250 gerações dura aproximadamente 7 dias, de acordo com os recursos computacionais disponíveis para a pesquisa, enquanto um AG com uma população de 10 indivíduos e 150 gerações requer 4 dias para processamento. Por isso, decidiu-se que o AG usado na 


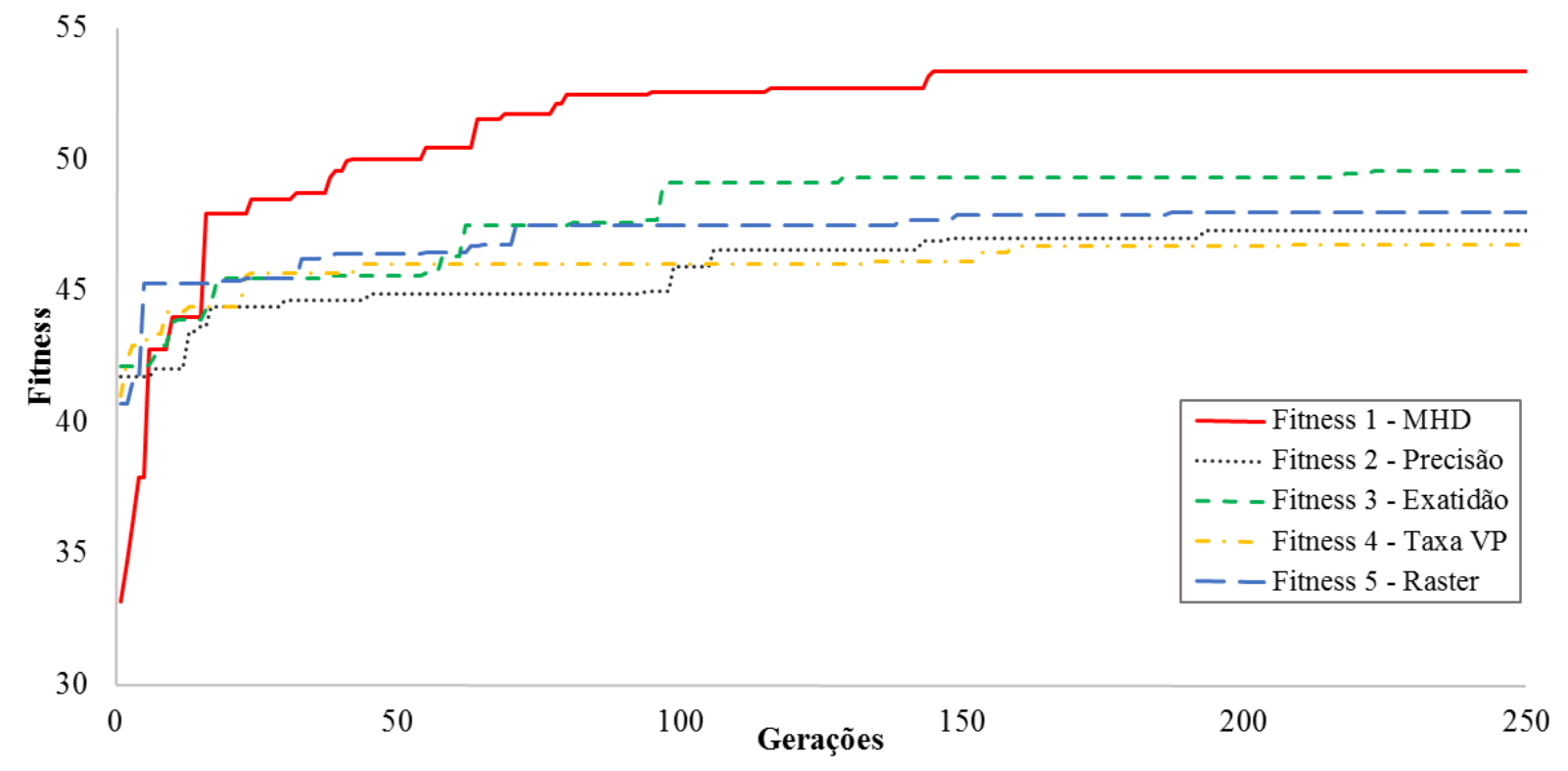

Figura 6.2 - Variação do valor da função fitness do indivíduo mais bem adaptado em função do número de gerações do AG, para uma população de 10 indivíduos

validação teria 150 gerações com 10 indivíduos cada.

Para avaliar se, utilizando a mesma função de calibração, o valor dos parâmetros convergiria para o mesmo resultado, processou-se o AG por mais de uma vez. Este procedimento foi realizado utilizando a função fitness que contemplava a MHD (função fitness 1) como medida de desempenho, para calibrar a rede duas vezes.

A Tabela 6.1 apresenta o resultado dessas duas calibrações, bem como os limites superiores e inferiores do espaço de busca dos parâmetros. Nota-se que diversos parâmetros das duas soluções apresentam valores próximos, e esse fato pode indicar que há uma convergência para um valor ideal para esses parâmetros. Ainda que alguns parâmetros apresentem discrepância, isso não significa necessariamente um erro de calibração: O parâmetro pode não ser tão sensível a mudanças quanto os demais, ou a discrepância é um sinal de uma combinação de parâmetros de melhor resultado, uma vez que os valores das funções fitness são distintos. Além disso, observa-se que os parâmetros apresentam valores distantes dos limites superiores e inferiores, o que indica que o espaço de busca adotado é apropriado.

Tabela 6.1 - Valores dos parâmetros comportamentais após calibrações através da função fitness 1

\begin{tabular}{lrrrrrrrrrrrr}
\hline \multicolumn{1}{c}{ Função } & OBSVEH & CC0 & CC1 & CC2 & CC3 & CC4 & CC5 & MH & SD & MD & TSL & Fitness \\
\hline Limite inferior & 1 & 0.50 & 0.20 & 1.50 & -15.00 & -2.00 & 0.10 & 0.50 & 0.10 & -9.00 & 0.00 & \\
Solução 1 & 4 & 2.56 & 0.75 & 7.13 & -12.92 & -0.54 & 0.69 & 1.75 & 0.39 & -1.28 & 3.11 & 53.34 \\
Solução 2 & 5 & 2.07 & 0.71 & 7.86 & -12.18 & -0.22 & 1.83 & 1.48 & 0.59 & -2.15 & 1.93 & 54.39 \\
Limite superior & 6 & 3.00 & 1.50 & 8.00 & -2.00 & -0.10 & 2.00 & 2.00 & 0.60 & -1.00 & 10.00 & \\
\hline
\end{tabular}




\subsection{Análise dos resultados}

A Tabela 6.2 apresenta uma comparação entre as cinco medidas de desempenho usadas para comparação dos gráficos fluxo-velocidade no AG. A primeira coluna da tabela mostra as cinco medidas de desempenho escolhidas para a comparação: MHD (Eq. 5.5); precisão (Eq. 5.7); exatidão (Eq. 2.12); taxa VP (Eq. 5.9); e raster (Eq. 5.6). As colunas 2 a 6 mostram os valores de fitness para a melhor solução encontrada pelo AG para cada caso. As colunas 7 e 8 mostram o valor de fitness para as outras duas medidas de desempenho usadas: MAEfluxo, que verifica a distribuição do fluxo pelas faixas de tráfego (Eq. 5.4); e MAE\%com, que foca na porcentagem de veículos pesados em cada faixa de tráfego (Eq. 5.3). A última coluna mostra o valor da função fitness usada pelo AG em cada caso (Eq. ??). A última linha da Tabela 6.2 mostra os valores calculados para essas medidas de desempenho a partir dos resultados da simulação com os valores default dos parâmetros de calibração.

Tabela 6.2 - Valor do fitness das medidas de desempenho segundo a função utilizada na calibração

\begin{tabular}{lcccccccc}
\hline \multirow{2}{*}{ Função de Calibração } & \multicolumn{9}{c}{ Fitness segundo a medida de desempenho } & \multicolumn{2}{c}{ Total } \\
& MHD & Precisão & Exatidão & TaxaVP & Raster & MAEfluxo & MAE\%com & \\
\hline Fitness 1 (MHD) & 36.674 & & & & & 9.146 & 7.520 & 53.340 \\
Fitness 2 (Precisão) & & 30.291 & & & & 9.117 & 8.255 & 47.664 \\
Fitness 3 (Exatidão) & & & 32.384 & & & 8.717 & 8.437 & 49.538 \\
Fitness 4 (Taxa VP) & & & & 28.586 & & 8.988 & 9.160 & 46.733 \\
Fitness 5 (Raster) & & & & & 29.907 & 8.844 & 9.191 & 47.943 \\
\hline Default & 16.418 & 18.949 & 22.257 & 19.276 & 18.712 & 8.511 & 9.164 & - \\
\hline
\end{tabular}

A evolução dos melhores indivíduos de cada função fitness é apresentada nas tabelas contidas no Apêndice A. Nas seções a seguir, discute-se qual dessas cinco alternativas para a função fitness do AG é a mais adequada, com base no estudo de caso conduzido nesta pesquisa.

\subsubsection{Análise das medidas de comparação entre conjuntos}

O uso de medidas de comparação entre os conjuntos teve como objetivo tornar a representação gráfica dos dados simulados o mais semelhante possível à dos dados observados. A avaliação da eficiência das medidas foi feita a partir da análise visual do gráfico fluxo-velocidade das melhores soluções encontradas pelo AG.

\section{Distância de Hausdorff modificada (MHD)}

A Figura 6.3 apresenta o resultado da melhor solução encontrada pelo AG segundo a função fitness 1 (MHD), em comparação aos dados do sensor.

Observa-se que, em todas as faixas de tráfego, a velocidade média das observações corresponde aos dados obtidos em campo, bem como a tendência à diminuição da velocidade com o aumento do fluxo. Em relação aos dados dos sensores, os fluxos máximos simulados na faixa 1 foram inferiores aos fluxos observados, embora seja possível observar alguns registros com 

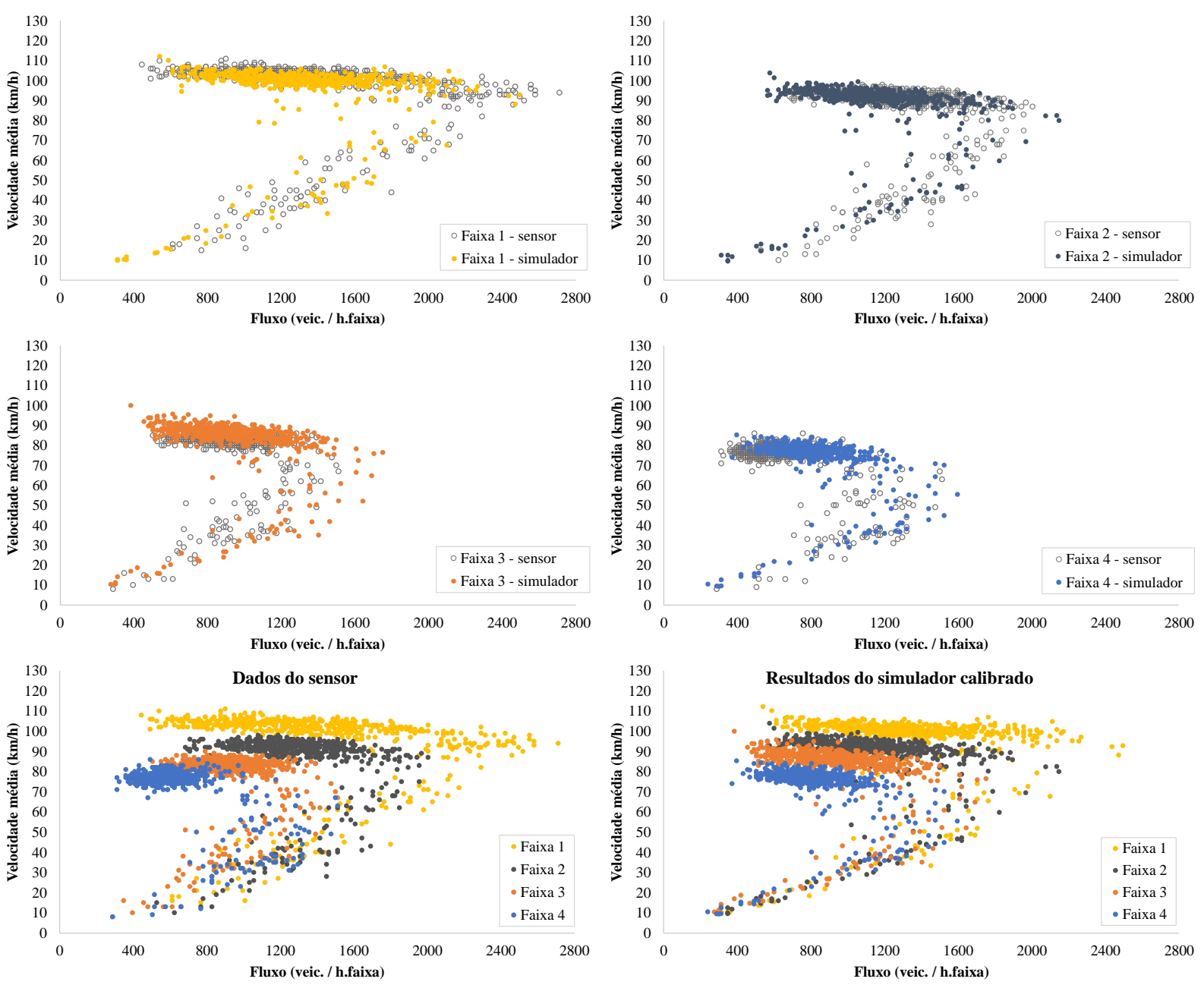

Figura 6.3 - Comparação entre os dados do sensor e o resultado da calibração através da função Fitness 1 (MHD)

fluxo superior a 2.400 veículos/hora.faixa; por outro lado, na faixa 3, os fluxos máximos simulados foram superiores aos fluxos máximos observados. Nas duas outras faixas, houve uma maior compatibilidade entre os fluxos simulados e observados.

Esses registros de fluxo acima de 2.400 veículos/hora.faixa possivelmente foram relevantes no cálculo do valor da função fitness, devido à influência que um ponto exerce sobre os pontos vizinhos, o que não ocorre nas demais medidas avaliadas. Essa influência sobre pontos ao redor pode ter efeito contrário, caso o ponto destoe dos demais e não esteja próximo de nenhuma observação do outro conjunto.

Considerando estes aspectos, pode-se considerar que a calibração atingiu o objetivo quanto à geração de pontos nas regiões de fluxo congestionado e de descarga por não apresentar pontos que fugissem à tendência da curva. Portanto, pode-se considerar que a MHD é uma medida de desempenho adequada para a calibração do simulador através do AG proposto. 


\section{Taxa de precisão da matriz de contingência}

A Figura 6.4 mostra o resultado do melhor solução encontrada pelo AG segundo a função fitness 2 (Precisão). A calibração mostrou-se adequada quanto à calibração da velocidade de-
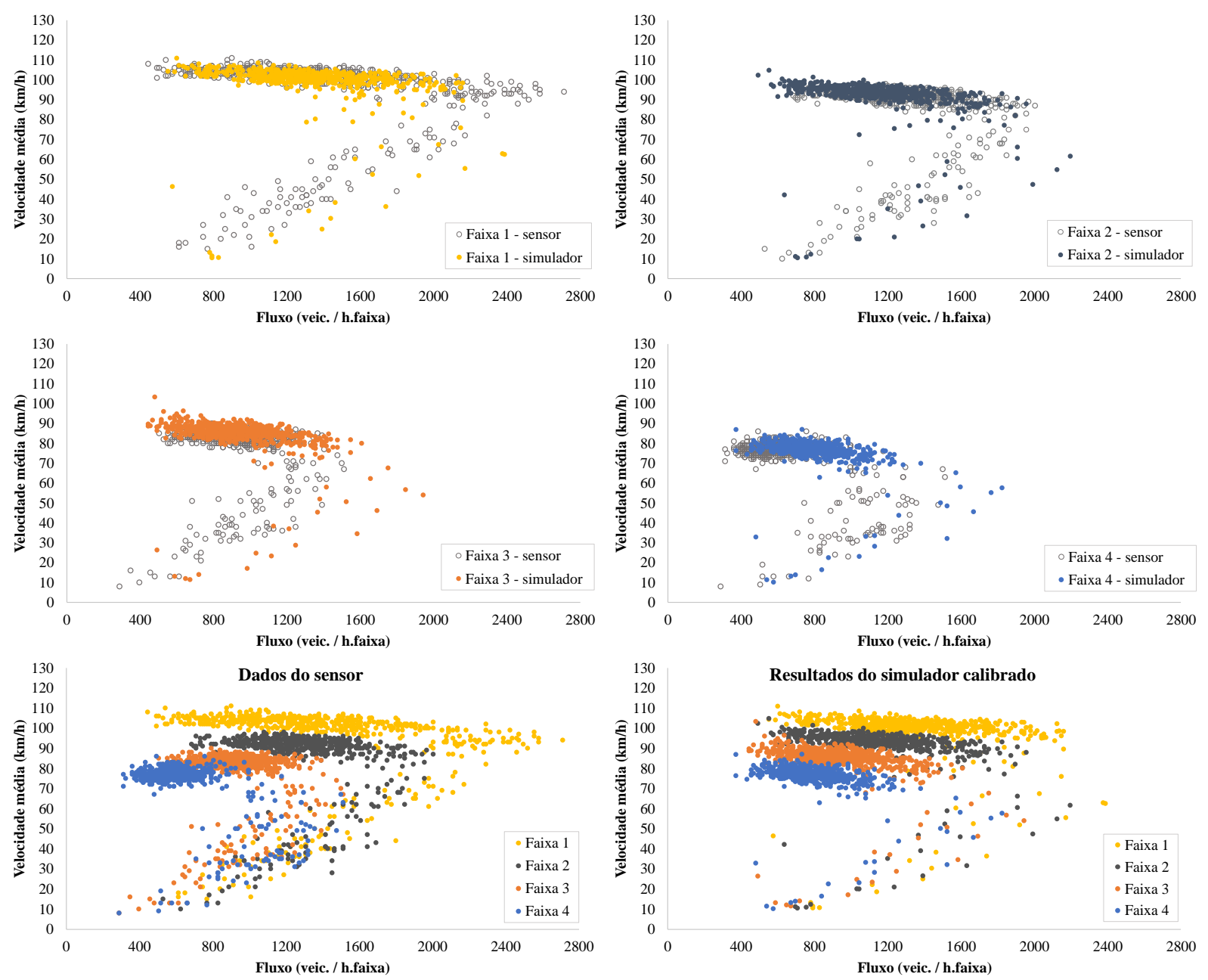

Figura 6.4 - Comparação entre os dados do sensor e o resultado da calibração através da função Fitness 2 (Precisão)

sejada ao observar a tendência da curva na região de fluxo livre, porém, nota-se que na faixa 1 , as taxas de fluxo máximas simuladas são significantemente inferiores aos dados obtidos pelo sensor. Também ressalta-se a presença de poucos registros de fluxo congestionado e de registros em áreas em que não há dados do sensor, devido ao fato de que a ocorrência destas observações têm pouca relevância no cálculo do fitness através dessa medida de desempenho.

Dada a dissemelhança entre o gráfico gerado pelo simulador e os dados obtidos em campo, esta medida foi considerada inadequada para uso no AG proposto. 


\section{Taxa de exatidão da matriz de contingência}

A melhor solução encontrada pelo AG usando esta medida de desempenho conseguiu produzir uma distribuição de velocidade média semelhante à dos dados obtidos em campo no regime de fluxo livre, como pode-se ver nos gráficos da Figura 6.5. Porém, a função fitness baseada na taxa de exatidão não foi eficaz quanto à reprodução dos regimes de descarga e congestionado, devido grande discrepância entre os fluxos simulados e observados na região de fluxo congestionado e de descarga da fila. Também observa-se, através da Figura 6.5 que na faixa 1 não foram obtidos registros suficientes próximos à capacidade da faixa de tráfego. Portanto, descartou-se o uso dessa medida na função fitness para o AG proposto.
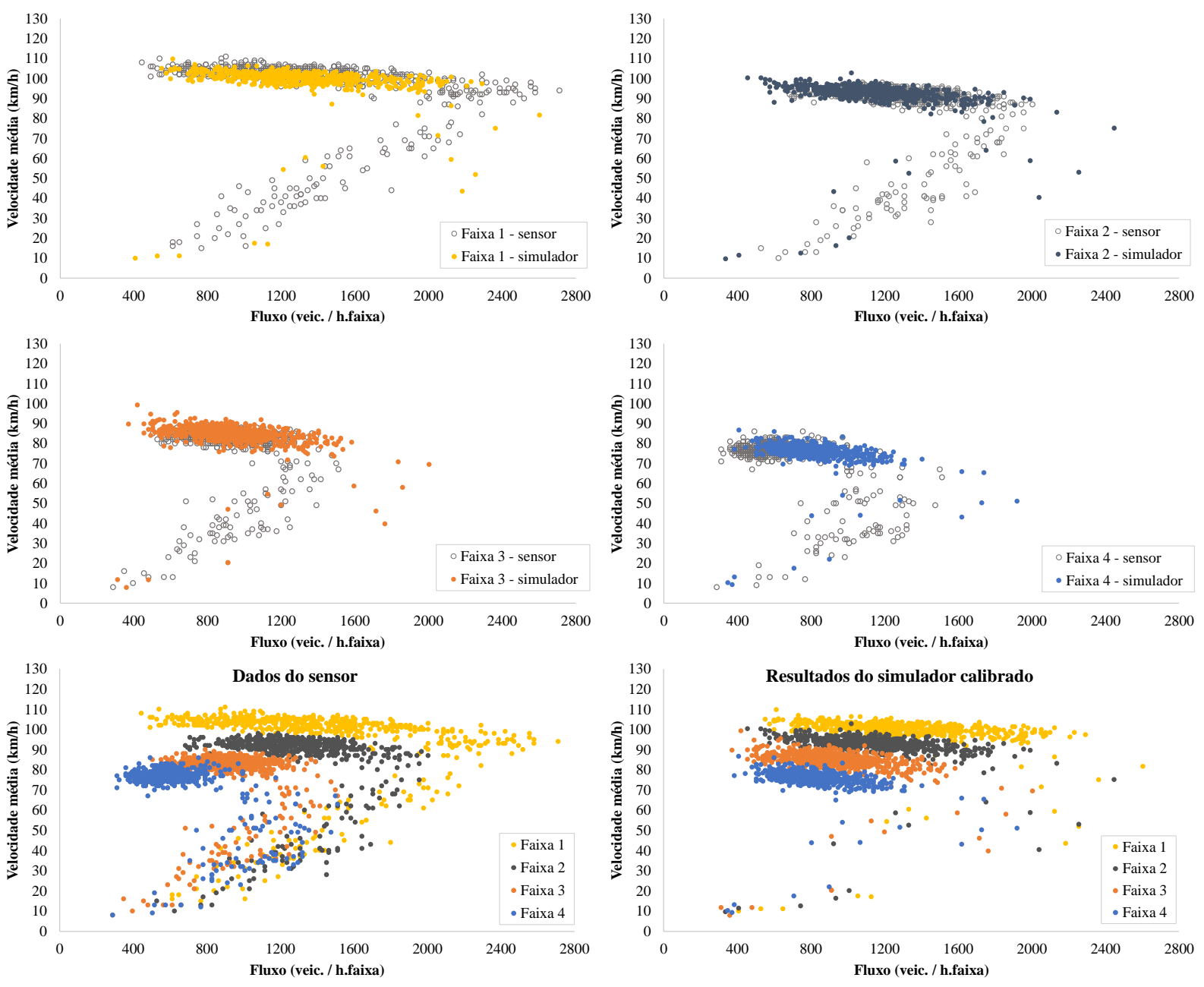

Figura 6.5 - Comparação entre os dados do sensor e o resultado da calibração através da função Fitness 3 (Exatidão)

\section{Taxa de verdadeiros positivos da matriz de contingência}

O resultado da melhor solução encontrada pelo AG através de uma função fitness baseada na medida de taxa de verdadeiros positivos destoa dos dados de campo tanto quanto à velocidade como quanto ao fluxo de veículos, conforme Figura 6.6. Nota-se uma significativa disseme- 
lhança entre os gráficos, o que mostra que uma função fitness baseada na taxa de VP não é capaz de produzir uma solução adequada usando-se o AG proposto..

A capacidade observada na faixa 1 é significantemente menor do que o que ocorre em campo, dessa forma, a taxa de verdadeiros positivos é inapropriada para a comparação dos conjuntos de dados de tráfego avaliados.
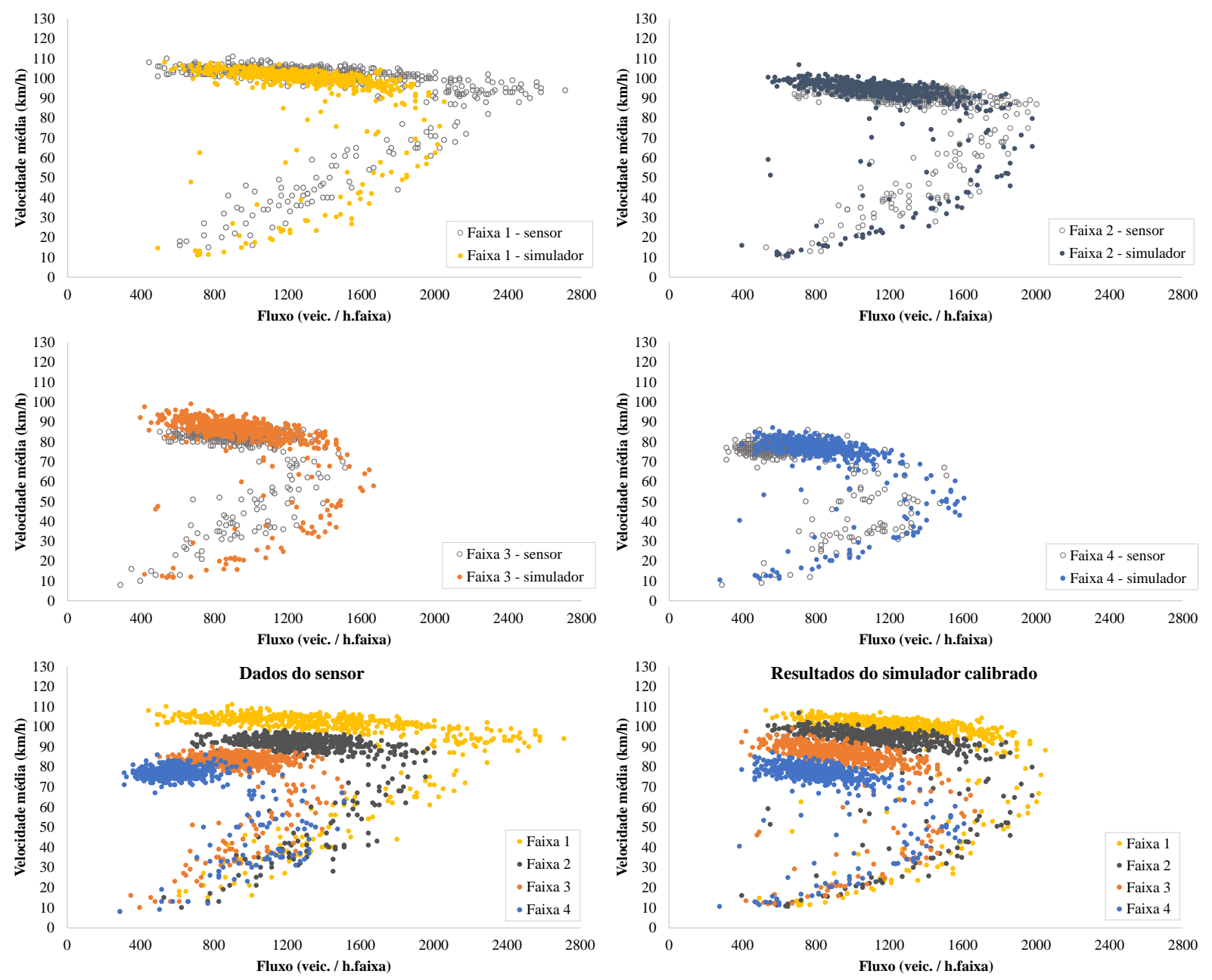

Figura 6.6 - Comparação entre os dados do sensor e o resultado da calibração através da função Fitness 4 (Taxa VP)

\section{Quantidade de acertos por pixel (Raster)}

A Figura 6.7 apresenta a melhor solução encontrada pelo AG proposto usando uma função fitness que considera a quantidade de registros corretos para cada elemento de imagem. Nas duas faixas mais próximas ao canteiro central os fluxos máximos simulados são significativamente inferiores aos observados, e os pontos que representam o fluxo congestionado não refletem a condição observada no local.

Trata-se de outra medida de desempenho para a qual os outliers têm pouca significância no cálculo do valor da função fitness, o que explica a existência de muitos pontos fora das regiões 
em que eram esperadas observações de tráfego. Portanto, o seu uso no AG proposto para calibrar o modelo deve ser descartado.
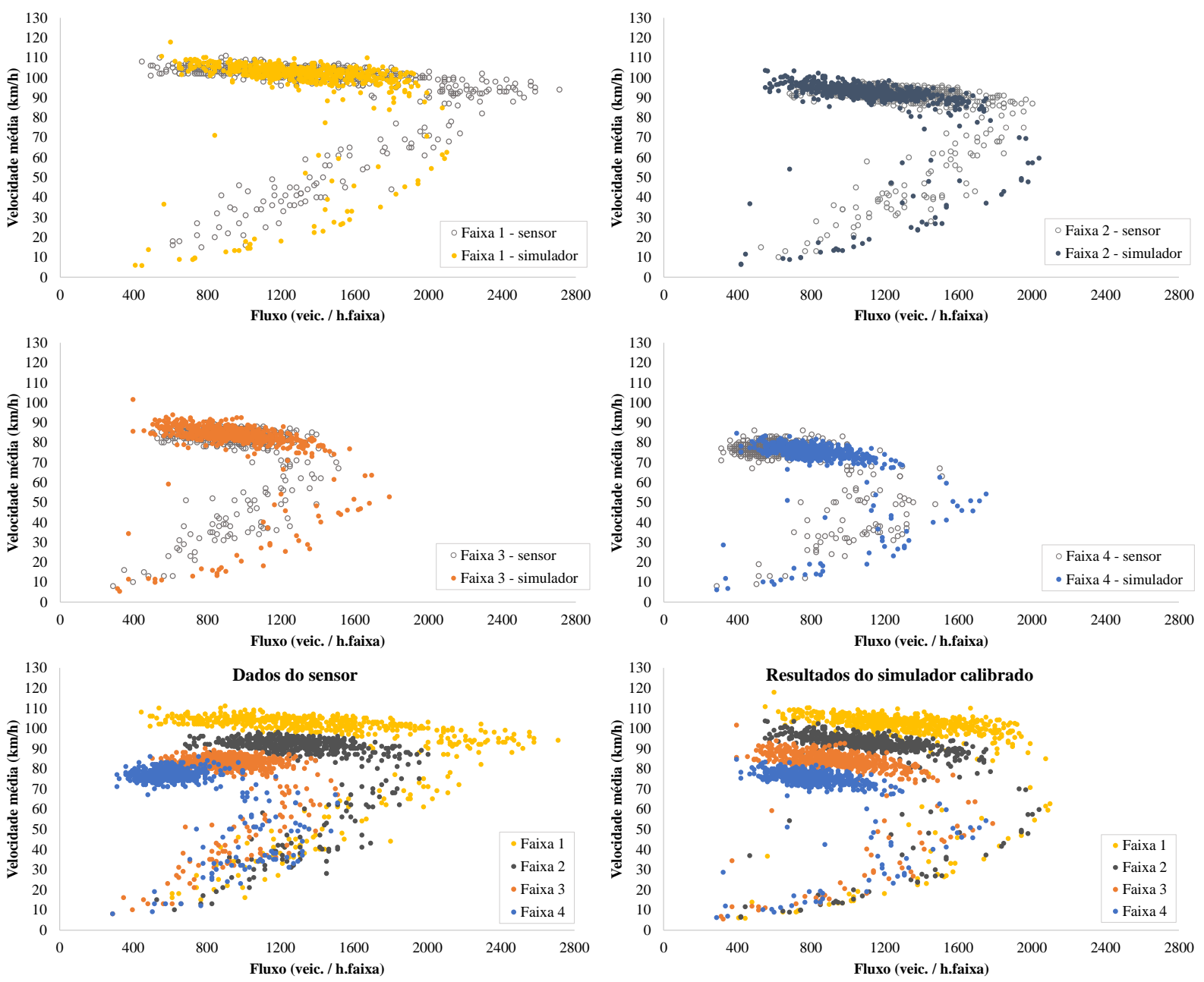

Figura 6.7 - Comparação entre os dados do sensor e o resultado da calibração através da função Fitness 5 (Raster)

\section{Considerações sobre as medidas de comparação avaliadas}

A análise das medidas de desempenho para comparação entre conjuntos mostrou uma maior eficiência da distância de Hausdorff modificada (MHD) em relação aos outros métodos testados por ter representado de maneira mais fiel todos os regimes de fluxo. Também foi possível analisar que a eficiência dos parâmetros de congestionamento está condicionada ao uso da medida de desempenho adequada para a calibração.

Os valores dos parâmetros comportamentais e de velocidade desejada encontrados através de uma função fitness baseada na MHD foram adotados para a etapa de validação do simulador, que utilizou o AG apenas para calibrar os parâmetros de congestionamento. 


\subsubsection{Percentual de veículos comerciais e distribuição de veículos pelas faixas de tráfego}

As medidas de desempenho relativas ao percentual de veículos comerciais e à distribuição de veículos por faixa de tráfego não apresentaram melhoria considerável em relação à simulação com os parâmetros default, como pode ser observado na Tabela 6.2.

Embora tenha-se reduzido o erro do percentual do fluxo de veículos por faixa em todas as funções fitness testadas, a função que melhor ajustou a medida de desempenho obteve uma melhoria de aproximadamente $1 \%$ em relação à simulação não-calibrada. Nota-se, pela Figura 6.8, que a faixa 4, a mais próxima ao acostamento, apresentou um erro maior em relação à distribuição de veículos do que as demais faixas. Isso sugere que o VISSIM tem uma deficiência inerente na reprodução do comportamento dos veículos pesados em rodovias brasileiras e tem uma certa dificuldade em representar a "preferência" dos veículos comerciais brasileiros pelas faixas mais à direita. Nenhum dos parâmetros escolhidos para calibração parece ser capaz de intensificar este comportamento. Por outro lado, deve-se ressaltar que as diferenças encontradas são relativamente pequenas (menores que 5\%), o que não impede o uso do simulador.

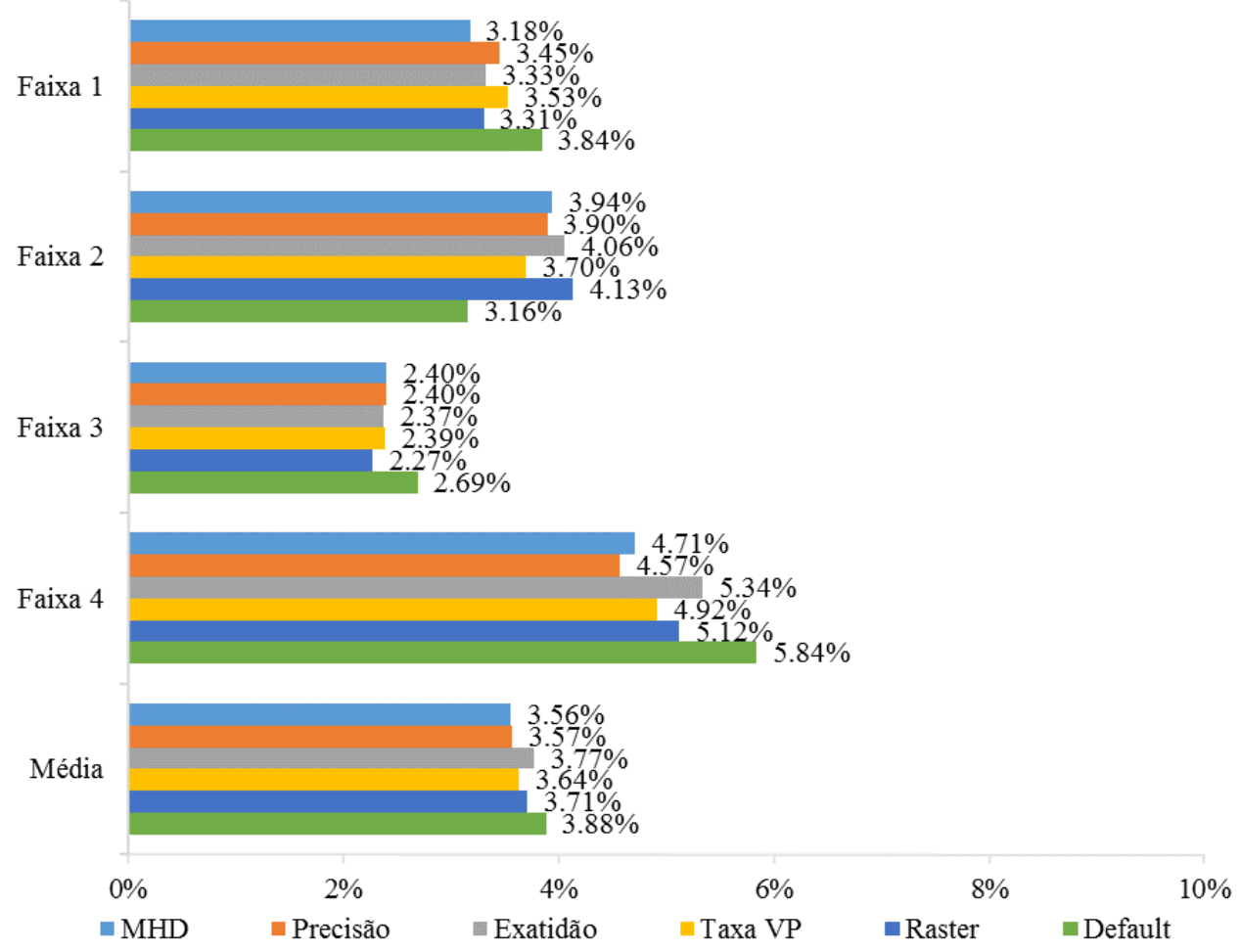

Figura 6.8 - Erro do percentual de fluxo de veículos por faixa

A Figura 6.9 apresenta o erro do percentual de veículos comerciais por faixa de tráfego. Deve-se ressaltar que na faixa 3 o erro é significativamente alto por ter apresentado, na simulação, um percentual de veículos comerciais inferior aos dados de campo. Pode-se notar que nenhuma das funções fitness avaliadas conseguiu reduzir o erro de forma significativa: apenas 
a faixa 4, mais próxima ao acostamento, apresentou redução em relação à simulação default. No entanto, deve-se ressaltar que, à exceção da faixa 3, os erros observados são relativamente pequenos, podendo-se concluir que o modelo calibrado não é pior que o default, no que diz respeito a este aspecto.

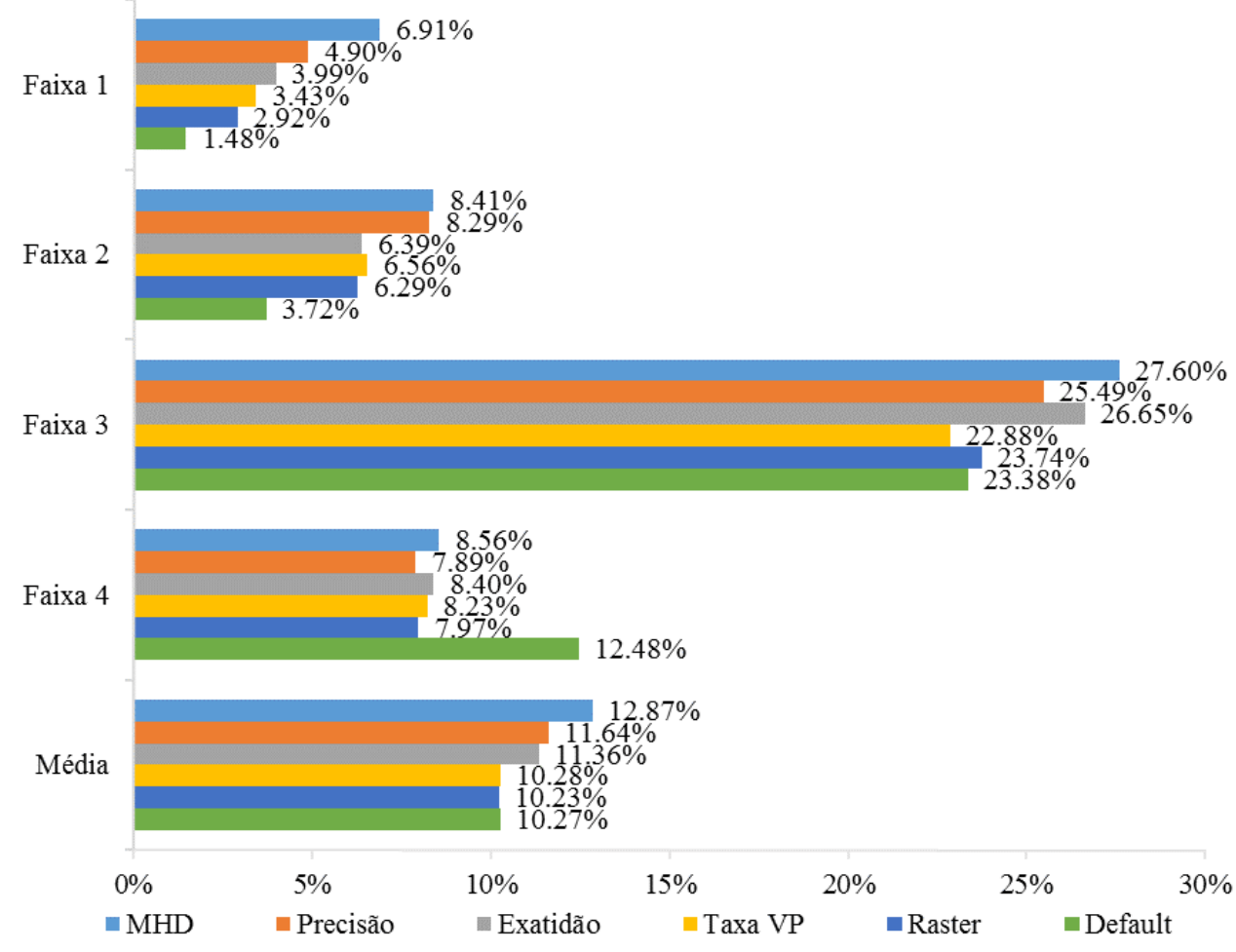

Figura 6.9 - Erro do percentual de veículos comerciais por faixa

Deve-se ter em mente, entretanto que as funções fitness adotadas para essas duas medidas de desempenho usam o valor médio para as quatro faixas de tráfego (Equações 5.3 e 5.4) e a eficiência do AG proposto fica evidente quando a análise é feita sobre a média das faixas. A média do erro do percentual de fluxo de veículos por faixa fica ligeiramente abaixo do erro da versão default do simulador, como mostra a Figura 6.8. Comparando-se a média do erro do percentual de veículos comerciais por faixa de tráfego, percebe-se que o AG proposto não foi capaz de reduzir o erro, mas que o erro fica dentro de uma margem que pode ser considerada aceitável.

Pode-se concluir que os parâmetros de calibração escolhidos para inclusão no AG têm pouca influência no comportamento dos veículos quanto à sua distribuição por faixa de tráfego e não conseguem representar adequadamente a tendência observada dos veículos comerciais trafegarem primordialmente pelas duas faixas da direita. Como não foram identificados, no manual do VISSIM, parâmetros que afetam esses componentes, isso pode ser uma deficiência intrínseca do modelo, que não pôde ser sanada através da calibração.

Um aspecto final que deve ser ressaltado é que essas duas medidas de desempenho, mesmo 
não registrando uma melhoria significativa depois da calibração, são importantes para o AG proposto, uma vez que foram capazes de manter a distribuição de veículos pelas faixas de tráfego dentro de uma margem de erro aceitável. Se deixadas de fora do AG, não haveria garantia alguma de que a distribuição de veículos pelas faixas de tráfego na simulação ficaria próxima da observada.

\subsection{Parâmetros de modelos comportamentais e de velocidade dese- jada}

Para avaliar as distribuições dos valores encontrados para os parâmetros de calibração, foi usado um conjunto com as melhores soluções encontradas pelo AG proposto, usando-se a função fitness baseada na MHD. Esse conjunto foi selecionado a partir da análise do histograma representado pela Figura 6.10, que agrupa os 2500 indivíduos pelo valor da função fitness. Os indivíduos que produzem valor de fitness maior que 50 representam 9,52\% da amostra, ou seja, 238 indivíduos. A Figura 6.11 apresenta os gráficos fluxo-velocidade para o $238^{\circ}$ indivíduo. É possível notar grande semelhança tanto com o gráfico fluxo-velocidade dos dados do sensor, como com o gráfico fluxo-velocidade do melhor indivíduo, mostrado na Figura ??. Estimase que todos os 238 indivíduos possuam esta mesma semelhança, por isso, utilizou-se este conjunto de indivíduos para avaliar a variação dos valores dos parâmetros.

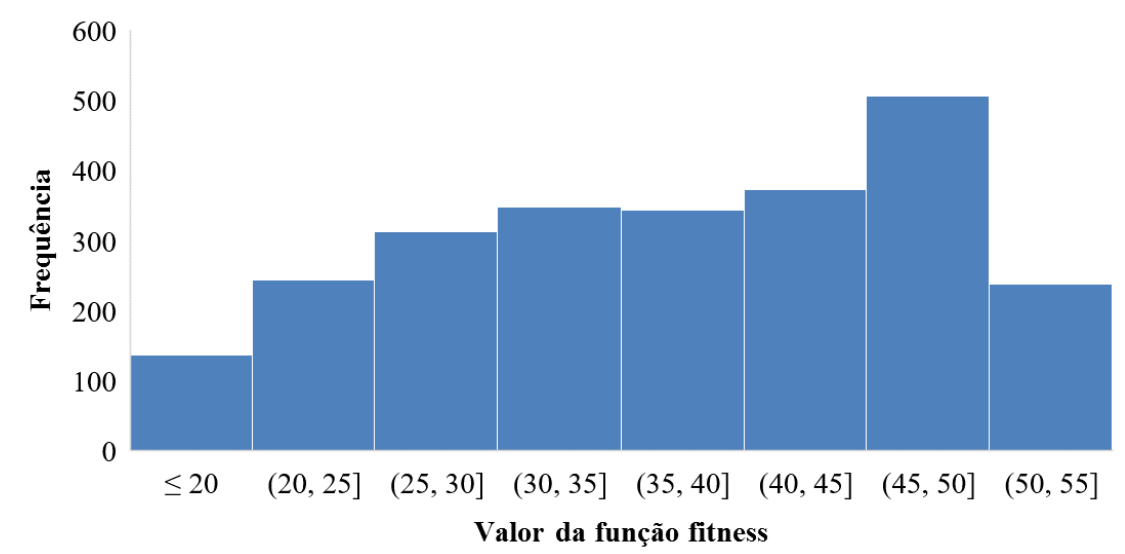

Figura 6.10 - Histograma dos 2500 indivíduos da calibração a partir da função fitness MHD

A Figura 6.12 mostra os gráficos box-plot de cada parâmetro, representando o valor médio, os outliers e, quando possível, o primeiro e o terceiro quartis e os limites superiores e inferiores. A análise evidencia que, em alguns parâmetros, a variação de valores é mínima, o que indica uma convergência a um valor ótimo para o parâmetro, uma vez que a maioria dos resultados apresenta-se distante dos limites inferiores e superiores do espaço de busca estabelecido para cada um. Observou-se também que a moda e a mediana dos parâmetros dos 238 melhores indivíduos possuem valores iguais aos dos parâmetros do melhor indivíduo. 

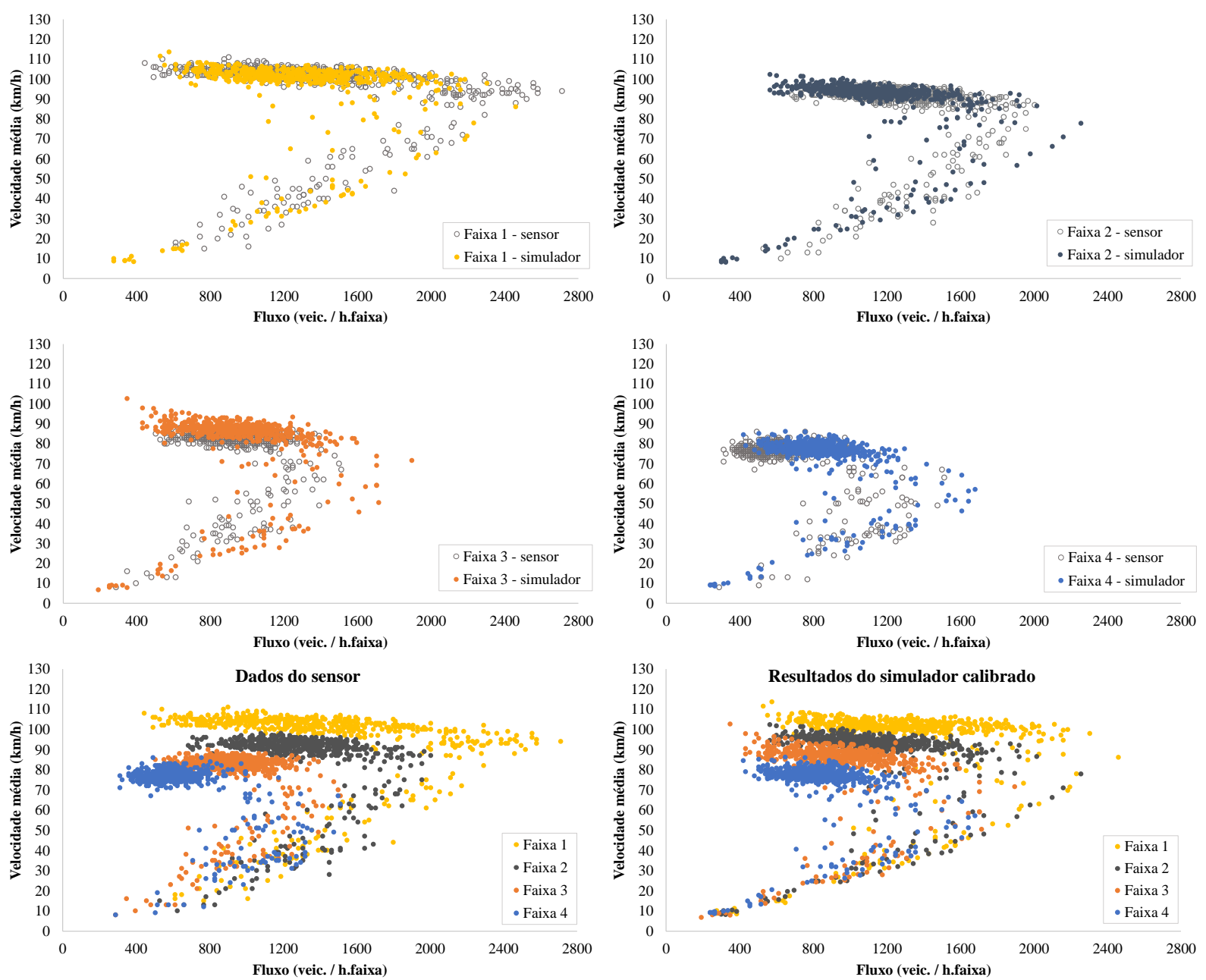

Figura 6.11 - Resultado do $238^{\circ}$ indivíduo, segundo ranqueamento dos melhores indivíduos de acordo com a função fitness MHD

Em parâmetros em que a variância é representativa, como $\mathrm{CC} 0, \mathrm{CC} 3, \mathrm{MH}, \mathrm{MD}$ e TSL, e o parâmetro de velocidade desejada DESIRED_1, avaliou-se a sensibilidade destes na calibração, considerando a hipótese de que estes parâmetros teriam pouca influência nas medidas avaliadas pela função fitness. A Tabela 6.3 apresenta as medidas estatísticas dos parâmetros dos melhores indivíduos e, destacados em negrito, os valores diferentes em relação ao melhor indivíduo. Estes valores diferentes foram simulados um a um para os parâmetros em que se observou uma variância representativa, mantendo-se os demais parâmetros iguais aos do melhor indivíduo.

Tabela 6.3 - Medidas estatísticas dos melhores indivíduos

\begin{tabular}{lrrrrrrrrrrrrrrr}
\hline Medida & OBSVEH & CC0 & CC1 & CC2 & CC3 & CC4 & CC5 & MH & SD & MD & TSL & D1 & D2 & D3 & D4 \\
\hline Melhor & 4 & 2.56 & 0.75 & 7.13 & -12.92 & -0.54 & 0.69 & 1.75 & 0.39 & -1.28 & 3.11 & 1.00 & 0.81 & 0.72 & 0.60 \\
Média & 4 & 2.22 & 0.75 & $\mathbf{7 . 0 4}$ & $\mathbf{- 1 1 . 3 1}$ & $\mathbf{- 0 . 6 0}$ & $\mathbf{0 . 7 4}$ & $\mathbf{1 . 5 4}$ & $\mathbf{0 . 4 1}$ & $\mathbf{- 2 . 4 8}$ & $\mathbf{3 . 9 3}$ & $\mathbf{0 . 9 9}$ & 0.81 & 0.72 & 0.60 \\
Moda & 4 & 2.56 & 0.75 & 7.13 & -12.92 & -0.54 & 0.69 & 1.75 & 0.39 & -1.28 & 3.11 & 1.00 & 0.81 & 0.72 & 0.60 \\
$1^{\circ}$ quartil & 4 & $\mathbf{1 . 8 3}$ & 0.75 & 7.13 & -12.92 & -0.54 & 0.69 & $\mathbf{1 . 5 1}$ & 0.39 & $-\mathbf{3 . 6 1}$ & 3.11 & $\mathbf{0 . 9 6}$ & 0.81 & 0.72 & 0.60 \\
$3^{\circ}$ quartil & 4 & 2.56 & 0.75 & 7.13 & $\mathbf{- 8 . 4 7}$ & -0.54 & 0.69 & 1.75 & 0.39 & -1.28 & 3.25 & 1.00 & 0.81 & 0.72 & 0.60 \\
Mediana & 4 & 2.56 & 0.75 & 7.13 & -12.92 & -0.54 & 0.69 & 1.75 & 0.39 & -1.28 & 3.11 & 1.00 & 0.81 & 0.72 & 0.60 \\
\hline
\end{tabular}




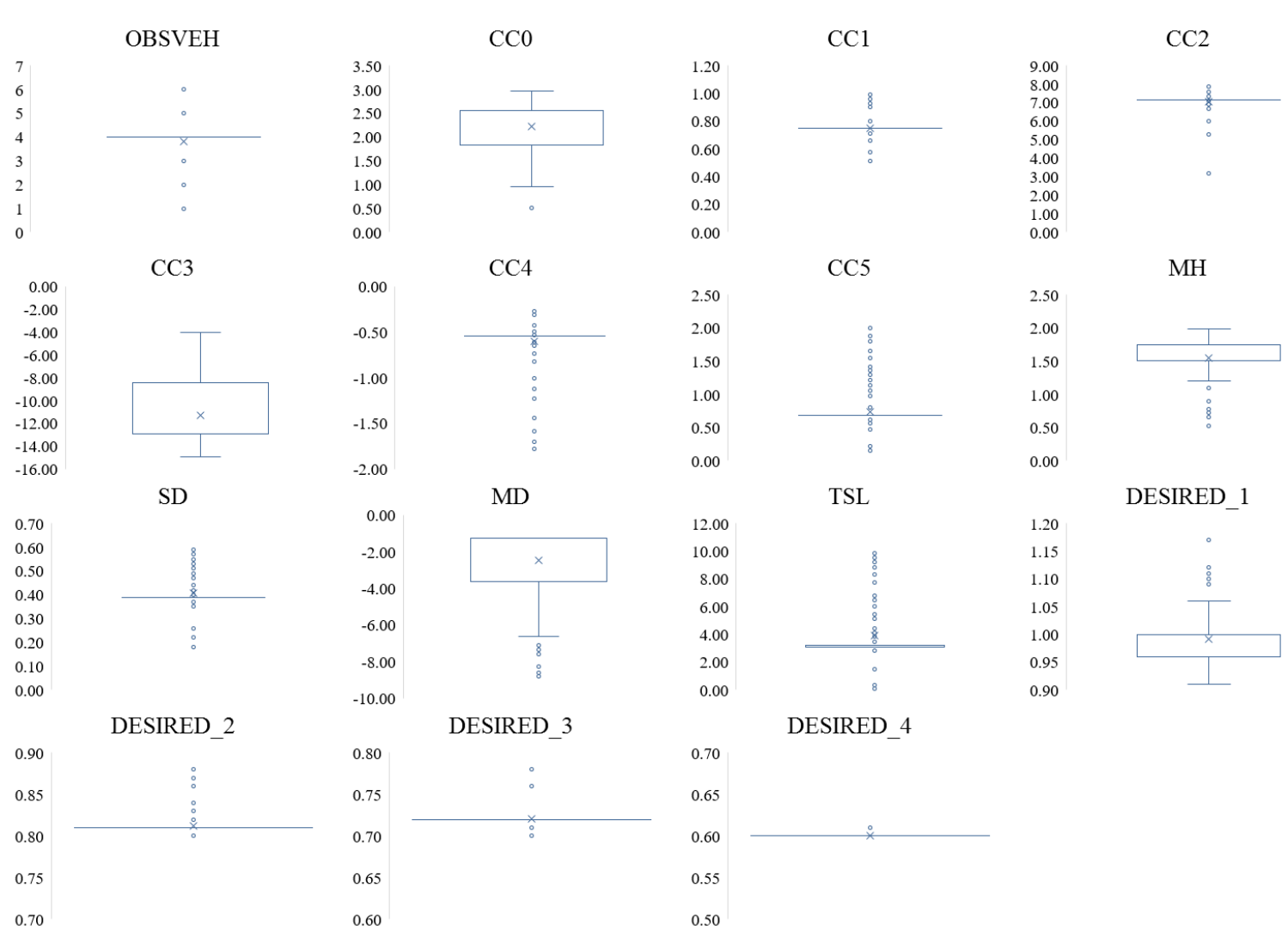

Figura 6.12 - Gráficos box-plot dos parâmetros dos melhores indivíduos da função MHD

Foram simulados 12 indivíduos, conforme apresentado na Tabela 6.4, que mostra o resultado do fitness de cada indivíduo, a variação do fitness em relação ao melhor indivíduo e os valores dos parâmetros que foram alterados. Os demais parâmetros não apresentados foram mantidos de acordo com o melhor indivíduo.

Tabela 6.4 - Resultado da análise de sensibilidade dos parâmetros

\begin{tabular}{lcccccrrr}
\hline Indivíduo & CC0 & CC3 & MH & MD & TSL & DESIRED_1 & Fitness & Variação \\
\hline Melhor & 2.56 & -12.92 & 1.75 & -1.28 & 3.11 & 1.00 & 53.34 & - \\
1 & 2.22 & -12.92 & 1.75 & -1.28 & 3.11 & 1.00 & 52.15 & $-2 \%$ \\
2 & $\mathbf{1 . 8 3}$ & -12.92 & 1.75 & -1.28 & 3.11 & 1.00 & 51.77 & $-3 \%$ \\
3 & 2.56 & $-\mathbf{1 1 . 3 1}$ & 1.75 & -1.28 & 3.11 & 1.00 & 51.63 & $-3 \%$ \\
4 & 2.56 & $-\mathbf{- 8 . 4 7}$ & 1.75 & -1.28 & 3.11 & 1.00 & 51.24 & $-4 \%$ \\
5 & 2.56 & -12.92 & $\mathbf{1 . 5 4}$ & -1.28 & 3.11 & 1.00 & 52.40 & $-2 \%$ \\
6 & 2.56 & -12.92 & $\mathbf{1 . 5 1}$ & -1.28 & 3.11 & 1.00 & 52.30 & $-2 \%$ \\
7 & 2.56 & -12.92 & 1.75 & -2.48 & 3.11 & 1.00 & 53.34 & $0 \%$ \\
8 & 2.56 & -12.92 & 1.75 & -3.61 & 3.11 & 1.00 & 53.34 & $0 \%$ \\
9 & 2.56 & -12.92 & 1.75 & -1.28 & 3.93 & 1.00 & 52.41 & $-2 \%$ \\
10 & 2.56 & -12.92 & 1.75 & -1.28 & 3.25 & 1.00 & 52.36 & $-2 \%$ \\
11 & 2.56 & -12.92 & 1.75 & -1.28 & 3.11 & $\mathbf{0 . 9 9}$ & 51.29 & $-4 \%$ \\
12 & 2.56 & -12.92 & 1.75 & -1.28 & 3.11 & $\mathbf{0 . 9 6}$ & 51.59 & $-3 \%$ \\
\hline
\end{tabular}

Nota-se que o parâmetro MD não apresentou alteração no valor do fitness em relação ao melhor indivíduo, desta forma, pode-se afirmar que este parâmetro não influencia nas medidas de desempenho avaliadas para a rede proposta, e poderia ser desconsiderado na calibração. Nos demais indivíduos, houve uma variação entre $2 \%$ e $4 \%$ nos novos indivíduos. Esta variação é 
representativa, o que indica que os parâmetros influenciam de forma significativa no resultado das medidas de desempenho avaliadas pela função fitness. Também não foi observada melhoria no valor da função em relação ao indivíduo utilizado como referência.

As análises mostram a necessidade de um estudo mais aprofundado da sensibilidade dos parâmetros para aprimorar o funcionamento do algoritmo. Para trabalhos futuros, sugere-se realizar esta análise para todos os parâmetros dos melhores resultados, e também avaliar os parâmetros que não foram contemplados nesta calibração.

\subsection{Validação da calibração}

A validação é a etapa de teste da calibração do modelo para avaliar se o procedimento conseguiu reproduzir, de maneira fiel, dados semelhantes aos que são coletados em campo.

Para a validação, foram utilizados dados do mesmo trecho de rodovia e mesmo sensor de tráfego, porém, de dias distintos, conforme tratamento detalhado no Capítulo 3. A quantidade de intervalos de dados de tráfego foi mantida, bem como uma proporção de registros de fluxo congestionado semelhante aos dados da calibração.

A validação foi feita a partir dos parâmetros obtidos através da calibração. Utilizou-se o algoritmo genético apenas para encontrar o conjunto de parâmetros de congestionamento adequado para os dias selecionados, visto que os dias escolhidos são diferentes, e os intervalos com registros de fluxo congestionado possivelmente ocorreram em momentos distintos. Além disso, a redução da velocidade pode não ser a mesma que ocorreu para um registro de um período equivalente ao da calibração.

O AG foi executado com uma população de 10 indivíduos e 150 gerações, mantendo-se a mesma configuração dos operadores genéticos utilizada para a calibração. Utilizou-se os valores encontrados pelo AG para os parâmetros comportamentais e de velocidade desejada, segundo a função fitness MHD.

O melhor indivíduo da etapa de validação apresentou o valor da função fitness igual a 53,30, semelhante à calibração, cujo fitness foi 53,34. A Figura 6.13 apresenta o resultado da validação após a execução do AG, e a Figura 6.14 compara os gráficos dos dados observados e simulados da calibração e da validação. Observa-se que a velocidade da corrente de tráfego da simulação é semelhante aos dados de campo. Os registros de fluxo congestionado correspondem à tendência apresentada. A região de fluxo de descarga apresentou uma quantidade de ocorrências um inferior à esperada, assim como a região de fluxo congestionado da faixa 1. As demais faixas obtiveram boas respostas quanto à presença de registros nessa região. Desta forma, pode-se afirmar que a validação apresentou resultados satisfatórios e atendeu às expectativas quanto ao objetivo de assegurar a extensibilidade da calibração. 

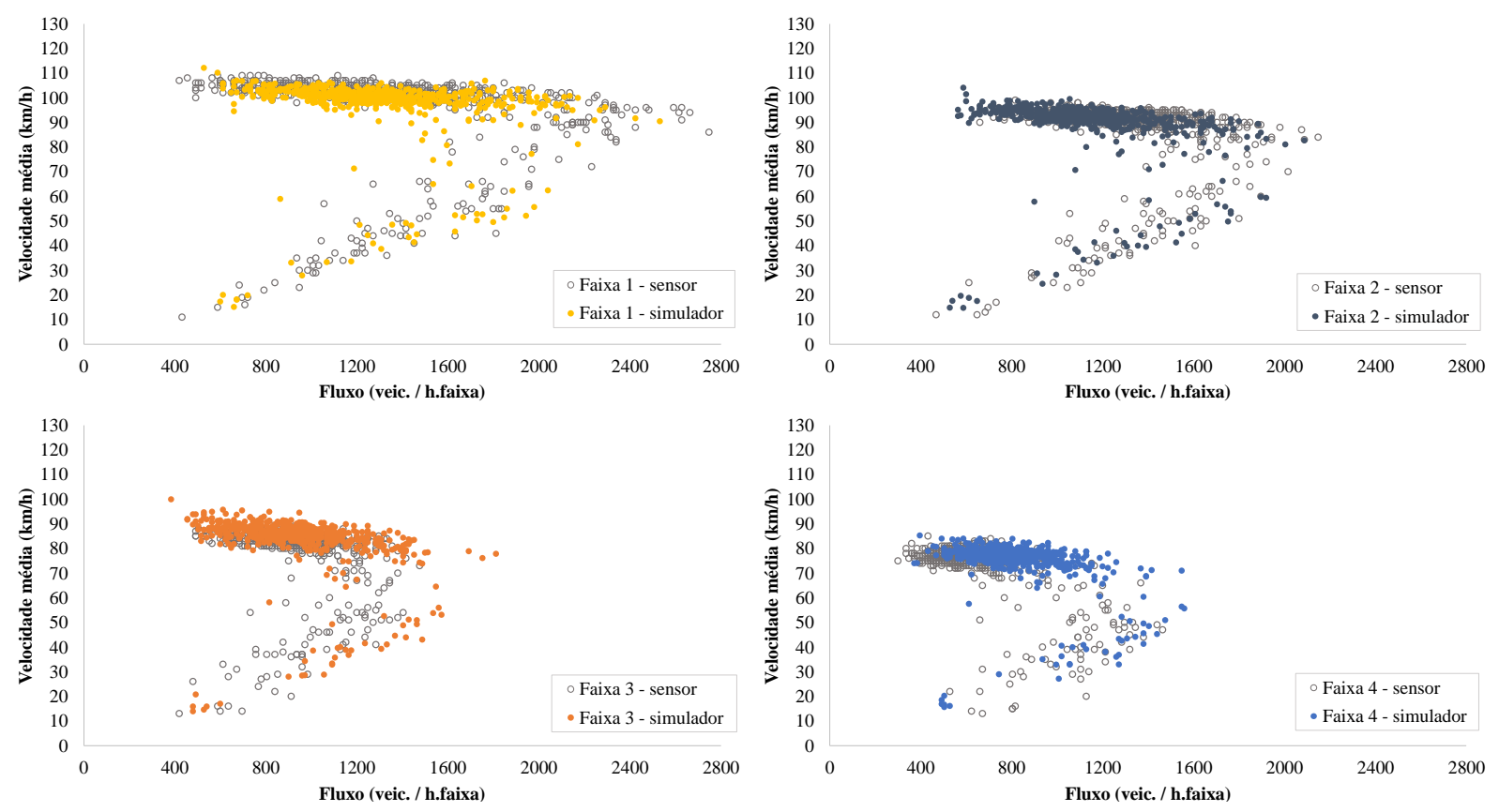

Figura 6.13 - Validação com parâmetros comportamentais e de velocidade desejada obtidos pela função fitness MHD
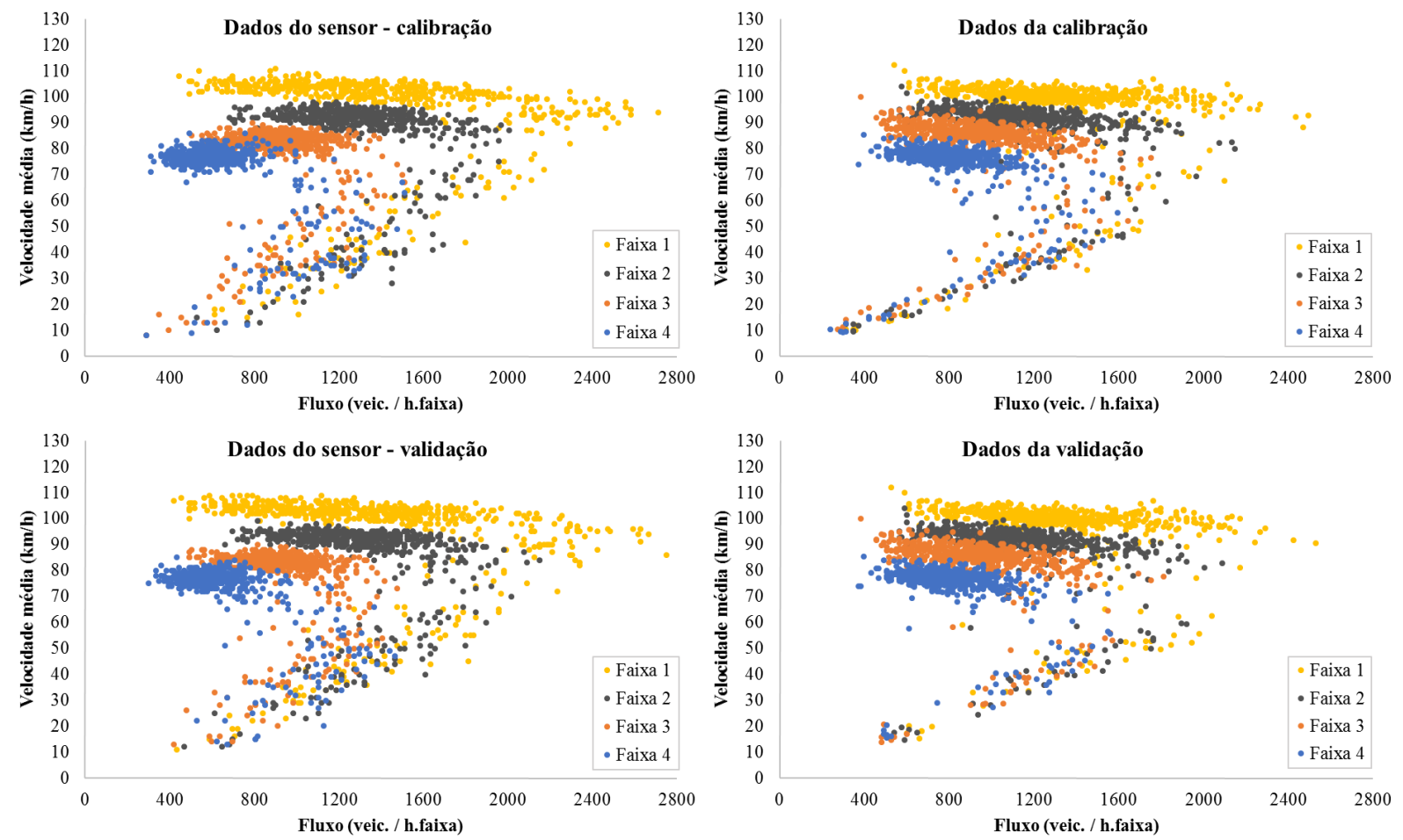

Figura 6.14 - Comparação entre dados observados e simulados da calibração e da validação

\subsection{Considerações finais}

O presente capítulo detalhou os resultados obtidos através da calibração, bem como apresentou o método proposto para a validação e seu resultado. O método proposto atendeu à expectativa 
de calibrar o simulador através de dados de sensores de tráfego. Foi possível observar que a medida da distância de Hausdorff foi a mais eficaz no processo de calibração, e que as medidas de erro do percentual de veículos pesados e do percentual de fluxo por faixa mantiveram o erro dentro de uma faixa aceitável. Também notou-se que o método proposto para obtenção de fluxo congestionado foi eficiente através da medida de reconhecimento de padrões adotada. O capítulo a seguir apresenta as recomendações para trabalhos futuros, bem como as considerações relevantes da pesquisa. 


\section{Capítulo}

\section{Conclusões e recomendações}

Este trabalho teve como objetivo propor um método para calibrar um simulador microscópico de tráfego a partir de dados obtidos por estações de monitoramento. A viabilidade do método proposto foi confirmada através de um estudo de caso em que o VISSIM foi calibrado para uma típica rodovia de pista dupla do estado de São Paulo.

Uma das vantagens de se utilizar dados de sensores é que há uma grande quantidade de informações de estações de monitoramento disponíveis, o que dispensa a necessidade de se realizar uma coleta de dados de tráfego somente para calibrar o modelo. Os dados das estações de monitoramento utilizados na pesquisa, fornecidos pela ARTESP e pela concessionária CCR AutoBan, foram suficientes para calibrar os parâmetros utilizados no algoritmo genético para o trecho proposto.

Os filtros propostos para selecionar apenas observações representativas de dias típicos de tráfego e apenas observações em que não houve registros de chuva, através de informações meteorológicas do IPMet, foram essenciais na identificação da operação típica do trecho da rodovia analisado.

O simulador e o algoritmo genético foram preparados para atender às necessidades do trecho analisado e do modo de calibração proposto. O método utilizado para obtenção de fluxo congestionado no simulador mostrou-se eficiente com a medida de desempenho apropriada. A medida de distância modificada de Hausdorff (MHD) foi a mais adequada para a comparação entre dois conjuntos para a quantidade de ocorrências utilizadas nos processos de calibração e validação do simulador. Além disso, a medida de MHD também foi fundamental para garantir a eficiência do método de simulação do congestionamento de tráfego. As outras quatro medidas de comparação (Precisão, Exatidão, TaxaVP e Raster) não foram eficazes na análise da dissemelhança entre os gráficos.

As medidas do erro do percentual de fluxo de veículos por faixa e do percentual de percentual de veículos comerciais por faixa de tráfego do melhor resultado encontrado pelo AG 
apresentaram resultados semelhantes à simulação default. Assim, o AG proposto não reduziu o erro de forma significativa, mas o erro manteve-se dentro de uma margem satisfatória. Essas duas medidas de desempenho são importantes para o AG proposto, pois compararam o percentual de veículos pesados por faixa de tráfego em função do tempo. Caso as medidas não fossem mantidas no AG, não haveria garantia de que a distribuição de veículos pelas faixas de tráfego na simulação ficaria próxima da observada.

As análises de redução da quantidade de observações no gráfico de fluxo vs. velocidade e do time-step da simulação mostraram que foi possível minimizar o tempo de processamento sem que os resultados da calibração sofressem alterações significativas.

Por fim, a validação apontou que calibração foi bem sucedida ao apresentar dados semelhantes aos dados alternativos do tráfego no local. Assim, o método proposto pelo estudo apresentou-se como uma alternativa aos métodos tradicionais de calibração por contemplar o uso de dados coletados por estações de monitoramento.

\subsection{Recomendações}

A limitação dos prazos para o projeto não permitiu abranger uma gama maior de experimentos para aprimoramento do trabalho. Por isso, algumas recomendações são sugeridas para trabalhos futuros após a análise dos resultados do método proposto.

O método deve ser testado em redes de tráfego distintas, especialmente em redes mais complexas, com presença de acessos. Esse procedimento irá assegurar a sua extensibilidade, caso o resultado seja satisfatório. Sugere-se avaliar também outros possíveis métodos para criar congestionamento, quando houver necessidade.

Nesta pesquisa, não foi realizada a calibração do modelo de desempenho veicular por não haver nenhum aclive que se enquadrasse em casos que o HCM recomenda uma análise mais detalhada. Assim, é recomendável a avaliação de uma rede com tal característica para aprimorar a calibração através do ajuste do modelo de desempenho de veículos pesados.

Quanto aos parâmetros de modelos comportamentais usados na calibração, deve-se realizar um estudo mais aprofundado para avaliar a sensibilidade de cada parâmetro na rede de tráfego proposta, bem como definir espaços de busca coerentes.

Para a etapa de tratamento de dados, sugere-se o método proposto por Ribeiro (2016), em pesquisa de mestrado em andamento, para a detecção de anomalias em dados de tráfego para realizar, de forma automatizada, o filtro de dados inconsistentes. O trabalho propõe o uso de transformada Wavelet para identificar singularidades durante o processamento de sinais, compostos por dados de tráfego obtidos através de estações de monitoramento.

Quanto às medidas de desempenho, é recomendável avaliar medidas que realizem uma comparação temporal entre os dados de campo e os dados simulados. O uso isolado de medidas de 
dissimilaridade pode gerar resultados que, embora pareçam aceitáveis, não refletem as condições reais de tráfego por não contemplar o período de ocorrência.

A calibração das distribuições de velocidade desejada, embora tenha apresentado resultados satisfatórios, pode ser aprimorada caso a distribuição seja ajustável não apenas por um escalar, mas pela quantidade de pontos que definem a curva e suas frequências.

O algoritmo genético também é passível de análise quanto à eficiência dos operadores genéticos de mutação e seleção natural, e a periodicidade destes eventos, caso sejam testados valores diferentes aos propostos para a pesquisa. A quantidade de indivíduos por geração e o método de cruzamento de genes podem ser reavaliados para o aprimoramento do processo de calibração. 


\section{Referências}

ABDULHAI, B.; SHEU, J.-B.; RECKER, W. Simulation of ITS on the Irvine FOT area using Paramics 1.5 scalable microscopic traffic simulator: Phase I: Model calibration and validation. California Partners for Advanced Transit and Highways (PATH), 1999. 1999.

ANACLETO, J. C. Utilização de algoritmo genético para apoiar a simulação de sistemas complexos. Tese (Doutorado em Física Aplicada) - Instituto de Física de São Carlos, Universidade de São Paulo, 1996.

ANDRADE, G. R. d. Capacidade e relação fluxo-velocidade em autoestradas e rodovias de pista dupla paulistas. Dissertação (Mestrado) - Programa de Engenharia de Transportes, Escola de Engenharia de São Carlos, USP, 2012.

ANDRADE, G. R. d.; SETTI, J. R. Speed flow relationship and capacity for expressways in Brazil. Transportation Research Circular, v. E-C190, 2014. p. 10-25, 2014.

ASTARITA, V. et al. Comparison of three methods for dynamic network loading. Transportation Research Record: Journal of the Transportation Research Board, 2001. v. 1771, p. 179-190, 2001.

AYALA, R. J. L. Procedimento para identificação dos principais parâmetros dos microssimuladores a serem considerados no processo de calibração. Dissertação (Mestrado) - Universidade de Brasília, UNB, 2013.

BESSA Jr., J. E. Caracterização do fluxo de tráfego em rodovias de pista simples do estado de São Paulo. Dissertação (Mestrado) - Programa de Engenharia de Transportes, Escola de Engenharia de S. Carlos, USP, 2009.

BESSA Jr., J. E. Medidas de desempenho para avaliação da qualidade de serviço em rodovias de pista simples no Brasil. Tese (Doutorado) - Universidade de São Paulo, 2015.

BHAM, G. H.; VALLATI, M. Slip ramp spacing design for truck only lanes using microscopic simulation. In: ASCE. Reston, VA: Proceedings of the First Transportation and Development Institute Congress. Chicago, Illinois, EUA, 2011. p. 13-16.

BRACKSTONE, M.; PUNZO, V. Traffic Simulation: Case for guidelines. Ispra, Itália, 2014. 
BROCKFELD, E.; KÜHNE, R. D.; WAGNER, P. Calibration and validation of microscopic traffic flow models. Transportation Research Record: Fournal of the Transportation Research Board, 2004. v. 1876, p. 62-70, 2004.

CALEFFI, F. et al. Simulação de alternativas operacionais de um segmento especial de autoestrada através do software VISSIM. In: ANPET. Anais do XXVI Congresso de Pesquisa e Ensino em Transportes. Joinville, Santa Catarina, 2012.

CHU, L. et al. A calibration procedure for microscopic traffic simulation. In: IEEE. Intelligent Transportation Systems. Washington D.C., EUA, 2003. v. 2, p. 1574-1579.

CUNHA, A. L. Avaliação do impacto da medida de desempenho no equivalente veicular de caminhões. Dissertação (Mestrado) - Programa de Engenharia de Transportes, Escola de Engenharia de São Carlos, USP, 2007.

CUNHA, A. L.; BESSA Jr., J. E.; SETTI, J. R. Genetic algorithm for the calibration of vehicle performance models of microscopic traffic simulators. In: Progress in Artificial Intelligence - Proceedings of the 14th Portuguese Conference on Artificial Intelligence, EPIA 2009. Aveiro, Portugal: Springer-Verlag Berlin Heidelberg, 2009. p. 3-14.

CUNHA, A. L.; SETTI, J. R. Calibração do modelo de desempenho de caminhões do CORSIM através de um algoritmo genético. In: ANPET. Anais do XX Congresso de Pesquisa e Ensino em Transportes. Fortaleza, Ceará, 2006. v. 1, p. 88-99.

CUNHA, A. L. B. N. Sistema automático para obtenção de parâmetros do tráfego veicular a partir de imagens de vídeo usando OpenCV. Tese (Doutorado) - Programa de Engenharia de Transportes, Escola de Engenharia de São Carlos, USP, 2013.

DEMARCHI, S. H. Influência dos veículos pesados na capacidade e nível de serviço de rodovias de pista dupla. Tese (Doutorado) - Programa de Engenharia de Transportes, Escola de Engenharia de S. Carlos, USP, 2000.

DNIT. Manual de estudos de tráfego - Departamento Nacional de Infraestrutura e Transportes. Rio de Janeiro, RJ, 2006.

DOWLING, R.; SKABARDONIS, A.; ALEXIADIS, V. Traffic analysis toolbox volume III: guidelines for applying traffic microsimulation modeling software. McLean, Virginia, 2004.

DUBUISSON, M.-P.; JAIN, A. K. A modified Hausdorff distance for object matching. In: IEEE. Pattern Recognition, 1994. Vol. 1-Conference A: Computer Vision \& Image Processing, Proceedings of the 12th IAPR International Conference on. Jerusalem, Israel, 1994. v. 1, p. 566-568.

EGAMI, C. Y. Adaptação do HCM-2000 para determinação do nível de serviço em rodovias de pista simples sem faixas adicionais no Brasil. Tese (Doutorado) - Programa de Engenharia de Transportes, Escola de Engenharia de São Carlos, USP, 2006.

EGAMI, C. Y.; SETTI, J. R.; RILLET, L. R. Algoritmo genético para calibração automática de um simulador de tráfego em rodovias de pista simples. TRANSPORTES, 2004. v. 12, n. 2, 2004.

FAWCETT, T. An introduction to roc analysis. Pattern recognition letters, 2006. Elsevier, v. 27, n. 8, p. 861-874, 2006. 
FELLENDORF, M.; VORTISCH, P. Validation of the microscopic traffic flow model VISSIM in different real-world situations. In: Transportation Research Board 80th Annual Meeting. Washington D.C., EUA: , 2001.

FELLENDORF, M.; VORTISCH, P. Microscopic traffic flow simulator VISSIM. In: Fundamentals of Traffic Simulation. Barcelona, Spain: International Series in Operations Research and Management Science, 2010. cap. 2, p. 63-93.

GAO, Y. Calibration and Comparison of the VISSIM and INTEGRATION Microscopic Traffic Simulation Models. Dissertação (Mestrado) - Virginia Tech, 2008.

GEISTEFELDT, J. Empirical estimation of desired speed distributions on freeways for microscopic traffic simulation. In: TRB. Transportation Research Board 94th Annual Meeting. Washington D.C., EUA, 2015. v. 2701.

GOLDBERG, D. E. E. 1989. genetic algorithms in search, optimization, and machine learning. Reading: Addison-Wesley, 1989. 1989.

GOMES, G.; MAY, A.; HOROWITZ, R. Congested freeway microsimulation model using VISSIM. In: CITESEER. Transportation Research Record. Pasadena, California, EUA, 2004. v. 1876, p. $71-81$.

GONZALEZ, R. C.; WOODS, R. E. Processamento de imagens digitais. 3a.. ed. São Paulo: Editora Blucher, 2007.

GUO, B. et al. Human face recognition based on spatially weighted Hausdorff distance. Pattern Recognition Letters, 2003. Elsevier, v. 24, n. 1, p. 499-507, 2003.

HELLINGA, B. R. Requirements for the calibration of traffic simulation models. Proceedings of the Canadian Society for Civil Engineering, 1998. v. 4, p. 211-222, 1998.

HOLLANDER, Y.; LIU, R. The principles of calibrating traffic microsimulation models. Transportation, 2008. Springer, v. 35, n. 3, p. 347-362, 2008.

HOURDAKIS, J.; MICHALOPOULOS, P. G.; KOTTOMMANNIL, J. Practical procedure for calibrating microscopic traffic simulation models. Transportation Research Record: fournal of the Transportation Research Board, 2003. v. 1852, p. 130-139, 2003.

HUTTENLOCHER, D. P.; KLANDERMAN, G. A.; RUCKLIDGE, W. J. Comparing images using the Hausdorff distance. Pattern Analysis and Machine Intelligence, IEEE Transactions on, 1993. IEEE, v. 15, n. 9, p. 850-863, 1993.

JGP CONSULTORIA. Relatório de análise ambiental da concessão do trecho Oeste do Rodoanel Mario Covas. São Paulo, SP, 2009.

KIM, K.-O.; RILETT, L. Simplex-based calibration of traffic microsimulation models with intelligent transportation systems data. Transportation Research Record: Fournal of the Transportation Research Board, 2003. v. 1855, p. 80-89, 2003.

KIM, K.-O.; RILETT, L. R. Genetic-algorithm based approach for calibrating microscopic simulation models. In: IEEE. Intelligent Transportation Systems, 2001. Proceedings. 2001 IEEE. Oakland, California, EUA, 2001. p. 698-704. 
KIM, S.-J.; KIM, W.; RILETT, L. R. Calibration of microsimulation models using nonparametric statistical techniques. Transportation Research Record: Fournal of the Transportation Research Board, 2005. v. 1935, p. 111-119, 2005.

KLEIN, L. A. Sensor technologies and data requirements for ITS. Norwood, Massachusetts: Artech House Publishers, 2001.

KWON, O.-K.; SIM, D.-G.; PARK, R.-H. Robust Hausdorff distance matching algorithms using pyramidal structures. Pattern Recognition, 2001. Elsevier, v. 34, n. 10, p. 2005-2013, 2001.

LACERDA, V. M.; CASTRO NETO, M. M. Considerações sobre a calibração do modelo de car-following do VISSIM para vias arteriais. In: ANPET. Anais do XXVIII Congresso de Pesquisa e Ensino em Transportes. Curitiba, Paraná, 2014.

LEICA. Leica Geosystems GPS1200+ User Manual. Heerbrugg, Switzerland, 2008.

LIN, K.-H.; LAM, K.-M.; SIU, W.-C. Spatially eigen-weighted Hausdorff distances for human face recognition. Pattern Recognition, 2003. Elsevier, v. 36, n. 8, p. 1827-1834, 2003.

LU, Y. et al. An approach to word image matching based on weighted Hausdorff distance. In: IEEE. Sixth International Conference on Document Analysis and Recognition. Washington D.C., EUA, 2001. p. 921-925.

MA, J.; DONG, H.; ZHANG, H. M. Calibration of microsimulation with heuristic optimization methods. Transportation Research Record: Journal of the Transportation Research Board, 2007. v. 1999, p. 208-217, 2007.

MA, T.; ABDULHAI, B. Genetic algorithm-based optimization approach and generic tool for calibrating traffic microscopic simulation parameters. Transportation Research Record: fournal of the Transportation Research Board, 2002. v. 1800, p. 6-15, 2002.

MENNENI, S. Pattern recognition based microsimulation calibration and innovative traffic representations. Tese (Doutorado) - University of Missouri-Columbia, 2008.

MENNENI, S.; SUN, C.; VORTISCH, P. Microsimulation calibration using speed-flow relationships. Transportation Research Record: Journal of the Transportation Research Board, 2008. v. 2088, p. 1-9, 2008.

MOEN, B. et al. A comparison of the VISSIM model to other widely used traffic simulation and analysis programs. In: ITE - Institute of Transportation Engineers. ITE 2000 Annual Meeting and Exhibit. Washington D.C., EUA, 2000.

OLIVEIRA, M. L. d.; CYBIS, H. B. B. Revisão da experiência de calibração do software VISSIM aplicado a um estudo de caso de autoestrada brasileira. In: SEPROSUL. VIII Semana de Engenharia de Produção Sul-Americana. Porto Alegre, Rio Grande do Sul, 2008.

PAL, N. R.; PAL, S. K. A review on image segmentation techniques. Pattern recognition, 1993. Elsevier, v. 26, n. 9, p. 1277-1294, 1993.

PARK, B.; QI, H. Development and evaluation of a procedure for the calibration of simulation models. Transportation Research Record: Journal of the Transportation Research Board, 2005. v. 1934, p. 208-217, 2005. 
PIZZOL, B.; SETTI, J. R. Fusão de bancos de dados para estudo do efeito das condições meteorológicas no fluxo de veículos em rodovias paulistas. In: ANPET. Anais do XXVII Congresso de Pesquisa e Ensino em Transportes. Belém, Pará, 2013.

PTV. VISSIM 5.20 user manual. Karlsruhe, Germany, 2009.

RIBEIRO, E. R. Proposta de detecção de padrões e anomalias de tráfego veicular utilizando a transformada wavelet em dados históricos. Dissertação (Mestrado em andamento) - Programa de Engenharia de Transportes, Escola de Engenharia de São Carlos, USP, 2016.

SCHULTZ, G. G.; RILETT, L. R. Calibration of distributions of commercial motor vehicles in corsim. Transportation Research Record: Journal of the Transportation Research Board, 2005. v. 1934, p. 246-255, 2005.

SETTI, J. R. Highway capacity manual ou manual de capacidade viária? In: CBR\&C. Anais do 6 Congresso Brasileiro de Rodovias e Concessões. Florianópolis, Santa Catarina, 2009.

SHAABAN, K. S.; RADWAN, E. A calibration and validation procedure for microscopic simulation model: A case study of simtraffic for arterial streets. In: TRB. Proceedings of the 84rd TRB Annual Meeting. Washington D.C., EUA, 2005.

SILVA, P. C. M.; TYLER, N. Sobre a validação de modelos microscópicos de simulação de tráfego. TRANSPORTES, 2002. v. 10, n. 1, 2002.

SPARMANN, U. Spurwechselvorgänge auf zweispurigen bab-richtungsfahrbahnen. Forsch Strassenbau U Stranssenverkehrstech, 1978. v. 263, 1978.

TAN, H.; ZHANG, Y.-J. A novel weighted Hausdorff distance for face localization. Image and Vision Computing, 2006. Elsevier, v. 24, n. 7, p. 656-662, 2006.

TOLEDO, T. et al. Calibration of microscopic traffic simulation models with aggregate data. Transportation Research Record: Journal of the Transportation Research Board, 2004. v. 1876, p. 10-19, 2004.

TOLEDO, T.; KOUTSOPOULOS, H. N. Statistical validation of traffic simulation models. Transportation Research Record: Journal of the Transportation Research Board, 2004. v. 1876, p. 142-150, 2004.

TOLEDO, T. et al. Calibration and validation of microscopic traffic simulation tools: Stockholm case study. Transportation Research Record: Fournal of the Transportation Research Board, 2003. v. 1831, p. 65-75, 2003.

TOMASSINI, M. A survey of genetic algorithms. Annual Reviews of Computational Physics, 1995. v. 3, n. 2, p. 87-118, 1995.

TRB. Highway Capacity Manual 2010. Transportation Research Board. Washington D.C., EUA, 2010.

VIVEK, E. P.; SUDHA, N. Robust Hausdorff distance measure for face recognition. Pattern Recognition, 2007. Elsevier, v. 40, n. 2, p. 431-442, 2007.

WIEDEMANN, R. Simulation des Strassenverkehrsflusses. Tese (Doutorado) - Schriftenreihe des Instituts für Verkehrswesen Heft 8, Universität Karlsruhe, 1974. 
WIEDEMANN, R. Modelling of rti-elements on multi-lane roads. In: COMMISSION OF THE EUROPEAN COMMUNITY. Advanced Telematics in Road Transport. Brussels, 1991. v. 2.

ZHAO, C.; SHI, W.; DENG, Y. A new Hausdorff distance for image matching. Pattern Recognition Letters, 2005. Elsevier, v. 26, n. 5, p. 581-586, 2005. 
Apêndices 
APÊNDICE

\section{Tabelas da calibração do simulador}

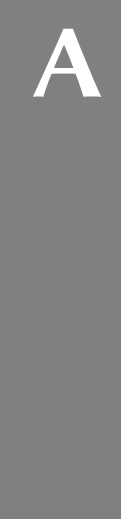

Este apêndice apresenta a evolução dos melhores indivíduos durante a calibração do simulador, segundo as cinco funções avaliadas.

A primeira coluna refere-se à geração em que houve a ocorrência de um indivíduo com fitness superior ao atual melhor indivíduo. O valor da função fitness é apresentado na última coluna. As demais colunas mostram os valores dos parâmetros comportamentais e de velocidade desejada dos indivíduos mais bem adaptados. 


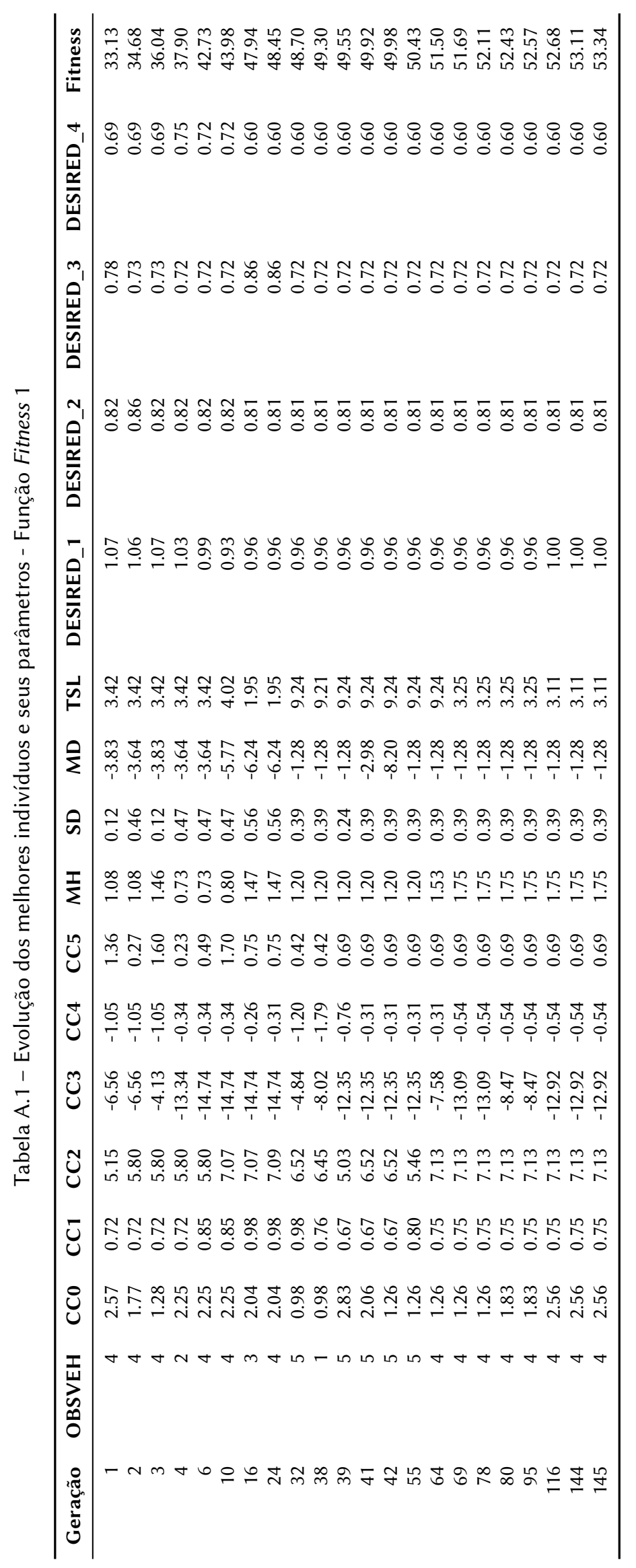




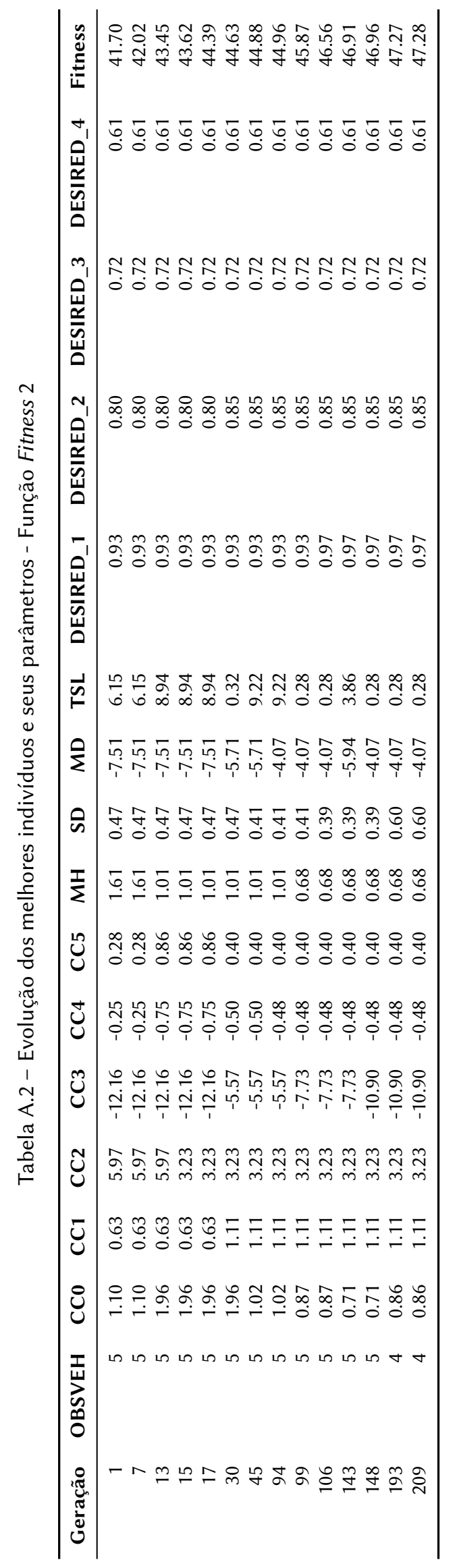




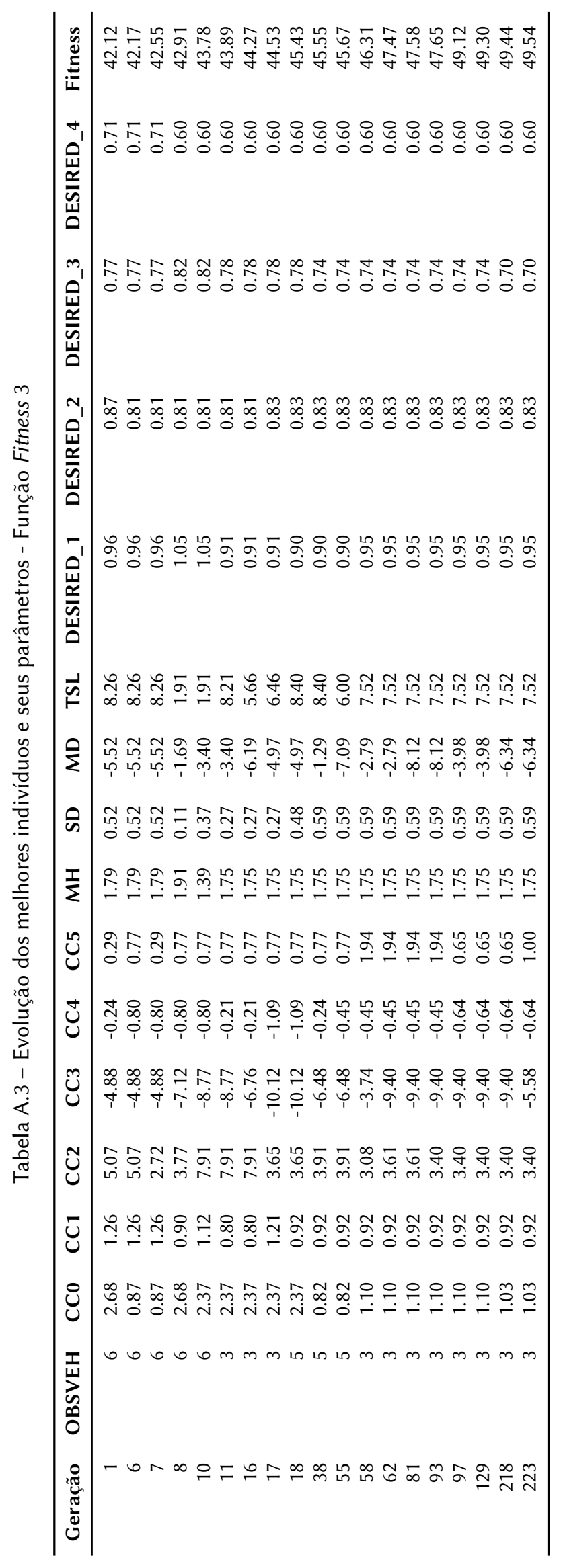




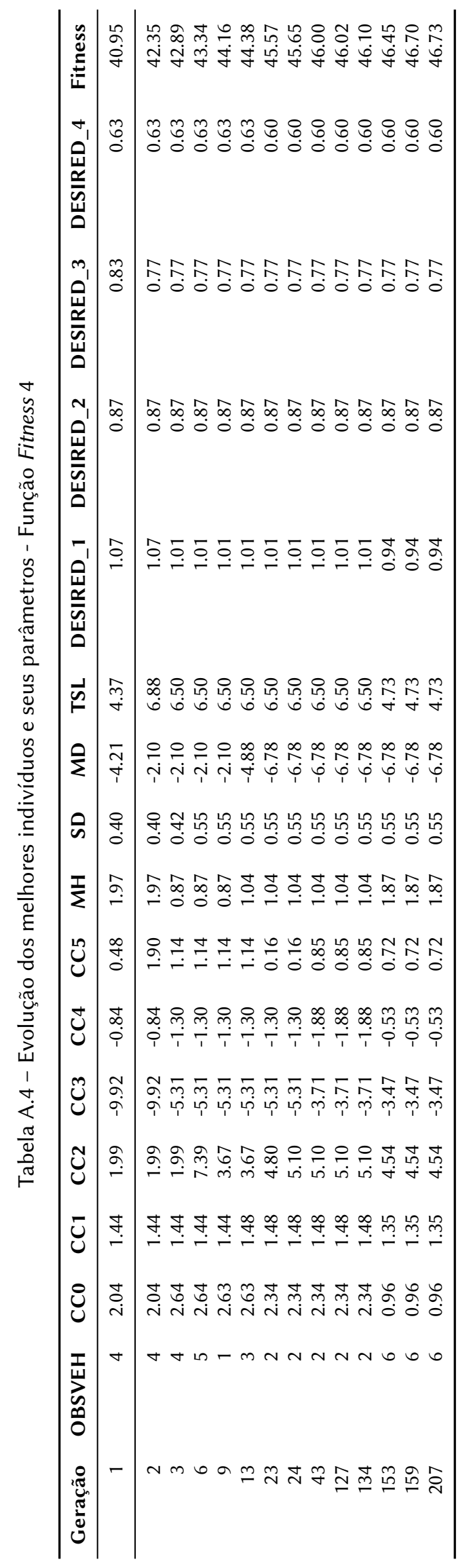




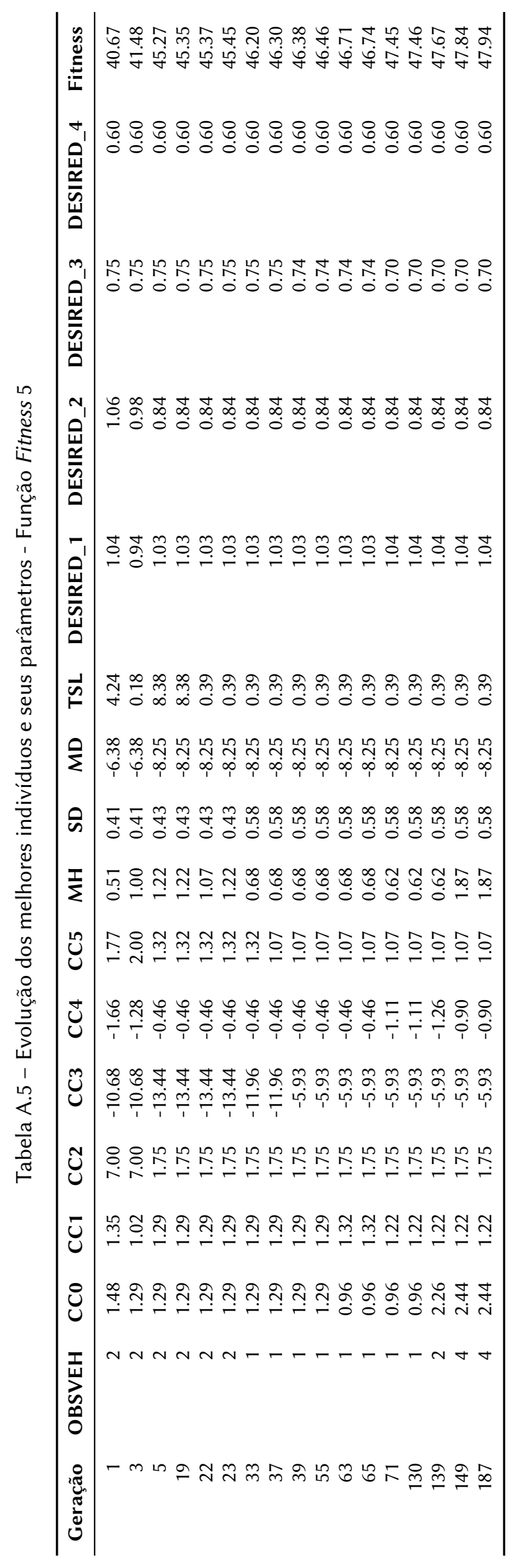

